\title{
DÉCLARATION SUR LA VACCINATION ANTIGRIPPALE POUR LA SAISON 2012-2013
}

\author{
Annexe I : Examen des nouveaux éléments de preuve pour les enfants \\ âgés de 24 à 59 mois
}

\section{Préambule}

Le Comité consultatif national de l'immunisation (CCNI) donne à l'Agence de la santé publique du Canada des conseils constants et à jour liés à l'immunisation dans le domaine de la médecine, des sciences et de la santé publique. L'Agence de la santé publique du Canada reconnaît que les conseils et les recommandations figurant dans le présent document reposent sur les connaissances scientifiques les plus récentes et diffuse ce document à des fins d'information. Les personnes qui administrent le vaccin doivent également connaître le contenu du ou des monographies pertinentes sur le produit. Les recommandations du CCNI concernant l'utilisation et les autres renseignements qui figurent dans le présent document peuvent différer du contenu des monographies de produit. Les fabricants ont fait approuver les vaccins et ont démontré leur innocuité et leur efficacité uniquement lorsqu'ils sont utilisés conformément à la monographie de produit. Les membres du CCNI et les agents de liaison doivent se conformer à la politique de l'Agence de la santé publique du Canada régissant les conflits d'intérêts notamment déclarer chaque année les conflits d'intérêts possibles.

Membres du CCNI : Dre Bryna Warshawsky (Présidente), Dre Natasha Crowcroft, M ${ }^{\text {me }}$ Anita Hanrahan, D ${ }^{r e}$ Bonnie Henry, Dre Shainoor Ismail (Secrétaire exécutive), D'e Deepali Kumar, Dre Shelly McNeil, Dre Caroline Quach-Thanh, Dre Marina Salvadori, Dr Blair Seifert, Dre Nadine Sicard, Dre Wendy Vaudry, Dr Richard Warrington.

Représentants de liaison : Dr Jason Brophy (Association canadienne pour la recherche et l'évaluation en immunisation); Dr lan Gemmill (Association canadienne de santé publique); Dre Alison Mawle (Centers for Disease Control and Prevention des É.-U.); Dre Dorothy Moore (Société canadienne de pédiatrie); Dre Heather Morrison (Conseil des médecins hygiénistes en chef); Dre Anne Opavsky (Association pour la microbiologie médicale et l'infectiologie Canada); D' Pierre Plourde (Comité consultatif de la médecine tropicale et de la médecine des voyages); Dre Shelley Rechner (Collège des médecins de famille du Canada) et Dre Vyta Senikas (Société des obstétriciens et gynécologues du Canada).

Représentants d'office : Lt.-Col. Dr Jim Anderson (Forces canadiennes, Groupe des services liés à la santé, Ministère de la défense nationale); D'e Agnes Klein (Direction des produits biologiques et des thérapies génétiques, Santé Canada); Dre Barbara Law (Centre de l'immunisation et des maladies respiratoires infectieuses, Agence de la santé publique du Canada); Dr Marcus Lem (Direction générale de la santé des Premières nations et des Inuits, Santé Canada); Mme Danielle Poulin (Centre de l'immunisation et des maladies respiratoires infectieuses, Agence de la santé publique du Canada), Dre Joanne Xiong (Direction des produits biologiques et des thérapies génétiques, Santé Canada).

Membres du Groupe de travail sur l'influenza : Dre Brenda Cholin, Dr Curtis Cooper, Dr Scott Halperin, Dre Joanne Langley, Dre Allison McGeer, et Dr Paul Van Buynder. 


\section{Table des matières}

I.1 Introduction

I.2 Fardeau de la maladie

1.2.1 Consultations externes

1.2.2 Hospitalisations

1.2.3 Mortalité

I.3 Efficacité potentielle, efficacité réelle

I.3.1 Vaccins trivalents inactivés contre l'influenza (VTI)

I.3.2 Vaccins à virus vivant atténué (VAl)

1.3.3 Otite moyenne aiguë (OMA)

I.3.4 Protection indirecte

I.4 Immunogénicité

I.5 Innocuité

I.5.1 Vaccins trivalents inactivés contre l'influenza (VTI)

I.5.2 Vaccins à virus vivant atténué contre l'influenza (VVAl)

1.5.3 Études portant sur les vaccins trivalents inactivés et les vaccins à virus vivant atténué contre l'influenza

I.6 Tableaux

Liste des abréviations

Références 


\section{I.1 Introduction}

Le CCNI inclut désormais les enfants âgés de 24 à 59 mois parmi les personnes qui devraient recevoir le vaccin contre I'influenza saisonnière (recommandations du CCNI de catégorie A).

Chez les enfants âgés de 24 à 59 mois, le risque de complications liées à la grippe est élevé et le fardeau de la maladie est important, comme en témoignent les consultations médicales, les hospitalisations et les décès liés à la grippe. En outre, les enfants âgés de 24 à 59 mois transmettent efficacement la maladie et leur vaccination pourrait protéger les sujets appartenant à des groupes à risque élevé (p. ex. les jeunes nourrissons, les personnes âgées et les personnes immunodéprimées), qui pourraient être trop jeunes pour recevoir le vaccin ou ne pas répondre efficacement à ce dernier.

Afin d'étayer cette recommandation, nous avons procédé à une recension des écrits relatifs aux enfants âgés de 24 à 59 mois. Une recherche a été réalisée dans les bases de données Medline et Embase et a porté sur la période

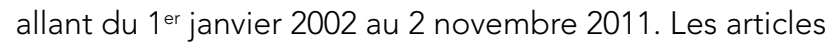
retenus pour examen reposaient notamment sur des études relatives au vaccin trivalent inactivé et au vaccin à virus vivant atténué contre l'influenza. Les articles fondés sur des études ayant trait au vaccin monovalent contre le virus pandémique A (H1N1) pdm 2009 n'ont pas été inclus dans cet examen des données. Dans les diverses études examinées, l'intervalle d'âges ne se limitait pas toujours au groupe des 24 à 59 mois, mais les études étaient soit composées dans une forte proportion de participants appartenant au groupe d'âge cible ou comprenaient une analyse d'un sous -groupe de participants du groupe d'âge cible.

Dans cette annexe, nous analyserons les données examinées, sous l'angle du fardeau de la maladie, de l'efficacité potentielle et de l'efficacité réelle, de l'immunogénicité et de l'innocuité des vaccins.

\section{I.2 FARDEAU DE LA MALADIE}

Le fardeau de l'infection grippale, de la maladie et de ses complications est important chez les enfants ${ }^{(1)-(4)}$. Même si le fardeau est moins lourd chez les enfants en bonne santé âgés de 24 à 59 mois que chez les enfants de moins de 2 ans, ce groupe d'âge affiche une morbidité et une mortalité ainsi que des taux importants de consultations externes et d'hospitalisations attribuables à l'influenza (1)-(6).
Le taux d'attaque annuel estimatif de l'influenza chez les enfants de 24 à 59 mois se situerait entre 10 et $40 \%{ }^{(1)(2)(7)}$. Dans certains milieux, on a observé un taux d'attaque plus élevé. Aux États-Unis, 50 \% des enfants fréquentant la garderie avaient été infectés au cours d'une saison grippale ${ }^{(7)}$. Dans une étude prospective sur 25 ans portant sur des enfants de moins de 5 ans recrutés à la Vanderbilt Vaccine Clinic au Tennessee (États-Unis), le taux d'attaque annuel de l'influenza confirmée en laboratoire se situait entre 15 et $42 \%$ (2)

En se fondant sur les cas déclarés par les hôpitaux, les unités de soins intensifs pédiatriques et les services de santé publique de la Californie au cours des saisons grippales 2003-2004 et 2005-2006, Louie et coll. ont constaté que parmi les 160 cas d'infection grippale confirmée en laboratoire chez des personnes de moins de 18 ans, 47 \% étaient des enfants et des adolescents auparavant en bonne santé (8). En outre, parmi les 131 cas signalés chez les enfants de moins de 5 ans, $52 \%$ étaient des enfants auparavant en bonne santé.

Dans une étude rétrospective réalisée chez des enfants en Finlande, environ $12 \%$ des sujets hospitalisés en raison de l'influenza $A$ ( $n=544)$, dont l'âge médian était de 2,0 ans (intervalle interquartile [IIO] 0,9-4,8), ont souffert de convulsions fébriles ${ }^{(9)}$. Parmi l'ensemble des sujets hospitalisés, $25 \%$ souffraient d'une affection sous-jacente. Les auteurs d'une étude de cohorte rétrospective réalisée à Hong Kong en 1997-1998 ont examiné les dossiers médicaux d'enfants âgés de 6 mois à 5 ans, qui présentaient de la fièvre au moment de leur hospitalisation, $\mathrm{n}=144$ en 1997 (âge médian 24,9 mois, écart type 14,7) et $\mathrm{n}=272$ en 1998 (âge médian 27,7 mois, écart type 14,5)(10). L'étude a révélé que l'incidence globale des convulsions fébriles était significativement plus élevée chez les enfants hospitalisés pour l'influenza A (19,5\%) que chez ceux hospitalisés pour une infection par le virus parainfluenza $(12,2 \%)$ ou par l'adénovirus (9\%), après ajustement pour tenir compte de l'âge, du sexe et des antécédents familiaux de convulsions fébriles. Dans une étude réalisée par Schanzer et coll. chez des enfants canadiens de moins de 19 ans, les convulsions fébriles parmi les sujets hospitalisés pour la grippe touchaient presque exclusivement les enfants de moins de 5 ans, et la majorité des cas concernaient des enfants de 6 à 23 mois $^{(11)}$.

La surveillance de la grippe au Canada s'exerce dans le cadre du programme Surveillance de l'influenza, un réseau national regroupant des laboratoires, des hôpitaux, des 
médecins sentinelles et des ministères provinciaux et territoriaux de la Santé. Les enfants âgés de 24 à 59 mois représentaient entre 7 et $9 \%$ de la totalité des cas déclarés annuellement au cours des saisons grippales 2005-2006 à 2010-2011 (12).

\section{I.2.1 Consultations externes}

Les consultations externes ont été évaluées dans deux études prospectives et deux études rétrospectives portant sur des groupes de population et comportant des analyses ayant trait aux participants âgés de 24 à 59 mois. Le taux annuel de consultations externes attribuables à l'influenza variait d'une étude à l'autre et a été évalué pour l'ensemble des consultations externes et des consultations pour une infection aiguë des voies respiratoires.

Dans une étude de cohorte prospective sur 25 ans (1974-1999) auprès d'enfants en bonne santé âgés de 5 ans et moins, Neuzil et coll. ont observé un taux d'incidence annuel de 82 pour 1000 (IC à $95 \%$ : 65-99) des consultations médicales chez des enfants symptomatiques âgés de 24 à 59 mois ayant fait l'objet d'une culture positive pour le virus de l'influenza (2). En ce qui a trait aux enfants et aux nourrissons âgés de moins de 1 an et de 1 an à moins de 2 ans, le taux annuel de consultations médicales était de 93 pour 1000 (IC à $95 \%$ : 76-109) et de 110 pour 1000 (IC à $95 \%$ : 93-135), respectivement.

Entre 2002 et 2004, Poehling et coll. ont mené une étude prospective pluriannuelle en population chez des enfants de moins de 5 ans dans trois comtés des États-Unis ${ }^{(6)}$. Parmi les 1742 enfants recrutés dans des services de consultations externes (certaines cliniques et certains services des urgences), $16 \%(n=267)$ ont reçu un diagnostic de grippe. Au nombre de ces 267 cas de grippe, $52 \%, 40 \%$ et $7 \%$ concernaient des enfants âgés de 24 à 59 mois, de 6 à 23 mois et de 0 à 5 mois, respectivement. Environ $20 \%$ des patients des services de consultations externes atteints de grippe confirmée en laboratoire souffraient d'une affection à risque élevé. Chez les enfants âgés de 24 à 59 mois, le taux annuel moyen de consultations externes attribuables à la grippe (85,5 pour $1000)$ était environ 250 fois plus élevé que le taux d'hospitalisation (0,3 pour 1000$)$.

À partir de bases de données sur la santé, O’Brien et coll. ont effectué une analyse rétrospective des consultations externes liées à l'influenza chez les enfants et les adolescents âgés de 6 mois à 17 ans, au cours de six saisons grippales (entre 1994 et 2000)(13). Le taux estimatif de consultations externes chez les enfants en bonne santé âgés de 24 à 59 mois, au cours des saisons grippales définies, s'établissait à 10,2 pour 100 personnes-mois (IC à $95 \%$ : 9,9-10,6). Chez les enfants de 6 à 23 mois, le taux de consultations externes était de 14,5 pour 100 personnes-mois (IC à $95 \%$ : 13,9-15,1).

Bourgeois et coll. ont effectué une étude en population entre 1993 et 2004 afin d'estimer le taux de consultations au service des urgences (SU) au cours de la saison hivernale pour une infection aiguë des voies respiratoires chez les enfants âgés de 7 ans et moins à Boston, au Massachusetts ${ }^{(14)}$. Le taux d'incidence estimatif moyen, selon l'âge, des consultations pour la grippe au SU du Children's Hospital Boston au cours de la saison hivernale était de 48 pour 1000 consultations pour une IAVR (IC à $95 \%$ : 37-62) chez les enfants de 6 à 23 mois et de 45 pour 1000 consultations pour une IAVR (IC à $95 \%$ : 33-61) chez les enfants de 24 à 59 mois. Le taux d'incidence estimatif moyen, selon l'âge, des consultations pour la grippe à plusieurs SU de Boston était de 22,1 pour 1000 consultations pour une IAVR (IC à $95 \%$ : 20,4-23,7) chez les enfants de 6 à 23 mois et de 11,5 pour 1000 consultations pour une IAVR (IC à $95 \%$ : 10,6-12,3) chez les enfants de 24 à 59 mois.

\section{I.2.2 Hospitalisations}

Six études, faisant appel aussi bien à des méthodes prospectives que rétrospectives, ont examiné les taux d'hospitalisation chez les enfants de moins de 5 ans, les taux d'hospitalisation associée à l'influenza variant d'une étude à I'autre. Au cours des saisons grippales 2004-2005 à 20102011, les données de surveillance recueillies par le réseau canadien de surveillance, le Programme canadien de surveillance active de l'immunisation (IMPACT), ont également été examinées pour les enfants âgés de 24 à 59 mois.

Thompson et coll. ont estimé le taux d'hospitalisation associée à la grippe, en utilisant pour ce faire les codes de la CIM-9-MC ainsi que les données américaines fondées sur la surveillance du virus et les congés des hôpitaux entre 1979 et 2001. Chez les enfants de moins de 5 ans, le taux annuel moyen d'hospitalisation associée à la grippe était d'environ 1,1 pour 1000 personnes-années ${ }^{(5)}$. Les auteurs ont également constaté que le taux annuel d'hospitalisation associée à l'influenza chez les enfants de moins de 5 ans était plus élevé que chez les personnes de 5 à 54 ans dans l'ensemble des catégories de diagnostic de la CIM-9-MC pour les hospitalisations liées à la pneumonie et à I'influenza (codes 480-487 de la CIM-9-MC) et aux maladies 
de l'appareil respiratoire et de l'appareil circulatoire (codes 390-519 de la CIM-9-MC). Le taux était également plus élevé chez les enfants de moins de 5 ans comparativement aux personnes âgées de 50 à 64 ans pour le diagnostic de maladies de l'appareil respiratoire et de l'appareil circulatoire au moment du congé de l'hôpital.

Dans l'étude prospective pluriannuelle en population d'enfants âgés de moins de 5 ans réalisée par Poehling et coll., $6 \%$ de la totalité des sujets hospitalisés recrutés ( $n=2797$ ) ont reçu un diagnostic de grippe. Parmi ces 160 cas, $49 \%$ étaient âgés de 0 à 5 mois, $31 \%$ de 6 à 23 mois et $20 \%$ de 24 à 59 mois ${ }^{(6)}$. Le taux annuel moyen d'hospitalisation pour l'influenza confirmée en laboratoire était de 0,3 pour 1000 (IC à $95 \%$ : 0,2-0,5) chez les enfants de 24 à 59 mois, comparativement à 0,9 pour 1000 (IC à $95 \%$ : 0,7-1,2) chez les enfants de 6 à 23 mois, et à 4,5 pour 1000 (IC à $95 \%: 3,4-5,5)$ chez les enfants de 0 à 5 mois. Environ $20 \%$ des cas de grippe confirmée en laboratoire chez des patients hospitalisés souffraient d'une affection à risque élevé.

À partir de bases de données sur la santé, O’Brien et coll. ont effectué une analyse rétrospective, portant sur la période 1994-2000, des hospitalisations liées à la grippe chez les enfants et les adolescents âgés de 6 mois à 17 ans ${ }^{(13)}$. Le taux d'hospitalisation estimatif chez les enfants en bonne santé âgés de 24 à 59 mois, au cours des saisons grippales définies, était de 5,7 pour 10000 personnes-mois (IC à $95 \%: 3,0-9,0)$. Chez les enfants en bonne santé âgés de 6 à 23 mois, le taux d'hospitalisation estimatif était de 10,4 pour 10000 personnes-mois (IC à $95 \%$ : 6,0-17,0).

Izurieta et coll. ont estimé le taux d'hospitalisation pour la grippe chez les enfants et les adolescents de moins de 18 ans, en se fondant sur les données du Kaiser Permanente Medical Care Program of Northern California et du Group Health Cooperative of Puget Sound, Seattle,

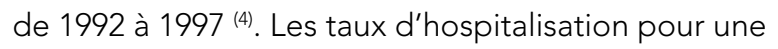
maladie respiratoire aiguë en Caroline du Nord, au cours des périodes d'activité du virus grippal, étaient les suivants chez les enfants ne présentant pas d'affection à risque élevé : 231 pour 100000 personnes-mois (IC à $95 \%$ : 197-271) chez les enfants de moins de 2 ans; 53 pour 100000 personnes-mois (IC à $95 \%$ : 38-72) chez les enfants de 2 à 4 ans; 19 pour 100000 personnes-mois (IC à $95 \%$ : 15-24) chez les enfants et les adolescents de 5 à 17 ans. Les taux d'hospitalisation pour une maladie respiratoire aiguë, au Puget Sound, Seattle, au cours des périodes d'activité du virus grippal étaient les suivants chez les enfants ne présentant pas d'affection à risque élevé : 193 pour 100000 personnes-mois (IC à $95 \%$ : 154-238) chez les enfants de moins de 2 ans; 21 pour 100000 (IC à $95 \%$ : 11-38) chez les enfants de 2 à 4 ans; 16 pour 100000 ( $\mathrm{ICl}$ à $95 \%$ : 12-22) chez les enfants et les adolescents de 5 à 17 ans.

Parmi les enfants et les adolescents âgés de moins de 21 ans, Coffin et coll. ont observé un taux d'incidence des hospitalisations liées à l'influenza confirmée en laboratoire ( $n=231$ ) de 6,8 pour 10000 enfants-années (IC à $95 \%$ :

2,6-14,4) dans leur « cohorte de quartier "(5). Chez les enfants de 0 à 23 mois, le taux était de 41,6 pour 10000 enfantsannées (IC à $95 \%$ : 30,2-56,7), tandis que chez les enfants de 2 à 4 ans, il était de 7,0 pour 10000 enfants-années (IC à $95 \%$ : 2,8-14,4). Parmi l'échantillon total, $77 \%$ des sujets étaient âgés de moins de 5 ans et $49 \%$ étaient atteints d'une affection à risque élevé. Entre 2000 et 2004, $18 \%$ du nombre total d'hospitalisations attribuables à l'influenza ( $n=745$ ) concernaient des enfants de 2 à 4 ans, tandis que $60 \%$ concernaient des enfants de moins de 24 mois. Au nombre des enfants de 2 à 4 ans ( $n=135), 39 \%$ étaient auparavant en bonne santé. Le taux de complications chez les enfants auparavant en bonne santé n'était pas statistiquement différent d'un groupe d'âge à l'autre.

Entre 1973 et 1999, Neuzil et coll. ont mené une étude de cohorte rétrospective portant sur des enfants et des adolescents en bonne santé âgés de moins de 15 ans $^{(3)}$. Le taux standardisé d'hospitalisation pour des problèmes cardiopulmonaires attribués à l'influenza a été estimé à 43 pour 10000 personnes années chez les enfants de 3 à 5 ans, à 79 pour 10000 chez les enfants de 1 à 3 ans et à 22 pour 10000 chez les enfants de 5 à 15 ans. Comme dans les autres études, les taux d'hospitalisation étaient plus élevés dans le groupe des enfants de moins de 6 mois et ils diminuaient avec l'âge.

Le Programme canadien de surveillance active de l'immunisation (IMPACT), un réseau de surveillance dans les hôpitaux pédiatriques, recueille des données sur les effets secondaires suivant l'immunisation, les échecs vaccinaux ainsi que des données de surveillance sur d'autres maladies infectieuses dans 12 centres un peu partout au Canada, relativement aux enfants et aux adolescents de moins de 16 ans. Au cours des saisons grippales 2004-2005 à 2010-2011 (voir le tableau 1, ci-dessous), la proportion d'enfants âgés de 24 à 59 mois qui ont été hospitalisés en raison d'influenza confirmée en laboratoire, parmi le nombre total de cas de grippe admis dans les hôpitaux pédiatriques chez les enfants et les adolescents de moins de 16 ans (moins de 18 ans au cours des années de pandémie), se situait entre 20 et $29 \%$. 
TABLEAU 1: Proportion d'admissions dans les hôpitaux pédiatriques attribuables à l'influenza confirmée en laboratoire chez les enfants âgés de 24 à 59 mois, selon le Programme canadien de surveillance active de l'immunisation (IMPACT), au cours des saisons grippales 2004-005 à 2010-2011

\begin{tabular}{l|l|l|l}
\hline Saison grippale & Type de la saison & $\begin{array}{l}\text { Proportion des admissions dans les } \\
\text { hôpitaux pédiatriques chez les enfants } \\
\text { de } \mathbf{2 4} \text { à } \mathbf{5 9} \text { mois } \\
(\%(\mathbf{n} / \mathbf{N}))\end{array}$ & $\begin{array}{l}\text { Groupes d'âge prédominants parmi les } \\
\text { admissions dans les hôpitaux pédiatriques }\end{array}$ \\
\hline $2004-2005$ & A & $20,2 \%(79 / 391)$ & Groupe d'âge $(\%)$ \\
\hline $2005-2006$ & Mélange & $27,3 \%(102 / 374)$ & Moins de 2 ans $(54,7 \%)$ \\
\hline $2006-2007$ & A & $25,9 \%(96 / 370)$ & Moins de 2 ans $(38,5 \%)$ \\
\hline $2007-2008$ & Mélange & $23,3 \%(116 / 497)$ & Moins de 2 ans $(49,5 \%)$ \\
\hline $2008-200{ }^{\star}$ & A & $21,9 \%(168 / 767)$ & Moins de 2 ans $(46,7 \%)$ \\
\hline $2009-2010^{\star}$ & A & $22,7 \%(215 / 948)$ & Eoins de 2 ans $(36,2 \%)$ et \\
\hline $2010-2011$ & A & $29,1 \%(195 / 671)$ & Égal ou plus de 5 ans $(41,9 \%)$ \\
\hline
\end{tabular}

* Saisons correspondant à la pandémie de l'influenza A (H1N1) de 2009.

\section{I.2.3 Mortalité}

Il est difficile d'estimer directement le nombre de décès dus à l'influenza, étant donné que les infections grippales ne font généralement pas l'objet d'une confirmation virologique ni d'une mention spécifique sur les formulaires de congé des hôpitaux ou les certificats de décès. Les taux de mortalité ont été présentés dans deux analyses des données de systèmes de surveillance américains et deux études utilisant des données recueillies de manière prospective.

Thompson et coll. ont utilisé les données nationales sur la mortalité et celles de la surveillance du virus aux États-Unis pour modéliser le taux de mortalité attribuable à l'influenza au cours des saisons 1990-1991 à 1998-1999(16). Le taux annuel estimatif de mortalité attribuable à l'influenza était plus élevé chez les personnes de 65 ans et plus pour les causes de décès suivantes : pneumonie et influenza (codes 480-487 de la CIM 9), maladies sous-jacentes de l'appareil respiratoire et de l'appareil circulatoire (codes 390519 de la CIM 9 et codes 100-199, J00-J99 de la CIM 10,), toutes causes confondues (tous les codes de la CIM). Chez les enfants âgés de 1 à 4 ans, le taux annuel estimatif de mortalité attribuable à l'influenza (code de la CIM 9, pneumonie et influenza sous-jacentes) était de 0,2 pour 100000 personnes années, comparativement à 0,3 pour 100000 chez les enfants de moins de 1 an. En ce qui concerne les décès dus aux maladies sous-jacentes de I'appareil respiratoire et de l'appareil circulatoire (codes de la CIM 9), les enfants âgés de 1 à 4 ans présentaient un taux annuel estimatif de mortalité attribuable à l'influenza plus faible que celui des enfants de moins de 1 an, soit 0,4 contre 0,6 , respectivement. En ce qui a trait aux décès toutes causes confondues (tous les codes de la CIM), les enfants âgés de 1 à 4 ans affichaient un taux annuel estimatif de mortalité attribuable à l'influenza plus faible que celui des enfants de moins de 1 an, soit 2,2 contre 1,1 , respectivement. Dans tous les groupes d'âge, I'influenza était associée à un plus grand nombre de décès que l'infection par le VRS, sauf chez les enfants âgés de moins de 1 an.

Bhat et coll. ont utilisé des formulaires normalisés pour recueillir des données sur les décès d'enfants (moins de 18 ans) liés à l'influenza confirmée en laboratoire au cours de la saison grippale 2003-2004. Parmi les décès déclarés ( $n=153), 96$ (63\%) concernaient des enfants âgés de moins de 5 ans et 61 (40\%), des enfants de moins de 2 ans ${ }^{(17)}$. Trente-trois pour cent des 149 cas pour lesquelles les données avaient été déclarées étaient atteints d'une affection jugée à risque élevé par l'Advisory Committee on Immunization Practices. Dans l'ensemble, le taux de mortalité diminuait avec l'âge. Louie et coll. ont analysé les données relatives aux décès d'enfants (moins de 18 ans) liés à l'influenza confirmée en laboratoire au cours des saisons grippales 2003-2004 et 2004-2005 en Californie (États-Unis). Parmi les 160 cas déclarés d'influenza confirmée en laboratoire, 15 ont été fatals, la répartition selon l'âge étant la suivante : moins de 6 mois, $n=2 ; 6$ à 23 mois, $\mathrm{n}=5 ; 2$ à 4 ans, $\mathrm{n}=4 ; 5$ à 11 ans, $\mathrm{n}=2 ; 12$ à 17 ans, $n=2$. Vingt-sept pour cent des 15 personnes décédées étaient auparavant en bonne santé(8). 
Au cours de la saison grippale 2006-2007 aux États-Unis, 68 décès ont été dénombrés chez des personnes de moins de 18 ans. Parmi l'ensemble des décès, 10 sont survenus chez des enfants de moins de 6 mois, 10 chez des enfants de 6 à 23 mois, 9 chez des enfants de 2 à 4 ans, et 39 chez des enfants de 5 à 17 ans $^{(18)}$.

\section{I.3 EFFICACITÉ POTENTIELLE ET EFFICACITÉ RÉELLE}

Il a été établi que l'efficacité potentielle et l'efficacité réelle des vaccins antigrippaux variaient en fonction de facteurs tels que l'âge, l'immunocompétence, la correspondance entre les souches virales contenues dans les vaccins et les souches en circulation dans la collectivité et le critère d'évaluation mesuré. Dans des études sur l'efficacité potentielle et sur l'efficacité réelle des vaccins, on a évalué des critères tels que l'incidence de l'influenza confirmée en laboratoire, de la maladie respiratoire aiguë ayant nécessité une intervention médicale, du syndrome grippal auto-déclaré et de l'otite moyenne aiguë (OMA). En raison des différences entre le VTI et le VVAl, nous avons examiné séparément l'efficacité potentielle et l'efficacité réelle des deux vaccins.

\section{I.3.1 Vaccin trivalent inactivé (VTI)}

Au cours de la période visée par la recension des écrits, nous avons relevé 10 études de cohorte, sept études cas-témoins, une étude longitudinale, une étude écologique et deux études descriptives ayant évalué I'efficacité potentielle et l'efficacité réelle du vaccin VTI. La majorité des 11 études portant sur l'influenza confirmée en laboratoire ont estimé que le VTI présentait une efficacité de 45 à $60 \%$ (intervalle : 39-86\%). Cinq études ${ }^{(19)-(23)}$ ont établi que les enfants ayant reçu deux doses du vaccin étaient mieux protégés contre la maladie et contre les hospitalisations ou consultations externes que ceux n'ayant reçu qu'une seule dose. Une étude a fait ressortir une efficacité réelle supérieure du vaccin lors de la vaccination partielle que lors la vaccination complète, mais on notait un chevauchement des intervalles de confiance ${ }^{(24)}$.

\section{Influenza confirmée en laboratoire}

L'incidence de l'influenza confirmée en laboratoire était le critère évalué dans 11 des études examinées, la majorité d'entre elles ayant fait appel à la culture du virus et/ou à la RT-PCR (20)-(28). Une étude a eu recours à un test diagnostique rapide(29), et une autre, à un dosage immunologique sur membrane ${ }^{(30)}$ pour confirmer les infections grippales.
Belongia et coll. ${ }^{25)}$ ont observé une protection modérée chez les enfants au cours de la saison grippale 2007-2008 au Wisconsin (États-Unis). Les participants ayant fait l'objet d'une intervention médicale ont été sélectionnés pour une analyse cas-témoins réalisée à partir d'une cohorte prospective communautaire. Parmi les 1914 participants à l'étude, 412 (22\%) étaient des enfants âgés de 6 à 59 mois. L'efficacité réelle du vaccin (EV) chez les enfants de 6 à 59 mois était de $39 \%$ (IC à $95 \%$ : 2-62). Lorsque l'analyse portait uniquement sur les enfants ayant subi le test 0 à 3 jours après le début de la maladie, l'efficacité du vaccin chutait à $31 \%$ (IC à $95 \%$ : -24 à 62). II s'agit de la plus faible valeur estimée comparativement aux valeurs des autres groupes d'âge (48\% chez les 5 à 49 mois et $53 \%$ chez les 50 mois et plus). Dans l'étude portant sur la saison 20072008, on a observé une faible correspondance entre les lignées de la souche $B$.

Eisenberg et coll.(20) ont observé une efficacité du vaccin (EV) à la fois faible et modérée au cours des deux saisons grippales examinées dans une étude cas-témoins portant sur 2474 enfants âgés de 6 à 59 mois atteints d'une infection respiratoire aiguë ayant nécessité une intervention médicale. Dans une analyse d'un sous-groupe d'enfants de 24 à 59 mois ayant reçu la série vaccinale complète, on a estimé que l'efficacité du vaccin était de $66 \%$ (IC à $95 \%$ : -106 à 94) en 2003-2004 et de $63 \%$ (IC à $95 \%$ : 16-84) en 2004-2005. La vaccination partielle s'est avérée inefficace au cours des deux saisons. On a émis I'hypothèse qu'une correspondance sous optimale entre les souches vaccinales et les souches en circulation, plus marquée en 2003-2004 qu'en 2004-2005, pouvait avoir eu une incidence sur les estimations de l'efficacité du vaccin.

Dans une étude de cohorte prospective effectuée par Heinonen et coll. ${ }^{(26)}, 631$ enfants âgés de 9 mois à 3 ans ont été suivis au cours de la saison grippale 2007-2008 à Turku, en Finlande. Cinquante-six pour cent de la population était âgée de 2-3 ans $(n=353)$, et une analyse visant à comparer, dans ce sous-groupe, l'efficacité du vaccin chez des participants ayant reçu la série vaccinale complète et des participants non vaccinés a conclu à une efficacité de 100 $\%$ (IC à $95 \%$ : 6-100; $p=0,05)$ contre l'influenza de type $A$ et de $33 \%$ (IC à $95 \%$ : -97 à 78; $p=0,78)$ contre le type $B$. Une analyse cas témoins des participants a fait ressortir une efficacité du vaccin semblable, les sujets partiellement vaccinés étant considérés comme non vaccinés.

Deux études pluriannuelles ont été menées au Japon par Joshi et coll. ${ }^{(21)}$ et Katayose et coll. ${ }^{(29)}$ chez des enfants âgés de 6 mois à moins de 6 ans. Joshi et coll. ont suivi 206 enfants âgés de 6 à 59 mois de 1999-2000 à 2006-2007. 
Une comparaison entre les enfants vaccinés et les enfants non vaccinés a fait ressortir une efficacité du vaccin de $86 \%$ (IC à $95 \%$ : 29-97) chez les enfants ayant reçu la série vaccinale complète comparativement à $73 \%$ (IC à $95 \%$ : 3-93) chez les enfants partiellement vaccinés. Katayose et coll. ont réalisé une étude d'observation prospective non randomisée dans une petite région du Japon entre 2002-2003 et 2007-2008 auprès de 14788 enfants âgés de 6 mois à moins de 6 ans. L'efficacité du vaccin chez les enfants ayant entre 2 et moins de 3 ans, entre 3 et moins de 4 ans et entre 4 et moins de 5 ans s'établissait à $57 \%$ (IC à $95 \%$ : 49-68; $p<0,01)$, à $53 \%$ (IC à $95 \%$ : 42-67; $p<0,01)$ et à $45 \%$ (IC à $95 \%$ : 25-67; $p<0,01)$, respectivement, contre l'influenza A. Contre l'influenza de type B, l'efficacité du vaccin était de $71 \%(p<0,01)$ chez les enfants ayant entre 2 et moins de 3 ans, de $60 \%(p<0,01)$ chez les enfants ayant entre 3 et moins de 4 ans et de $51 \%$ ( $p<$ $0,01)$ chez les enfants ayant entre 4 et moins de 5 ans.

Dans une étude cas-témoins réalisée en Australie ${ }^{(22)}$, on a recruté 289 enfants âgés de 6 à 59 mois dans des cabinets d'omnipraticiens ( $n=75$ ) et un service d'urgences pédiatriques $(n=214)$. Environ la moitié de ces enfants étaient âgés de 2 ans et plus. L'efficacité du vaccin a été évaluée à $58 \%$ (IC à $95 \%$ : 9-81) parmi l'ensemble des enfants, à $51 \%$ (IC à $95 \%$ : -21 à 80 ) chez les enfants recrutés au service des urgences, et à $87 \%$ (IC à $95 \%$ : 8-98) chez les enfants recrutés dans des cabinets d'omnipraticiens. Le VTI était plus efficace contre I'influenza de type A (efficacité du vaccin : $82 \%$, IC à $95 \%$ : 21-96) que contre le type $B$, pour laquelle l'efficacité était de $43 \%$ (IC à $95 \%$ : -39 à 77). L'efficacité plus élevée du vaccin chez les enfants faisant partie du groupe « omnipraticiens » de l'étude pourrait être attribuable au fait qu'un cabinet d'omnipraticien doté d'un programme de vaccination particulièrement dynamique a fourni à lui seul la moitié des participants de ce groupe. Dans ce cabinet d'omnipraticien, $64 \%$ des enfants avaient reçu la série vaccinale complète comparativement à $37 \%$ des enfants du groupe «service des urgences ». Treize échecs de la vaccination ont été signalés, dont neuf étaient dus à une correspondance insatisfaisante avec la souche du virus de l'influenza de type B.

Szilagyi et coll. (28) ont mené une étude cas cohorte dans laquelle ils ont recruté des enfants âgés de 6 à 59 mois, dont 9468 étaient hospitalisés et 1438 traités en consultations externes au cours de deux saisons grippales (entre 2003 et 2005) aux États-Unis. Ils ont sélectionné les cas de manière prospective en se fondant sur les consultations pour une infection aiguë des voies respiratoires, tandis que les témoins ont été déterminés de manière rétrospective et stratifiés selon l'âge à partir des dossiers médicaux. L'efficacité du vaccin chez les enfants de 24 à 59 mois se situait entre -108 et $77 \%$ pour les enfants ayant reçu la série vaccinale complète et les enfants partiellement vaccinés au cours des deux saisons grippales; aucune des estimations n'était statistiquement significative. Comme on l'avait constaté dans d'autres études, une correspondance antigénique sous optimale entre les souches vaccinales et les souches en circulation en 2003-2004 et en 2004-2005 a miné la capacité de démontrer que le vaccin permettait de prévenir efficacement les hospitalisations et les consultations externes liées à l'influenza.

Dans le cadre d'une étude cas témoins, Shuler et coll.(24) ont suivi 870 enfants âgés de 6 à 59 mois fréquentant une même clinique pédiatrique en Géorgie (États-Unis). Les témoins ont été appariés selon l'âge, par mois, avec des cas d'influenza confirmée en laboratoire selon un rapport 2:1. Après ajustement pour tenir compte des affections à risque élevé et de l'utilisation des soins de santé, une analyse de sous-groupe portant sur des enfants de 24 à 59 mois a mis en évidence une efficacité du vaccin de $45 \%$ ( $R C$ : 0,55, IC à $95 \%: 0,3-0,9 ; p<0,05$ ) chez les enfants ayant reçu la série vaccinale complète comparativement aux enfants non vaccinés. Chez les enfants partiellement vaccinés de ce groupe d'âge, l'efficacité du vaccin était plus élevée (65\%) (RC : 0,35, IC à $95 \%$ : 0,2-0,7; $p<0,05)$, mais on notait un chevauchement des intervalles de confiance. L'efficacité du vaccin chez les sujets partiellement vaccinés n'était pas significative lorsque l'évaluation portait sur l'ensemble de la population à l'étude. Comme il avait été constaté dans d'autres études, on a estimé qu'une correspondance antigénique sous optimale entre les souches vaccinales et les souches en circulation avait joué un rôle au cours de la saison 2003-2004.

Au cours des deux saisons grippales entre 2005 et 2007, Staat et coll. ${ }^{(23)}$ ont mené une étude prospective cas témoins en population chez des enfants âgés de 6 à 59 mois aux États Unis. Les témoins ont été appariés avec les cas selon le centre régional, le plus haut niveau de soins reçu, le groupe d'âge et la date d'apparition de la maladie. Les patients recrutés dans l'étude fréquentaient des établissements pour patients hospitalisés et patients externes; 268 enfants ont été recrutés en 2005-2006 et 528 en 2006-2007. L'analyse portant sur les enfants de 24 à 59 mois a révélé une efficacité du vaccin de $43 \%$ (IC à $95 \%$ : -62 à 80) au cours de la première saison et de 76 \% (IC à 95 
$\%$ : -16 à 95) au cours de la deuxième saison chez les enfants ayant reçu la série vaccinale complète. L'efficacité estimative du vaccin chez les enfants partiellement vaccinés était de $6 \%$ (IC à $95 \%$ : -330 à 80 ) et de $44 \%$ (IC à $95 \%$ : -77 à 82) au cours des première et deuxième saisons, respectivement. Lorsque les deux saisons étaient examinées globalement, l'efficacité du vaccin était de $56 \%$ (IC à $95 \%$ : 3-80) chez les enfants ayant reçu la série vaccinale complète, et de $34 \%$ (IC à $95 \%$ : -64 à 73) chez les enfants partiellement vaccinés.

\section{Syndrome grippal (SG)}

Le SG a été examiné dans cinq études distinctes, dont quatre portaient sur des patients ayant consulté un médecin (clinique de consultations externes ou service des urgences) ${ }^{(19)(31)-(34)}$. Toutes les études ont fait état de réductions du résultat à l'étude chez les enfants vaccinés.

Ghendon et coll. ${ }^{(32)}$ se sont penchés sur l'efficacité clinique réelle du VTI dans le cadre d'un programme de vaccination de masse chez des enfants d'âge scolaire en Russie. Une comparaison des taux de SG diagnostiqué par un médecin (température $>38^{\circ} \mathrm{C}$, accompagné de toux ou de maux de gorge) dans deux collectivités visées par l'intervention et deux collectivités témoins a montré que chez les enfants en bonne santé âgés de 3 à 6 ans, on dénombrait 2,56 moins de cas de maladie, l'efficacité du vaccin s'établissant à $60,9 \%(p<0,01)$. Il y avait une correspondance antigénique satisfaisante entre les souches vaccinales et les souches $A$ (H3N2) et B en circulation au cours de la saison à l'étude.

Dans deux études, Ritzwoller et coll. ${ }^{(19)}$ et Hoen et coll. ${ }^{(35)}$ ont examiné les dossiers médicaux des patients afin d'évaluer les critères liés au SG parmi des populations pédiatriques aux États-Unis et au Canada. Dans une étude de cohorte rétrospective, Ritzwoller et coll. ont passé en revue les dossiers électroniques des consultations externes et des consultations aux services des urgences au Colorado (États-Unis) pour un SG et pour une pneumonie et l'influenza ( $P$ et I) chez les enfants de 6 mois à 8 ans. Environ $92 \%$ des cas de SG et 90,5\% des cas de $P$ et I ont été recensés dans les services de consultations externes. En ce qui concerne le SG, le rapport d'incidence instantanée (RII) ajusté pour le sexe, l'âge et la maladie antérieure était de 0,77 (IC à $95 \%$ : 0,66-0,90; $p<0,001$ ) chez les enfants de 2 à 8 ans ayant reçu la série vaccinale complète et n'était pas statistiquement significatif chez les enfants partiellement vaccinés. Dans le cas de la $P$ et $I$, on observait un effet protecteur chez les enfants ayant reçu la série vaccinale complète, le RII s'établissant à 0,49 (IC à $95 \%$ : 0,36-0,67; $p<0,001)$, tandis que l'effet était moindre chez les enfants partiellement vaccinés, avec un RII de 0,77
(IC à $95 \%$ : 0,62-0,95; $\mathrm{p}<0,001)$. Dans une étude écologique, Hoen et coll. ont examiné les consultations aux urgences pédiatriques liées au SG entre 2000-2001 et 2008-2009 dans un hôpital canadien et un hôpital américain. La recommandation de I'ACIP de vacciner tous les enfants âgés de 2 à 5 ans a été mise en application en 2006-2007, et une réduction des consultations a par la suite été observée (rapports de cotes : 0,66, IC à $95 \%$ : 0,58$0,75)$ chez les enfants de 2 à 4 ans dans I'hôpital américain comparativement à l'hôpital canadien. Cette étude ne tient cependant pas compte des différences entre des facteurs tels que les caractéristiques démographiques ou les systèmes de santé des deux villes étudiées, et les taux de vaccination sont estimés à partir d'autres enquêtes en milieu communautaire.

Une étude de cohorte prospective réalisée dans des cliniques pédiatriques dans l'ensemble du Japon ${ }^{(31)}$ a évalué l'incidence du SG et la fréquence des consultations au cabinet du médecin chez des enfants vaccinés et des enfants non vaccinés de moins de six ans. Les auteurs se sont fondés sur les symptômes déclarés par les parents et sur les dossiers des cliniques. Le rapport de cotes ajusté n'était significatif que durant le pic de la période épidémique pour le SG grave (SG avec fièvre $\geq 39,0^{\circ} \mathrm{C}$ ), $R C: 0,75$ (IC à $95 \%: 0,58-0,91 ; p=0,031$ ), et seulement chez les enfants de 3,0 à 3,9 ans (RC : 0,50, IC à $95 \%$ : $0,26-0,96)$. Selon les auteurs, cette observation pourrait s'expliquer par la puissance statistique réduite associée aux analyses de sous-groupes. Lorsque tous les enfants étaient inclus dans l'analyse, on observait une faible réduction des consultations au cabinet du médecin liées à un SG grave chez les enfants vaccinés par rapport aux enfants non vaccinés (RC : 0,73, IC à $95 \%$ : 0,59-0,96; $p=0,023)$. Les consultations médicales, toutes causes confondues, étaient aussi moins nombreuses chez les enfants vaccinés ( $R C: 0,79, I C$ à $95 \%: 0,64-0,98 ; p=0,028$ ) lorsque tous les enfants étaient inclus.

Dans l'étude de cohorte multicentrique menée par Fujieda et coll. ${ }^{(33-34)}$, les participants ont été recrutés dans des cliniques pédiatriques, et les cas fébriles ont été déterminés à partir des déclarations des parents. L'échantillon comprenait 2913 enfants de moins de 6 ans et les parents indiquaient eux-mêmes si leur enfant était ou non vacciné. L'efficacité du vaccin parmi les enfants de 2,0 à 5,9 ans était de $33 \%$ (IC à $95 \%$ : 21-44). Une analyse portant sur des groupes d'âge plus jeunes a mis en évidence un RC statistiquement significatif chez les enfants de 2,0 à 2,9 ans $(0,61, I C$ à $95 \%: 0,44-0,84 ; p=0,002)$ et de 3,0 à 3,9 ans $(0,60$, IC à $95 \%: 0,43-0,84 ; p=0,003)$, mais non chez les enfants de 4,0 à 4,9 ans. 


\section{Hospitalisations}

La recherche effectuée en vue de l'analyse des données n'a fait ressortir que deux études permettant d'évaluer les hospitalisations liées à l'influenza dans ce groupe d'âge. L'étude d'observation réalisée par Katayose et coll. ${ }^{(29)}$ a évalué l'efficacité de deux doses du VTI dans la prévention des hospitalisations liées à l'influenza de type $A$ et à I'influenza de type B au Japon. Au cours des 6 saisons grippales de suivi, l'efficacité du vaccin contre l'influenza A chez les enfants âgés de 2 à moins de 3 ans, de 3 à moins de 4 ans et de 4 à moins de 5 ans était de $61 \%(p<0,05)$, $74 \%(p<0,01)$ et $74 \%(p<0,01)$, respectivement. L'efficacité du vaccin à l'égard des hospitalisations pour I'influenza de type B se situait entre 68 et $88 \%$, mais elle n'était pas significative. Dans l'étude de Dixon et coll.(27), I'efficacité du vaccin chez les enfants ayant reçu la série vaccinale complète comparativement aux enfants non vaccinés hospitalisés en Australie-Occidentale (résultats laboratoires confirmés positifs ou négatifs pour l'influenza) était de $83 \%$, mais n'était pas significative.

\section{I.3.2 Vaccin vivant atténué (VVAl)}

Six études visant à déterminer l'efficacité potentielle et l'efficacité réelle de ce vaccin ont été analysées. Les six études étaient des essais comparatifs randomisés, dont cinq utilisaient comme critère d'évaluation l'influenza confirmée en laboratoire et un évaluait l'utilisation des médicaments en vente libre et des médicaments d'ordonnance. Trois études étaient des essais communautaires de terrain qui évaluaient les maladies respiratoires aiguës ayant nécessité une intervention médicale (MRAIM) dans des collectivités où une campagne de vaccination de masse des enfants d'âge scolaire avait été lancée. Les estimations de l'efficacité variaient de 44 à $85 \%$, et la plupart se situaient entre 50 et $85 \%$ pour l'influenza confirmée en laboratoire. Vu l'arrivée relativement récente du WAl sur le marché, peu de ces études évaluaient l'efficacité du vaccin chez les enfants de 24 à 59 mois ou effectuaient des analyses de sous-groupes parmi les enfants de ce groupe d'âge. Pour de plus amples renseignements sur le WAl, veuillez consulter les Recommandations relatives à l'utilisation du vaccin antigrippal vivant atténué (FluMist $\left.{ }^{\circledR}\right)$ : Déclaration complémentaire sur la vaccination antigrippale pour la saison 2011-2012, à l'adresse (http://www.phac-aspc.gc.ca/ publicat/ccdr-rmtc/11vol37/acs-dcc-7/assets/pdf/acs-dcc-7fra.pdf $)^{(36)}$.

\section{Influenza confirmée en laboratoire}

Dans un essai comparatif randomisé du VAI et du VTI, Ashkenazi et coll. ${ }^{(37)}$ ont réparti au hasard 2187 enfants âgés de 6 à 71 mois ayant des antécédents d'infections récurrentes des voies respiratoires, notamment le rhume, l'otite moyenne aiguë, la bronchite, la pneumonie et la bronchiolite. L'efficacité potentielle du vaccin a été évaluée parmi 2085 enfants de cette population traitée selon le protocole. Les chercheurs ont constaté qu'il y avait $53 \%$ (IC à $95 \%$ : 22-72) moins de cas de grippe confirmée par culture attribuable à une souche présente dans le vaccin parmi les enfants ayant reçu le WAl que parmi ceux ayant reçu le VTI (24/1 050 c. 50/1 035, respectivement). Dans l'évaluation des conséquences sur la santé des maladies respiratoires toutes causes confondues (grippe et autres), les sujets ayant reçu le WAI ont signalé $9 \%$ (IC à $95 \%$ : 2-16) moins de jours de consultation chez un dispensateur de soins de santé et $16 \%$ (IC à $95 \%$ : 10-22) moins de jours d'absentéisme de l'école ou de la garderie que les sujets ayant reçu le VTI. Aucune répercussion n'a été observée en ce qui concerne les médicaments ou les antibiotiques administrés contre les infections des voies respiratoires, les hospitalisations de nuit ni la respiration sifflante associés au syndrome grippale. Une analyse a posteriori (38) a révélé que le WAI entraînait une diminution de la gravité de la grippe qui survenait en dépit de la vaccination (grippe postvaccination) comparativement au VTI.

En 2004-2005, Belshe et coll. ${ }^{(39)}$ ont comparé l'efficacité potentielle du WAI et du VTI dans le cadre d'un essai clinique randomisé à double insu multinational auquel ont participé 7852 enfants âgés de 6 à 59 mois. Les groupes d'étude étaient bien appariés sur les plans de la vaccination antérieure contre l'influenza (22 à $23 \%$ ), les antécédents de respiration sifflante (21 à $22 \%$ ), la respiration sifflante récurrente (6 à $7 \%$ ) et l'asthme (4\%). Une enquête sur l'influenza était amorcée lorsqu'une fièvre était signalée en plus d'au moins un des symptômes suivants : toux, mal de gorge ou écoulement nasal / congestion nasale. II y a eu $45 \%$ (IC à $95 \%$ : 22-61) moins de cas de grippe causée par des souches contenues dans le vaccin dans le groupe WAI que dans le groupe VTI (53/3 916 c. 93/3 936, respectivement) et $58 \%$ (IC à $95 \%$ : 47-67) moins de cas causés par des souches non incluses dans le vaccin (102/3 916 c. 245/3 936, respectivement). Dans une étude a posteriori ${ }^{(40)} \mathrm{d}^{\prime}$ enfants âgés de 24 à 35 mois, de 36 à 47 mois et de 48 à 59 mois, l'efficacité potentielle relative du WAI par rapport à celle du VTI était de $57 \%$ (IC à $95 \%$ : 40-69), $42 \%$ (IC à $95 \%$ : 5-66) et $56 \%$ (IC à $95 \%$ : 25-75) respectivement, pour toutes les souches de virus grippal. 
Les essais randomisés pluriannuels contrôlés par placebo réalisés par Tam et coll. et Vesikari et coll. sur deux saisons (2000 à 2002) ont montré que le WAl était efficace pour prévenir l'influenza confirmée par culture attribuable à des souches antigéniquement apparentées chez les enfants vaccinés et les enfants revaccinés. La première étude, par Tam et coll. ${ }^{(41)}$, a été menée dans huit pays d'Asie auprès d'enfants en bonne santé âgés de 12 à 35 mois (efficacité potentielle générale du vaccin la $1^{\text {re }}$ année de $73 \%$, IC à $95 \%$ : 62-80; la 2e année de 84 \%, IC à $95 \%$ : 70-92). La deuxième étude, par Vesikari et coll. ${ }^{(42)}$, portait sur des enfants en bonne santé de cinq pays européens qui étaient âgés de 6 à 35 mois et qui fréquentaient une garderie (efficacité potentielle générale du vaccin la $1^{\text {re }}$ année de $85 \%$, IC à $95 \%$ : 74-92; la $2^{\mathrm{e}}$ année de $89 \%$, IC à $95 \%$ : 82-93). Dans l'étude de Tam et coll., le nombre de cas dus à des souches $A(\mathrm{H} 1 \mathrm{~N} 1)$ ou $B$ était insuffisant pour obtenir une signification statistique, mais l'efficacité potentielle contre ces souches a été déterminée par la suite par Gaglani et coll. et Halloran et coll., qui ont évalué la diminution du nombre de cas de MRAIM par rapport à une souche $A(H 1 N 1)$ résultant d'une dérive antigénique et à une souche $\mathrm{B}^{(43)}$. Dans l'étude de Vesikari et coll., lorsque le vaccin correspondait bien aux souches en circulation, son efficacité contre les souches $A(H 1 N 1)$ était de $91,8 \%$ (IC à $95 \%: 80,8-97,1$ ) la $1^{\text {re }}$ année et de 90,0\% (IC à $95 \%$ : $56,3-98,9)$ la 2 e année. L'efficacité contre les souches B était de $72,6 \%$ (IC à $95 \%$ : 38,6-88,9) la $1^{\text {re }}$ année et de $81,7 \%$ (IC à $95 \%: 53,7-91,9)$ la $2^{\mathrm{e}}$ année. L'efficacité contre la souche A (H3N2) n'a pas été évaluée la $1^{\text {re }}$ année, mais il $\mathrm{s}^{\prime}$ agissait de la souche prédominante en circulation la $2^{\mathrm{e}}$ année et l'efficacité était de 90,3\% (IC à $95 \%$ : 82,9-94,9).

De même, Bracco Neto et coll. ${ }^{(44)}$ ont mené une étude en Afrique du Sud, au Brésil et en Argentine pendant les saisons grippales 2001et 2002, sur des enfants en bonne santé âgés de 6 mois à moins de 36 mois n'ayant jamais reçu le vaccin, et ils ont constaté une réduction de la grippe confirmée par culture attribuable à des souches correspondant ou non à celles du vaccin. La $1^{\text {re }}$ année, l'efficacité potentielle du vaccin par rapport au placebo chez les enfants ayant reçu une ou deux doses de VVAI était de $57,7 \%$ (IC à $95 \%: 44,7-67,9)$ et de 73,5\% (IC à $95 \%: 63,6-81,0)$, respectivement, contre des souches correspondant à celles du vaccin. La $2^{\mathrm{e}}$ année, l'efficacité absolue d'une seule dose de WAI était de 65,2 \% (IC à $95 \%$ : 31,2-82,8) et de 73,6\% (IC à $95 \%$ : 33,3-91,2), respectivement, chez les sujets ayant reçu une ou deux doses de WAI la $1^{\text {re }}$ année. L'efficacité la $2^{\mathrm{e}}$ année chez les sujets ayant reçu deux doses de WAI la $1^{\text {re }}$ année et un placebo la $2^{\mathrm{e}}$ année était de $57 \%$ (IC à $\left.95 \%: 6,1-81,7\right)$ contre des souches antigéniquement semblables en comparaison de ceux qui avaient reçu le placebo les deux années. L'efficacité était de 35,3\% (IC à $95 \%$ : -0,3 à 58,7) et de $20,4 \%$ contre toutes les souches contractées dans la collectivité et contre les souches grippales de type B antigéniquement différentes, respectivement. De plus, lorsque les groupes qui avaient reçu un placebo la $1^{\text {re }}$ année et une dose de VVAl ou un placebo la $2^{\mathrm{e}}$ année étaient comparés, l'efficacité d'une seule dose de VVAI s'établissait à 60,3\% contre les souches correspondant à celles du vaccin, à 59,4\% (IC à $95 \%: 32,3-76,4)$ contre toutes les souches circulant dans la collectivité et à $54,9 \%$ (IC à $95 \%: 16,6-76,6)$ contre les souches de type B ne correspondant pas à celle du vaccin.

L'efficacité absolue du WAI chez les jeunes enfants a aussi été établie par une méta-analyse effectuée en 2009 par Rhorer et coll. ${ }^{(45)}$ qui portait sur l'efficacité contre l'influenza confirmée par culture, comparativement à un placebo, dans des essais cliniques randomisés portant sur 25000 enfants âgés de 6 à 71 mois. Dans cette analyse, l'efficacité combinée la $1^{\text {re }}$ année (par rapport au placebo) de deux doses du vaccin administrées à de jeunes enfants $n$ 'ayant jamais été vaccinés auparavant était de $77 \%(p<0,001)$ contre les souches correspondant à celles du vaccin et de $72 \%(p<0,001)$ sans égard à la correspondance antigénique dans la population traitée selon le protocole. On a observé que l'efficacité variait selon la souche : I'efficacité du vaccin par rapport au placebo après deux doses était de $85 \%$ (IC à $95 \%$ : 78-90), $76 \%$ (IC à $95 \%$ : $70-81$ ) et $73 \%$ (IC à $95 \%: 63-80$ ) contre les souches $A$ (H1N1), A (H3N2) et B antigéniquement semblables, respectivement.

En résumé le WAl a une forte efficacité potentielle chez les enfants de tous les groupes d'âge comparativement au placebo, sans égard au sous type en circulation.

\section{Syndrome grippal et maladie respiratoire aiguë ayant nécessité une intervention médicale}

Dans les études communautaires non randomisées, d'autres mesures de l'efficacité réelle des vaccins ont été évaluées. Gaglani et coll. ${ }^{(43)}$ ont étudié des enfants en bonne santé âgés de 18 mois à 18 ans sur trois saisons grippales (de 1998 à 2001) au Texas (É.-U.). L'étude mesurait l'efficacité réelle directe du WAI contre les infections par les virus de l'influenza $A(H 1 N 1)$ et $B$ en comparant les taux de MRAIM chez les sujets vaccinés (WAl) et des sujets non vaccinés d'âge admissible dans les collectivités visées par l'intervention. En tout, 9765 enfants âgés de 1,5 à 18 ans sur 19700 ont reçu une dose unique 
de VAI pendant l'étude. Chez les sujets de 1,5 à 4 ans qui ont reçu le VVAl les trois années consécutives jusqu'en 2000-2001 inclusivement, l'efficacité directe globale était de $20 \%$ (IC à $95 \%$ : 10-28) pour ce qui est de la diminution des taux de MRAIM pendant les semaines de la saison grippale 2000-2001 où était survenue une épidémie d'influenza $A$ et $B$, et de $16 \%$ (IC à $95 \%$ : 1-28) pendant les semaines où seule l'influenza $A(H 1 N 1)$ était prédominante. L'efficacité réelle totale du WAI a également été mesurée en comparant les taux de MRAIM chez les sujets vaccinés et les taux parmi les sujets non vaccinés dans des collectivités témoins où le WVAl n'était pas offert. Chez les sujets de 2,5 à 4 ans qui avaient reçu le VVAl les trois années consécutives, l'efficacité réelle totale était de $18 \%$ (IC à $95 \%$ : 8-26) pour ce qui est de la diminution des taux de MRAIM pendant les semaines où était survenue une épidémie d'influenza $\mathrm{A}$ et $\mathrm{B}$ et de $16 \%$ (IC à $95 \%$ : 2-28) pendant les semaines où seule l'influenza $A$ (H1N1) était prédominante.

\section{I.3.3 Otite moyenne aiguë}

Le VTI et le VVAl se sont révélés efficaces pour réduire I'incidence de l'otite moyenne aiguë (OMA). Dans une étude de cohorte prospective menée par Ozgur et coll. (46), 119 enfants âgés de 6 à 60 mois qui fréquentaient une garderie à Ankara, en Turquie, ont subi un examen visant à déceler une OMA, une otite moyenne avec épanchement (OME) ou une OM (OMA et OME combinées) toutes les 6 semaines pendant 6 mois au cours d'une saison grippale. À la fin de la période d'étude, les chercheurs avaient observé moins de cas d'OMA $(2,3 \%$ c. $5,2 \%, p=0,012)$, d'OME $(22,8 \%$ c. $31,1 \%, p=0,002)$ et d'OM $(25,2 \%$ c. $36,3 \%, p<0,001)$ parmi les enfants qui avaient reçu le VTI que parmi ceux qui n'avaient pas été vaccinés. La fréquence de l'OMA, de l'OME et de l'OM d'un groupe à l'autre n'était pas statistiquement différente avant ou après la saison grippale. L'efficacité réelle calculée du vaccin contre l'OMA était de 50,9\%. Dans une étude de Belshe et coll. ${ }^{(39)}$ comparant le VVAl au VTI, une réduction de $51 \%$ (IC à $95 \%$ : 22-70) des otites moyennes et de $46 \%$ (IC à $95 \%$ : 4-70) des maladies des voies respiratoires inférieures toutes souches confondues a été enregistrée sans égard à la correspondance avec les souches vaccinales.

\section{I.3.4 Protection indirecte}

$S$ 'il est entendu que la vaccination des enfants en bonne santé âgés de 24 à 59 mois entraîne une réduction directe du nombre de cas de maladies liées à l'influenza et de leurs répercussions, ces bienfaits s'étendraient aussi aux contacts, familiaux et autres, dans la collectivité. II ressort de certaines études que les membres de la famille des enfants en bonne santé vaccinés contre l'influenza sont moins nombreux à souffrir de maladies liées à l'influenza ou d'infections des voies respiratoires, à consulter un médecin, à s'absenter du travail ou de l'école, en plus d'avoir besoin de moins d'ordonnances d'antibiotiques et de médicaments en vente libre ${ }^{(32)(47-48)}$. Dans les études menées dans des collectivités disposant de programmes de vaccination systématique contre l'influenza pour les enfants, pas nécessairement limités aux enfants de 24 à 59 mois, des taux réduits de MRAIM ont été observés chez les adultes de 35 ans et plus ${ }^{(49)}$. Dans une étude canadienne menée dans des communautés huttérites, la protection indirecte conférée par le vaccin a été estimée à $61 \%$ (IC à $95 \%$ : $8-83, p=0,03$ ) chez les personnes de moins de 15 ans qui n'avaient pas été vaccinées contre l'influenza ${ }^{(50)}$.

À l'aide d'un modèle de transmission dynamique, Pitman et coll (51) ont évalué l'impact indirect de la vaccination des enfants (de 2 à 18 ans) par le WVAl sur la population générale de l'Angleterre et du pays de Galles. En présumant d'une efficacité réelle de $80 \%$ et d'une couverture vaccinale de $80 \%$ parmi les 2 à 5 ans sur une période de 15 ans (2009-2024), le modèle a prédit que 2,4 millions de cas, en moyenne, seraient évités chaque année ( $<2$ ans : 106 000; 5-18 ans : 1 million; $19-49$ ans : 840 000; 5064 ans : 310 000; 65 ans et plus : 75 000). De plus, le modèle a prédit une réduction de $44 \%, 40 \%$ et $36 \%$, respectivement, du nombre annuel moyen de consultations en médecine générale, d'hospitalisations et de décès dans la population totale de l'Angleterre et du pays de Galles.

\section{I.4 IMMUNOGÉNICITÉ}

Des études ont démontré que le VTI et le VVAl sont immunogènes chez les enfants âgés de 24 à 59 mois ${ }^{(41)(52-54)}$. Habituellement, l'immunogénicité du VTI s'accroît avec l'âge, dans la population pédiatrique cependant, I'immunité conférée par le VTI est plus durable chez les adultes que chez les enfants ${ }^{(55)}$. Dans le cas du VTI, l'immunogénicité observée est supérieure chez les enfants qui ont déjà eu l'infection naturelle ou ont déjà été vaccinés contre l'influenza ${ }^{(7)(56)}$.

Le WAI s'est révélé aussi immunogène, voire plus immunogène, que le VTI chez les enfants. On croit que, avec le WAl, l'exposition à un plus grand nombre $d^{\prime}$ 'antigènes présentés par un virus vaccinal vivant déclenche une réponse immunitaire qui s'apparente 
à la réponse induite par l'infection naturelle au virus de type sauvage. Le WVAl pourrait induire une réponse immunitaire muqueuse par les IgA et/ou provoquée par médiation des lymphocytes $T$ ainsi que la production $d^{\prime}$ anticorps humoraux présentant une plus grande réactivité croisée qui peuvent conférer une protection croisée lorsque la correspondance entre les souches vaccinales et les souches grippales épidémiques n'est pas optimale. (Prière de se reporter à la déclaration relative à FluMist au : http://www.phac-aspc.gc.ca/publicat/ccdrrmtc/11vol37/acs-dcc-7/index-fra.php pour en savoir plus sur l'immunogénicité du WVAl(36).

\section{I.5 INNOCUITÉ}

D'après les données issues des essais cliniques randomisés, d'autres études analytiques et des données de surveillance post-commercialisation, le vaccin vivant atténué et le vaccin inactivé trivalent contre l'influenza sont sécuritaires et bien tolérés chez les enfants âgés de 24 à 59 mois. Les taux d'effets secondaires suivant la vaccination sont faibles et les taux d'effets secondaires graves le sont encore plus. L'innocuité du VVAl et celle du VTI seront analysées séparément ci-après.

\section{I.5.1 Vaccin trivalent inactivé (VTI)}

L'évaluation des données sur l'innocuité du VTI chez les enfants âgés de 24 à 59 mois repose principalement sur cinq essais randomisés contre un comparateur actif (37)(39)/54) (57)(58), une étude de dépistage auto-contrôlée $e^{(59)}$ et une étude de cohorte communautaire ${ }^{(32)}$. L'innocuité a aussi été évaluée à l'aide des données de surveillance postcommercialisation des États-Unis et du Canada ${ }^{(60)(61)}$ ainsi que d'autres analyses d'études. Plusieurs des études analysées portaient à la fois sur le VTI et le VVAl. Ces études sont décrites en détail à la section I.5.3.

L'innocuité du VTI chez les enfants de 24 à 59 mois a été évaluée au moyen des effets secondaires courants signalés sur demande (locaux et généraux), dont l'érythème, la douleur/sensibilité, l'œdème, la gêne des mouvements des membres, les malaises, la somnolence, la fièvre, l'irritabilité, la perte d'appétit, les céphalées et les myalgies, ainsi que d'autres effets secondaires signalés spontanément ${ }^{(39)(57)(58)}$.

Au nombre des effets secondaires couramment signalés chez les sujets ayant reçu un VTI figuraient la sensibilité/ douleur au point d'injection, l'écoulement nasal/ congestion nasale, la toux, la perte d'appétit, l'irritabilité et la fièvre ${ }^{(37)(38 /(57)(58)}$. Plusieurs études ont révélé que la majorité des effets liés à la réactogénicité et des effets secondaires locaux et généraux étaient légers à modérés et transitoires ${ }^{(38)(39)(57)}$. Par ailleurs, dans un certain nombre d'études analysées, aucun effet secondaire grave e $^{(32)(54)(57)(58)}$ ni décès ${ }^{(37)(39)(57)}$ considérés comme liés aux vaccins à l'étude n'ont été signalés.

Glanz et coll. ${ }^{(59)}$ ont effectué une analyse auto-contrôlée de séries de cas parmi des enfants de 24 à 59 mois qui avaient été soignés par l'un des sept organismes de gestion de soins concernés aux États-Unis. Les auteurs ont fait des recherches dans les bases de données de ces organismes pour y déceler les événements ayant nécessité une intervention médicale (EIM) à l'aide des codes de la CMI-9-MC. Après la recherche initiale au moyen de ces codes, les auteurs ont confirmé les EIM par un examen des dossiers médicaux. Dans leur analyse des événements les moins graves, les auteurs ont observé que les douleurs aux membres ayant nécessité une intervention médicale étaient significativement associées au VTI dans les 2 jours suivant la vaccination $(p=0,04)$. La seule manifestation potentiellement grave qui était associée à la vaccination était les troubles digestifs aggravés dans la sous-cohorte des enfants atteints d'une affection à haut risque (rapport des taux d'incidence [RTI] 7,70; IC à $95 \%$ : 1,11-53,52).

Lors de leur analyse des doses annuelles sur de multiples années, les auteurs n'ont relevé aucune tendance significative au chapitre des EIM (non confirmé par l'examen des dossiers médicaux) associée à l'augmentation du nombre de doses, de 2 à 5 . Vu le petit nombre d'EIM observés après l'administration de la $4^{e}$ et de la $5^{e}$ dose et la tendance non significative, il est difficile d'établir la pertinence clinique de ces données ${ }^{(59)}$.

Dans un essai randomisé mené par Baxter et coll. ${ }^{(57)}$ auprès d'enfants âgés de 6 mois à 18 ans qui comparait Fluarix ${ }^{\circledR}$

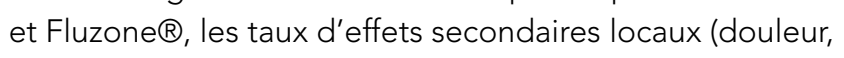
rougeur et œdème) étaient similaires dans les deux groupes parmi les participants de 6 à 36 mois et ceux de 3 à 5 ans. Dans les deux groupes, le pourcentage d'enfants qui présentaient de la douleur, de la rougeur et un œdème était inférieur à $50 \%, 30 \%$ et $20 \%$, respectivement. Les effets secondaires généraux étaient aussi comparables chez les enfants de 6 mois à moins de 5 ans dans tous les groupes d'étude, le pourcentage d'enfants présentant de la somnolence, de la fièvre, une irritabilité ou une perte d'appétit étant inférieur à $30 \%, 15 \%, 40 \%$ et $25 \%$, respectivement ${ }^{(57)}$. Les auteurs ont aussi noté qu'il ne s'était produit aucun effet secondaire mortel et qu'aucun effet secondaire grave n'était considéré comme étant lié aux vaccins à l'étude. 
La surveillance post-commercialisation des effets secondaires peut fournir d'importantes données sur l'innocuité des vaccins homologués ou autorisés, y compris la détection de nouveaux effets secondaires et de signaux. Au Canada et aux États-Unis, les données d'innocuité post commercialisation sont recueillies au moyen de systèmes de surveillance passive, les données étant signalées de façon volontaire. Bien que de tels systèmes permettent de percevoir d'importants signaux relatifs à l'innocuité, la taille de la population à risque ne peut pas être déterminée, et il est donc impossible d'estimer l'incidence des effets secondaires des vaccins et d'établir des liens de causalité.

Au Canada, les données du Système canadien de surveillance des effets secondaires suivant l'immunisation (SCSESSI)(61) ont montré que les vaccins antigrippaux saisonniers étaient sûrs, le profil des effets secondaires suivant l'immunisation (ESSI) étant stable et aucun effet secondaire nouveau ou inattendu n'étant signalé, si l'on exclut l'important signal lié au syndrome oculo-respiratoire observé en 2000-2001. De 2000-2001 à 2011-2012, un total de 15813 ESSI, dont 520 graves, ont été signalés au SCSESSI tous groupes d'âge confondus. Parmi ces ESSI, 949 concernaient des enfants de 2 à moins de 6 ans, et $6 \%$ ( $n=$ 59) étaient graves. Dans ce groupe d'âge, l'âge moyen et médian est de 3,7 ans, et $25 \%$ des ESSI déclarés (y compris les ESSI graves) concernaient des enfants de 2 à moins de 3 ans. Parmi les enfants de 2 à moins de 6 ans, aucun décès ni aucune incapacité résiduelle n'ont été signalés. Les ESSI les plus courantes étaient les réactions locales (35\%), suivies des éruptions cutanées, de la fièvre, des symptômes d'allergie et des symptômes gastro-intestinaux (10 \%). La fièvre, les convulsions, les éruptions cutanées, la cellulite et les réactions allergiques constituaient le groupe de symptômes le plus fréquemment signalé dans les cas graves. Les antécédents médicaux n'étaient disponibles que dans $24 \%$ des déclarations, et les allergies et l'asthme étaient les affections concomitantes les plus courantes.

À l'aide des données du Vaccine Adverse Event Reporting System (VAERS) des Centers for Disease Control and Prevention (CDC) des États-Unis, Muhammad et coll. ont recensé les effets secondaires du VTI déclarés entre 1990 et 2006 parmi les enfants et les adolescents de 2 à 17 $a^{(60)}$. Le nombre estimé de vaccinations contre l'influenza chez les enfants de 24 à 59 mois en 2004-2005 était de 2481 771. L'analyse des auteurs n'a révélé aucun effet secondaire nouveau ou inattendu. Sur le total des effets secondaires déclarés parmi les sujets âgés de 2 à 17 ans ( $n=22$ 054), $40 \%$ avaient été observés chez des enfants de 24 à 59 mois ( $n=819$ ), et $47 \%$ de ces enfants avaient reçu une dose de VTI auparavant. Parmi les enfants chez lesquels des effets secondaires avaient été observés et déclarés, $44 \%$ étaient des filles et leur âge médian était de 3 ans (intervalle de 2 à 4,9 ans). De 1990 à 2006, 10 décès ont été signalés parmi les enfants de 24 à 59 mois. Tous les enfants décédés souffraient d'une affection sous-jacente chronique qui a pu contribuer au décès. On a aussi signalé cinq cas de syndrome de Guillain-Barré (SGB) dans ce groupe d'âge. Parmi ces cas, quatre ont été vérifiés, dont trois survenus dans les 4 semaines suivant la vaccination et le dernier après 9 semaines. Dans trois des cas, le syndrome avait été précédé d'une maladie, dont un syndrome viral, de la fièvre/dysurie et une infection à streptocoque de la gorge.

\section{I.5.2 Vaccin à virus vivant atténué contre l'influenza (VVAI)}

L'évaluation des données sur l'innocuité du WAI chez les enfants âgés de 24 à 59 mois repose principalement sur les données de neuf essais comparatifs randomisés ${ }^{(37)(39)(41)(42)(44)}$ ${ }^{(54)(62-64)}$ et d'un essai non randomisé, prospectif et ouvert ${ }^{(49)}$. L'innocuité a aussi été évaluée à l'aide des données de surveillance post-commercialisation des États-Unis et du Canada(36)(61) ainsi que d'autres analyses d'études et des Recommandations relatives à I'utilisation du vaccin antigrippal vivant atténué (FluMist $囚)$ : Déclaration complémentaire sur la vaccination antigrippale pour la saison 2011-2012(36) Comme il a déjà été mentionné, plusieurs des études analysées portaient à la fois sur le VTI et le WAI. Ces études sont décrites en détail à la section 1.5.3.

L'innocuité du WAI a été évaluée au moyen de plusieurs effets liés à la réactogénicité et effets secondaires signalés sur demande ou déclarés spontanément (locaux et généraux), dont l'écoulement nasal, la congestion nasale, les malaises, la somnolence, la fièvre, la toux, le mal de gorge, l'irritabilité, la perte d'appétit, les céphalées et les myalgies ${ }^{(39)(41)(54)(64)}$. Dans plusieurs études analysées, les effets liés à la réactogénicité et les effets secondaires locaux et généraux étaient légers à modérés et transitoires ${ }^{(38)(39)(63)(65)}$. Au nombre des effets secondaires fréquemment signalés chez les sujets ayant reçu le WVAl figurent l'écoulement nasal, la congestion nasale, la toux, la perte d'appétit, l'irritabilité, les douleurs abdominales, la baisse d'activité, les céphalées, les vomissements, le mal de gorge, les myalgies, les frissons, les infections des voies respiratoires supérieures (IVRS) et la fièvre ${ }^{(36(37)(42)(44)(54)(63)(65-67)}$.

Dans un certain nombre des études analysées, aucun effet secondaire grave ${ }^{(49)(54)(62)(64)(66)(67)}$ ni décès (Belshe, 2004)(37)(41)(42) ${ }^{(44)(65)}$ considérés comme liés aux vaccins à l'étude n'ont été signalés. 
Dans un essai randomisé contrôlé par placebo du VVAI mené par Bracco et coll. ${ }^{(44)}$ auprès d'enfants en bonne santé de 6 à 36 mois, la proportion de sujets vaccinés qui ont signalé au moins un effet secondaire était comparable dans les deux groupes d'étude. Les auteurs ont aussi indiqué que, pendant les jours 0 à 11 de suivi, aucune différence statistiquement significative en ce qui concerne certains effets secondaires, dont ceux de nature respiratoire, n'a été constatée entre le groupe WVAl et le groupe placebo la $1^{\text {re }}$ et la $2^{\mathrm{e}}$ année, à l'exception de la gastro-entérite, qui a été signalée plus souvent dans le groupe placebo $(p=0,017)$. Dans leur évaluation des jours 0 à 28 de suivi, la seule différence significative était le plus grand pourcentage de bronchite chez les sujets ayant reçu le VVAl $(3,1 \%$ c. $1,6 \%, p=0,046)$ la $2^{\mathrm{e}}$ année $e^{(44)}$.

Dans leur essai randomisé contrôlé par placebo mené auprès d'enfants de 6 à 36 mois, Brieman et coll. (63) ont comparé les résultats dans trois groupes d'étude : WAl et vaccin contre la poliomyélite oral (VPO), placebo et VPO, et WAI seulement. Les chercheurs ont constaté que la proportion de participants ayant signalé sur demande au moins un effet général lié à la réactogénicité et le pourcentage de ceux ayant signalé au moins un effet secondaire grave, étaient comparables dans les deux groupes d'étude. En ce qui concerne certains effets secondaires précis, la fréquence de l'écoulement nasal/ congestion nasale était plus grande chez les sujets ayant reçu le WAI $(p=0,003)$, alors que la fréquence de la fièvre $\left(\geq 40^{\circ} \mathrm{C}\right)(p=0,037)$ et de la baisse d'activité $(p=0,017)$ était plus grande dans le groupe placebo. Les auteurs ont aussi noté que la fréquence des effets secondaires déclarés spontanément était similaire dans tous les groupes d'étude après la $1^{\text {re }}$ et la $2^{\mathrm{e}}$ dose, à l'exception de la conjonctivite, qui était déclarée plus souvent (seulement après la $1^{\text {re }}$ dose) chez les sujets ayant reçu uniquement le WAI, soit $0,7 \%$ comparativement à $0,1 \%$ chez les sujets ayant reçu le VAl et le VPO et ceux ayant reçu le placebo et le VPO $(p=0,04)^{(63)}$.

Dans un essai randomisé contrôlé par placebo du WAI mené par Vesikari et coll. auprès d'enfants en bonne santé âgés de 6 à 36 mois $^{(42)}$, des proportions similaires de sujets vaccinés ont signalé au moins un effet lié à la réactogénicité dans les deux groupes d'étude la $1^{\text {re }}$ année (1re dose, WAI $97,1 \%$ contre placebo $96,8 \%, p=0,764 ; 2^{\mathrm{e}}$ dose, WAI $95,5 \%$ contre placebo 95,3\%) et la $2^{e}$ année (VAI 80,5\% contre placebo $79,0 \%, p=0,583$ ). La seule différence significative concernait la proportion d'écoulement nasal/ sécrétions nasales la $1^{\text {re }}$ année, un plus grand nombre de cas $(p=0,001)$ ayant été déclaré dans le groupe WVAl. Les déclarations d'IVRS et d'infections des voies respiratoires inférieures (IVRI) étaient peu fréquentes et leur proportion était aussi comparable dans les deux groupes d'étude. Les effets secondaires graves signalés la $1^{\text {re }}$ année étaient similaires dans les deux groupes (VAl et placebo). Au cours de la première saison grippale, neuf effets secondaires graves considérés comme probablement, possiblement ou peut-être liés aux vaccins à l'étude ont été signalés chez les vaccinés (VAl) et chez cinq témoins (placebo). La $2^{\mathrm{e}}$ saison grippale, deux effets secondaires graves possiblement, probablement ou incontestablement liés au WAI sont survenus. La $2^{\mathrm{e}}$ année, les chercheurs n'ont observé aucune différence statistiquement significative entre le groupe WAl et le groupe placebo sur le plan des effets secondaires graves ${ }^{(42)}$.

Dans l'essai non randomisé, ouvert et communautaire qu'ont mené Piedra et coll. (49), les participants de 18 mois à 4 ans n'affichaient aucune hausse significative de l'utilisation des soins de santé en raison d'une MRAIM, des souscatégories de MRAIM ni de l'asthme comparativement à la période avant et après la vaccination les jours 0 à 14 sur les 4 années de l'étude. Lors de l'évaluation des jours 15 à 42 de suivi après la vaccination, la seule hausse significative de l'utilisation des soins de santé comparativement à la période pré-vaccination concernait l'asthme la $1^{\text {re }}$ année (risque relatif $[R R] 2,85$; IC à $95 \%$ : 1,01-8,03), qui n'a pas été observé les 3 années suivantes de l'étude. Les auteurs ont aussi indiqué que le risque relatif de MRAIM après la vaccination (jours 0 à 14) comparativement à la période pré-vaccination ne différait pas de façon significative chez les enfants de 18 mois à 4 ans qui avaient reçu deux, trois ou quatre doses annuelles séquentielles ${ }^{(49)}$.

Neuzil et coll. ${ }^{(54)}$ ont ré-analysé les données d'un essai comparatif randomisé antérieur en utilisant un sousensemble des données originales concernant les participants de 1 à 16 ans. Les taux d'effets généraux liés à la réactogénicité (fièvre, toux, rhinite et mal de gorge) se sont révélés analogues dans tous les groupes d'âge ( 1 à moins de 6 ans, 6 à moins de 11 ans et 11 à moins de 16 ans), de la $2^{\mathrm{e}}$ à la $5^{\mathrm{e}}$ année d'étude ${ }^{(54)}$.

Dans un essai randomisé contrôlé par placebo réalisé par Bergen et coll. ${ }^{(62)}$ auprès d'enfants de 1 à 8 ans, le risque d'IVRS, d'asthme et de douleurs musculo-squelettiques était plus élevé parmi les participants de 18 à 35 mois qui avaient reçu le VVAI. Parmi les événements liés à l'asthme déclarés, aucun n'avait nécessité d'hospitalisation et $44 \%$ des cas dans le groupe VAI faisaient partie des participants qui avaient déjà consulté un médecin à cause d'un problème d'asthme ${ }^{(62)}$. 
Piedra et coll.(64) ont évalué l'innocuité du WAI chez des enfants de 15 à 71 mois dans le cadre d'un essai multicentrique randomisé contrôlé par placebo. Dans leur analyse multi-variée qui tenait compte de l'âge, de la fréquentation d'une garderie et du mois de la vaccination, ils ont déterminé que le risque d'écoulement nasal/ congestion nasale (rapport des cotes [RC] 1,61; IC à $95 \%$ : 1,30-1,99), de vomissements (RC 1,78; IC à $95 \%$ : 1,05-3,01), de myalgies ( $R C 2,0 ;$ IC à $95 \%: 1,10-3,65$ ) et de fièvre (RC $1,52 ;$ IC à $95 \%: 1,11-2,07)$ était significativement plus élevé dans le groupe VAI que dans le groupe placebo la $1^{\text {re }}$ année suivant la $1^{\text {re }}$ dose. Après la $2^{\mathrm{e}}$ dose, la seule différence significative concernait l'écoulement nasal/ congestion nasale (RC 1,29; IC à $95 \%$ : 1,02-1,65), et aucune différence significative n'était notable la $2^{\mathrm{e}}$ année ${ }^{(64)}$.

Lors d'une analyse portant notamment sur des essais randomisés contrôlés par placebo du VVAl effectuée par Ambrose et coll. ${ }^{(38)}$, la proportion de sujets qui avaient signalé au moins un effet secondaire était similaire dans le groupe WAl et le groupe placebo les 10 premiers jours suivant l'immunisation la $1^{\text {re }}$ et la $2^{\mathrm{e}}$ année bien que certaines différences ont été observées pour des ES particuliers. Les auteurs ont constaté que les taux d'écoulement nasal/congestion nasale, de céphalées et de fatigue/baisse de l'activité la $1^{\text {re }}$ année suivant la $1^{\text {re }}$ dose étaient significativement plus élevés dans le groupe WVI que dans le groupe placebo, la différence de taux étant de $6,8 \%(p<0,01), 6,9 \%(p=0,02)$ et $2,1 \%(p=0,03)$, respectivement. Après la $2^{\mathrm{e}}$ dose, le taux de perte $d^{\prime}$ appétit était significativement plus faible dans le groupe WAI que dans le groupe placebo (différence de taux de 2,9\%, $p=0,04)$. La $2^{e}$ année, la seule différence statistiquement significative concernait le taux plus élevé de perte d'appétit parmi les sujets du groupe WAI (différence de taux de $3,9 \%, p=0,03)$. Parmi les effets secondaires déclarés spontanément, le taux des troubles généraux $(p<0,01)$ était plus grand dans le groupe WAl, alors que le taux des affections de l'oreille ( $1{ }^{\text {re }}$ année, $2^{\mathrm{e}}$ dose) $(p=0,02)$ et des maladies des voies respiratoires inférieures $(p=0,03)$ était significativement plus bas dans le groupe WVI que dans le groupe placebo. Une tendance constante en ce qui concerne tous les effets liés à la réactogénicité et effets secondaires a été observée, soit que les différences de taux étaient plus faibles après la revaccination la $1^{\text {re }}$ et la $2^{\mathrm{e}}$ année qu'après la vaccination initiale ${ }^{(38)}$.

Lors de leur analyse, Ambrose et coll. ont observé des taux comparables de tous les effets secondaires graves (période d'observation de 0 à 42 jours) signalés dans le groupe
VAll et le groupe placebo, soit de $0,5 \%$ et $0,6 \%$, respectivement, la $1^{\text {re }}$ et la $2^{\mathrm{e}}$ année. Dans toute la période d'observation (0 à 180 jours), 2,9\% des sujets du groupe VAll et $2,7 \%$ des sujets du groupe placebo ont signalé des effets secondaires graves la $1^{\text {re }}$ année, et $2,1 \%$ des sujets du groupe WAl et 1,7 \% de ceux du groupe placebo ont signalé des effets secondaires graves la $2^{\mathrm{e}}$ année. Les auteurs font aussi état de taux comparables de maladies des voies respiratoires inférieures / respiration sifflante dans le groupe WAll et le groupe placebo parmi les enfants de 24 à 35 mois, sauf après la $2^{\mathrm{e}}$ dose, la $1^{\text {re }}$ année, alors que l'incidence était plus faible dans le groupe WVAll $(p=0,03)$. Dans ce groupe d'âge, lorsqu'on procédait à une analyse selon la région et le sexe des sujets, les profils d'effets liés à la réactogénicité (ER), d'effets secondaires (ES) et d'effets secondaires graves (ESG) étaient conformes à ceux observés dans la population générale(38).

Dans un essai randomisé prospectif contrôlé par placebo de trois lots de WAll réalisé par Zangwill et coll. ${ }^{(66)}$ auprès d'enfants de 12 à 36 mois, la fréquence de l'écoulement nasal/congestion nasale était significativement plus grande avec les lots de WVII I qu'avec le placebo (63 à $68 \%$ avec les lots de WVAl contre $49 \%$ avec le placebo, $p<0,05)$. Des différences significatives entre le groupe WAll et le groupe placebo ont aussi été observées en ce qui concerne les céphalées après la $1^{\text {re }}$ dose (6 à $11 \%$ avec les lots de VVAll contre $2 \%$ avec le placebo) et les frissons après la $2^{\mathrm{e}}$ dose (2 à $8 \%$ avec les lots de WVAll contre $0 \%$ avec le placebo). Après la $2^{\mathrm{e}}$ dose du WVAll ou du placebo, la probabilité de tout effet lié à la réactogénicité diminuait comparativement à la $1^{\text {re }}$ dose(66).

Tam et coll. ${ }^{\left({ }^{41)}\right.}$ ont mené un essai randomisé contrôlé par placebo du WAl auprès d'enfants en bonne santé âgés de 12 à 36 mois. Au cours des jours 0 à 11 de la période d'observation, pour ce qui est des effets secondaires signalés à la demande après la $1^{\text {re }}$ dose la $1^{\text {re }}$ année de l'étude, une proportion significativement plus grande de sujets ayant reçu le WVAl avaient déclaré de la fièvre (> $\left.37,5^{\circ} \mathrm{C}\right)(22 \%$ contre $17,6 \%, p=0,004)$, un écoulement nasal/congestion nasale (62\% contre $52 \%, p<0,001)$, une perte d'appétit $(24,2 \%$ contre $19,7 \%, p=0,003)$, une baisse d'activité $(13,4 \%$ contre $10,7 \%, p=0,026)$ et la prise de médicaments contre la fièvre $(21,3 \%$ contre $18,4 \%, p=0,044)$. Après la $2^{e}$ dose, la seule différence significative concernait l'écoulement nasal/congestion nasale $(49,8 \%$ contre $45,6 \%, p=0,03)$. Des résultats analogues ont aussi été observés la $2^{\mathrm{e}}$ année. La fièvre était le seul effet secondaire déclaré spontanément dont le taux 
était significativement plus grand parmi les sujets ayant reçu le WAI ( $p=0,003$ et $p=0,017$, la $1^{\text {re }}$ et la $2^{2}$ année, respectivement). Un nombre comparable d'effets secondaires graves a été signalé dans les deux groupes d'étude ${ }^{(41)}$.

Dans un essai contrôlé par placebo du VVAl mené par Mendelman et coll. auprès d'enfants en bonne santé de 1 à 8 ans, la plus grande différence absolue entre le groupe VAl et le groupe placebo était de $9,5 \%$ pour ce qui est de l'écoulement nasal/congestion nasale, qui était plus fréquent dans le groupe placebo. Toutes les autres différences quant aux effets liés à la réactogénicité dans les deux groupes d'étude étaient $<5 \%$ (67).

Comme il a été mentionné précédemment, les systèmes de surveillance passive, tels le VAERS des États-Unis et le SCSESSI du Canada, permettent de percevoir d'importants signaux relatifs à l'innocuité, mais, comme la taille de la population à risque ne peut pas être déterminée, il est impossible d'estimer l'incidence des effets secondaires des vaccins ni d'établir des liens de causalité.

Au Canada, de 2000-2001 à 2011-2012, aucun effet secondaire du VVAl chez les enfants de 2 à moins de 6 ans n'a été signalé au SCSESSI. Dans le cadre d'une analyse de suivi des données du VAERS pour la période d'octobre 2007 à avril 2009, les déclarations d'effets secondaires concernant des enfants de 24 à 59 mois ont été évaluées ${ }^{(68)}$. Après plus de 10 millions de doses distribuées à des personnes de tous âges, le nombre de déclarations pertinentes concernant des enfants était de 222. Parmi celles-ci, les effets secondaires les plus fréquents étaient la fièvre (47\%), les vomissements (28\%) et la rhinite (21\%). Six déclarations faisaient état d'une exacerbation de l'asthme chez des enfants ayant des antécédents d'asthme, et huit, d'une respiration sifflante chez des enfants sans antécédents d'asthme. Aucun effet secondaire grave, comme le décès, I'anaphylaxie, le syndrome de GuillainBarré ou l'encéphalite, n'a été signalé.

\subsection{3 Études portant à la fois sur le vaccin trivalent inactivé et le vaccin à virus vivant atténué}

Comme il a déjà été mentionné, trois des essais comparatifs randomisés analysés ${ }^{(37)(39)(54)}$ portaient à la fois sur le VAI et le VTI. De plus, lors de l'analyse intégrée des essais comparatifs randomisés du WVAl réalisée par Ambrose et coll., tant les essais contre le VTI que ceux contrôlés par placebo ont été inclus (se référer à la section I.5.2 ci-dessus pour l'examen des études contrôlées par placebo portant sur du WAI).
Dans un essai randomisé ouvert contre un comparateur actif mené par Ashkenazi et coll. auprès d'enfants âgés de 6 à 71 mois souffrant d'infections respiratoires récurrentes, l'âge moyen (écart type) des enfants était de 38,1 $(17,4)$ mois et de 39,9 $(17,2)$ mois dans le groupe WVI et le groupe VTI, respectivement. Les effets liés à la réactogénicité les plus fréquents après la $1^{\text {re }}$ dose (VAI contre VTI) étaient l'écoulement nasal/congestion nasale ( 68,3 contre $55,1 \%, p<0,001)$, la toux ( 44,2 contre $44,1 \%)$, la perte d'appétit $(29,5$ contre $26,8 \%$ ), l'irritabilité $(25,5$ contre $22,9 \%)$ et la fièvre $>37,5^{\circ} \mathrm{C}(23,5$ contre $21,4 \%)$. II s'agissait aussi des effets le plus souvent déclarés après la $2^{\mathrm{e}}$ dose, mais le nombre de chacun était moindre. Les seules différences significatives au chapitre des effets liés à la réactogénicité entre le VVAl et le VTI étaient l'écoulement nasal/congestion nasale après la $1^{\text {re }}$ dose (VVAI 68,3\% contre VTI 55,1\%, $p=0,000$ ) et la $2^{\mathrm{e}}$ dose (VAI 52,1\% contre VTI 44,4\%, $p=0,001$ ) et la perte d'appétit après la $2^{\mathrm{e}}$ dose (VAI 23,9\% contre VTI 19,8\%, $p=0,031$ ). Parmi les effets secondaires suivant la $1^{\text {re }}$ dose, la rhinite était déclarée plus fréquemment dans le groupe VAI $(8,7$ contre $5,3 \%, p=0,002)$. En ce qui concerne les effets secondaires suivant la $2^{\mathrm{e}}$ dose, la rhinite et l'otite moyenne étaient plus souvent déclarées dans le groupe VAI $(6,1$ contre $3,8 \%, p=0,021$; et 3,7 contre $1,8 \%, p=$ 0,011 , respectivement). Les auteurs ont aussi indiqué que l'incidence du premier épisode de respiration sifflante était comparable dans les différents groupes et avec les différentes doses, variant de 12,3 à 13,8\%. Au cours de I'essai, quatre effets secondaires graves potentiellement liés aux vaccins à l'étude ont été signalés dans le groupe VTI et deux, dans le groupe WVAl; aucun décès n'est survenu.

Dans un essai comparatif randomisé du VVAl contre le VTI réalisé par Belshe et coll. ${ }^{(39)}$ auprès d'enfants de 6 à 59 mois sans antécédents récents de respiration sifflante ou d'asthme sévère, $52,5 \%$ des participants étaient âgés de 24 à 59 mois. Au cours de l'étude, la fièvre $\left(>37,8^{\circ} \mathrm{C}\right)$ a été observée plus souvent dans le groupe VVAl que dans le groupe $\mathrm{VTI}(5,4$ contre $2,0 \%, p<0,001)$ après la $1^{\text {re }}$ dose, et il n'y avait aucune différence significative après la $2^{\mathrm{e}}$ dose. Les auteurs ont aussi noté qu'une plus grande proportion de participants du groupe VTI présentait de la douleur, de la rougeur et de l'œdème au point d'injection par rapport au groupe qui avait reçu le WVI et un placebo administré par voie intramusculaire. Dans une analyse d'un sous-groupe d'enfants âgés de 12 à 59 mois, des taux comparables d'hospitalisation, d'effets secondaires graves et de respiration sifflante médicalement importante ont été mesurés dans les deux groupes d'étude. Parmi les participants de 24 à 59 mois qui avaient reçu le VVAl ou le VTI, les taux de respiration sifflante médicalement 
importante chez les enfants n'ayant jamais été vaccinés auparavant étaient analogues dans les deux groupes, et aucune admission aux soins intensifs, ventilation mécanique ni aucun décès n'ont été signalés.

Neuzil et coll. ont procédé à une analyse des données d'un essai randomisé à double insu contre un comparateur actif mené entre 1985 et 1990 auprès d'enfants âgés de 1 à 16 ans aux États-Unis. Les vaccins à l'étude comprenaient un $\mathrm{VTI}$ contenant des souches $A$ et $B$, un vaccin atténué contre I'influenza $A$ adapté au froid et un vaccin inactivé contre I'influenza B comme comparateur. Parmi les enfants de 1 à 6 ans, le taux de réactions locales (rougeur et induration) et de réactions générales (fièvre $\geq 37,8^{\circ} \mathrm{C}$, toux, rhinite et mal de gorge) était analogue dans les différents groupes d'étude. Parmi les enfants de 1 à 6 ans qui ont reçu le VTI, $3 \%$ (IC à $95 \%: 1,2-6,7)$ ont présenté une rougeur au point d'injection et $6 \%$ (IC à $95 \%$ : 3,3-10), une induration. La proportion d'enfants de ce groupe d'âge chez lesquels des réactions générales ont été signalées était de $11,5 \%$ (IC à $95 \%: 7,6-17$ ) pour la fièvre, 8,5 \% (IC à $95 \%: 5,213$ ) pour la toux, $16 \%$ (IC à $95 \%$ : 11-22) pour la rhinite et $4 \%$ (IC à $95 \%: 1,9-8,0)$ pour le mal de gorge. Les taux d'effets généraux liés à la réactogénicité (fièvre, toux, rhinite et mal de gorge) se sont aussi révélés comparables dans tous les groupes d'âge ( 1 à < 6 ans, 6 à $<11$ ans et 11 à $<16$ ans) de la $2^{e}$ à la $5^{e}$ année d'étude.
Ambrose et coll. ${ }^{(38)}$ ont effectué une analyse intégrée des essais comparatifs randomisés du WAI réalisés chez des enfants de 2 à 17 ans dont le comparateur était le VTI ou un placebo. Parmi les essais dont le comparateur était le VTI, ils ont noté une fréquence comparable des événements dans le groupe VAAl et le groupe VTI, soit, après la $1^{\text {re }}$ dose, une incidence approximative de la toux de $45 \%$, de la perte d'appétit de $15 \%$, de l'irritabilité de $14 \%$, des douleurs abdominales de $13 \%$, de la baisse de I'activité/fatigue de $14 \%$, des céphalées de $15 \%$, des vomissements de $6 \%$, du mal de gorge de $15 \%$ et des frissons de $6 \%$. Ils ont aussi constaté que la fréquence des myalgies signalées après la $1^{\text {re }}$ dose était significativement plus faible dans le groupe VAI que dans le groupe VTI $(p=0,04)$. En ce qui concerne l'écoulement nasal/ congestion nasale, le nombre de déclarations était plus grand parmi les sujets ayant reçu le WAl que parmi ceux ayant reçu le VTI, la différence absolue de taux étant de $11,8 \%$ après la $1^{\text {re }}$ dose et de $4,1 \%$ après la $2^{\mathrm{e}}$ dose ( $p<0,01$ pour les deux). Les auteurs ont observé des taux comparables de tous les effets secondaires graves dans le groupe VTI et le groupe VAI (période d'observation de 1 à 42 jours), soit de $0,75 \%$ et 1,01\%, respectivement. La proportion de tous les effets secondaires graves était aussi analogue dans les deux groupes lorsque la période d'observation était étendue à 180 jours. Dans le cas des enfants de 24 à 35 mois, lorsqu'on procédait à une analyse par région et sexe des sujets, les profils des effets liés à la réactogénicité, des effets secondaires et des effets secondaires graves étaient conformes à ceux observés dans la population générale(38). 


\section{I.6 TABLES}

\section{TABLEAU 2 : Degrés de preuve selon la méthodologie des études}

\begin{tabular}{|c|c|}
\hline I & Données probantes provenant d'un ou de plusieurs essais cliniques comparatifs randomisés. \\
\hline II-1 & Données probantes provenant d'un ou de plusieurs essais cliniques comparatifs sans randomisation. \\
\hline II-2 & $\begin{array}{l}\text { Données probantes provenant d'études analytiques de cohortes ou cas-témoins, de préférence de plus d'un centre ou groupe } \\
\text { de recherche utilisant des indicateurs cliniques de résultats de l'efficacité d'un vaccin. }\end{array}$ \\
\hline II-3 & $\begin{array}{l}\text { Données probantes provenant de multiples études de séries chronologiques avec ou sans intervention. Les résultats } \\
\text { spectaculaires obtenus dans un contexte non contrôlé (comme les résultats de l'introduction de la pénicilline dans les } \\
\text { années 1940) pourraient aussi être considérés comme faisant partie de ce type de données probantes. }\end{array}$ \\
\hline III & $\begin{array}{l}\text { Opinions d'experts respectés se basant sur des expériences cliniques, des études descriptives et des études de cas ou des } \\
\text { rapports de comités d'experts. }\end{array}$ \\
\hline
\end{tabular}

\section{TABLEAU 3 : Cote de qualité des preuves (validité interne)}

\begin{tabular}{l|l}
\hline Bonne & $\begin{array}{l}\text { Étude (notamment les méta-analyses ou les études systématiques) répondant bien à tous les critères propres } \\
\text { à la méthodologie*. }\end{array}$ \\
\hline Assez bonne & $\begin{array}{l}\text { Étude (notamment les méta-analyses ou les études systématiques) ne répondant pas (ou du moins pas clairement) } \\
\text { à au moins un critère propre à la méthodologie* mais n'ayant pas de « lacune majeure » connue. }\end{array}$ \\
\hline Médiocre & $\begin{array}{l}\text { Étude (notamment les méta-analyses ou les études systématiques) ayant au moins une « lacune majeure » propre } \\
\text { à la méthodologie* ou une accumulation de lacunes moins importantes ne permettant pas aux résultats de l'étude } \\
\text { d'alimenter les recommandations. }\end{array}$ \\
\hline $\mathbf{I}$ & $\begin{array}{l}\text { Les données probantes sont insuffisantes (en quantité ou en qualité) pour formuler une recommandation; cependant, } \\
\text { d'autres facteurs peuvent influencer la prise de décision. }\end{array}$ \\
\hline
\end{tabular}

* Les critères généraux propres à la méthodologie sont décrits dans l'article de Harris et al. 2001'.

\section{TABLE 4: NACl recommendation for immunization - Grades}

\begin{tabular}{|c|c|}
\hline A & Les données probantes sont suffisantes pour recommander l'immunisation. \\
\hline B & Les données probantes sont acceptables pour recommander l'immunisation. \\
\hline C & $\begin{array}{l}\text { Les données probantes existantes sont contradictoires et ne permettent pas de faire une recommandation pour ou contre } \\
\text { l'immunisation; cependant, d'autres facteurs peuvent influencer la prise de décision. }\end{array}$ \\
\hline D & Les données probantes sont acceptables pour déconseiller l'immunisation. \\
\hline E & Les données probantes sont suffisantes pour déconseiller l'immunisation. \\
\hline I & $\begin{array}{l}\text { Les données probantes sont insuffisantes (en quantité ou en qualité) pour formuler une recommandation; cependant, } \\
\text { d'autres facteurs peuvent influencer la prise de décision. }\end{array}$ \\
\hline
\end{tabular}


TABLEAU 5A : Sommaire des données concernant les enfants de 24 à 59 mois - Évidences liées à l'efficacité potentielle et réelle du VTI

\begin{tabular}{|c|c|c|c|c|c|c|}
\hline \multicolumn{7}{|c|}{ DONNÉES CONCERNANT L'EFFICACITÉ RÉELLE ET POTENTIELLE DU VTI } \\
\hline Étude & Vaccin & Plan d'étude & Participants & $\begin{array}{l}\text { Résumé des principaux résultats } \\
\text { (texte ou données) }\end{array}$ & $\begin{array}{l}\text { Degré de } \\
\text { preuve }\end{array}$ & Qualité \\
\hline $\begin{array}{l}\text { Belongia EA, } \\
\text { Kieke BA, } \\
\text { Donahue JG, } \\
\text { et coll. } \\
\text { Influenza } \\
\text { vaccine } \\
\text { effectiveness } \\
\text { in Wisconsin } \\
\text { during the } \\
\text { 2007-08 season: } \\
\text { comparison } \\
\text { of interim and } \\
\text { final results. } \\
\text { Vaccine } \\
\text { 2011 Sep } \\
\text { 2;29(38): } \\
\text { 6558-6563. }{ }^{(25)}\end{array}$ & $\begin{array}{l}\text { VTI } \\
\text { Mauvaise } \\
\text { concordance } \\
\text { avec les virus } \\
\text { de type B } \\
\text { pendant cette } \\
\text { saison } \\
\text { Vaccination } \\
\text { complète des } \\
\text { enfants de < } 9 \\
\text { ans : } 1 \text {. deux } \\
\text { doses ou } 2 \text {. une } \\
\text { dose et } \geq 1 \\
\text { dose reçue lors } \\
\text { d'une saison } \\
\text { antérieure }\end{array}$ & $\begin{array}{l}\text { Cohorte } \\
\text { prospective en } \\
\text { milieu } \\
\text { communautaire } \\
\text { et analyses } \\
\text { cas-témoins } \\
\text { Saison } \\
2007-2008 \\
\text { É.-U. }\end{array}$ & $\begin{array}{l}\mathrm{N}=1914 \\
\text { Résidents de } 6 \\
\text { mois à } 65+\text { ans } \\
\text { ayant une } \\
\text { résidence } \\
\text { continue d'au } \\
\text { moins } 12 \text { mois } \\
\text { (ou depuis la } \\
\text { naissance) } \\
\\
14 \% \text { de tous } \\
\text { les cas et } 20 \% \\
\text { de tous les } \\
\text { témoins avaient } \\
\text { une affection à } \\
\text { risque élevé } \\
\\
\text { De } 6 \text { à } 59 \text { mois } \\
\mathrm{n}_{\text {cas }}=118 \\
\mathrm{n}_{\text {témoin }}=294 \\
\text { Statut vaccinal } \\
\text { établi à partir } \\
\text { de dossiers } \\
\text { électroniques; } \\
\text { les enfants } \\
\text { partiellement } \\
\text { immunisés ont } \\
\text { été exclus } \\
\text { Recrutement } \\
\text { lors des } \\
\text { consultations } \\
\text { médicales } \\
\text { internes et } \\
\text { externes }\end{array}$ & $\begin{array}{l}\text { Paramètre : Influenza confirmée en } \\
\text { laboratoire (rRT-PCR et culture virale) } \\
\text { ayant nécessité une intervention } \\
\text { médicale } \\
\text { Cas : Présence d'influenza confirmée } \\
\text { en laboratoire } \\
\text { Témoin : Absence d'influenza } \\
\text { confirmée en laboratoire } \\
\text { Efficacité du vaccin : } \\
\text { Tous les sujets (6 à } 59 \text { mois) } \\
\text { Non ajustée : } 40 \% \\
\text { Ajustée : } 39 \% \text { (2, 62) } \\
\text { Sujets ayant fait l'objet de tests } 0-3 \\
\text { jours après l'apparition de la maladie } \\
\text { (6-59 mois) } \\
\text { Non ajustée : } 32 \% \\
\text { Ajustée : } 31 \% \text { (-24, 62) } \\
\text { Ajustement en fonction de l'âge, } \\
\text { de la semaine de recrutement et } \\
\text { de la présence d'une affection à } \\
\text { risque élevé }\end{array}$ & Niveau II-2 & Bonne \\
\hline
\end{tabular}




\begin{tabular}{|c|c|c|c|c|c|c|}
\hline \multicolumn{7}{|c|}{ DONNÉES CONCERNANT L'EFFICACITÉ RÉELLE ET POTENTIELLE DU VTI } \\
\hline Étude & Vaccin & Plan d'étude & Participants & $\begin{array}{l}\text { Résumé des principaux résultats } \\
\text { (texte ou données) }\end{array}$ & $\begin{array}{l}\text { Degré de } \\
\text { preuve }\end{array}$ & Qualité \\
\hline $\begin{array}{l}\text { Dixon GA, } \\
\text { Moore HC, } \\
\text { Kelly H, et coll. } \\
\text { Lessons from } \\
\text { the first year } \\
\text { of the } \\
\text { WAIVE study } \\
\text { investigating } \\
\text { the protective } \\
\text { effect of } \\
\text { influenza } \\
\text { vaccine against } \\
\text { laboratory- } \\
\text { confirmed } \\
\text { influenza in } \\
\text { hospitalised } \\
\text { children aged } \\
\text { 6-59 months. } \\
\text { Influenza other } \\
\text { respi viruses } \\
\text { 2010 Jul;4(4): } \\
\text { 231-234.(27) }\end{array}$ & $\begin{array}{l}\text { VTI } \\
\text { 0,5 ml chez les } \\
\text { enfants de } \geq 3 \\
\text { ans; } \\
0,25 \mathrm{ml} \text { chez les } \\
\text { enfants de } 6 \\
\text { mois à }<3 \text { ans } \\
\\
\text { Vaccination } \\
\text { complète } \\
\text { (toutes les } \\
\text { doses reçues }> \\
14 \text { jours avant } \\
\text { l'apparition du } \\
\text { SG) : } 1 \text {. deux } \\
\text { doses à } \geq 21 \\
\text { jours } \\
\text { d'intervalle ou } \\
\text { 2. une dose et } \geq \\
2 \text { doses reçues } \\
\text { lors de toute } \\
\text { saison } \\
\text { antérieure }\end{array}$ & $\begin{array}{l}\text { Étude } \\
\text { cas-témoins } \\
\text { nichée, } \\
\text { multicentrique } \\
\text { Saison } 2008 \\
\text { Australie }\end{array}$ & $\begin{array}{l}\mathrm{N}=76 \\
\mathrm{n}_{\text {cas }}=26 \\
\mathrm{n}_{\text {témoin }}=50 \\
\text { Enfants de } 6 \text { à } \\
59 \text { mois (>2 } \\
\text { ans }=52,6 \% \\
\text { des sujets) }\end{array}$ & $\begin{array}{l}\text { Cas : Hospitalisation pour l'influenza } \\
\text { confirmée en laboratoire (culture } \\
\text { seulement ou culture et RT-PCR si la } \\
\text { culture était négative) } \\
\text { Témoin : Hospitalisation pour une } \\
\text { maladie respiratoire non aiguë; } \\
\text { appariement en fonction de l'âge et } \\
\text { du statut d'Aborigène/d'habitant des } \\
\text { îles du détroit de Torres } \\
\text { Efficacité potentielle ajustée chez les } \\
\text { enfants ayant reçu toutes les doses du } \\
\text { vaccin comparativement aux enfants } \\
\text { non vaccinés: } 83 \text { \% (-54, 98) } \\
\text { Ajustement en fonction du sexe, de la } \\
\text { présence de comorbidités et du fait } \\
\text { d'être né prématurément ou non }\end{array}$ & Niveau II-2 & $\begin{array}{l}\begin{array}{l}\text { Assez } \\
\text { bonne }\end{array} \\
\text { Faibles } \\
\text { nombres }\end{array}$ \\
\hline
\end{tabular}




\begin{tabular}{|c|c|c|c|c|c|c|}
\hline \multicolumn{5}{|c|}{ DONNÉES CONCERNANT L'EFFICACITÉ RÉELLE ET POTENTIELLE DU VTI } & \multirow[b]{2}{*}{$\begin{array}{l}\text { Degré de } \\
\text { preuve }\end{array}$} & \multirow[b]{2}{*}{ Qualité } \\
\hline Étude & Vaccin & Plan d'étude & Participants & $\begin{array}{l}\text { Résumé des principaux résultats } \\
\text { (texte ou données) }\end{array}$ & & \\
\hline $\begin{array}{l}\text { Eisenberg KW, } \\
\text { Szilagyi PG, } \\
\text { Fairbrother G, } \\
\text { et coll. Vaccine } \\
\text { effectiveness } \\
\text { against } \\
\text { laboratory- } \\
\text { confirmed } \\
\text { influenza in } \\
\text { children } 6 \text { to } \\
59 \text { months of } \\
\text { age during } \\
\text { the 2003-2004 } \\
\text { and 2004-2005 } \\
\text { influenza } \\
\text { seasons. } \\
\text { Pediatrics } \\
\text { 2008;122(5): } \\
\text { 911-919.(20) }\end{array}$ & $\begin{array}{l}\text { Non précisé; } \\
\text { selon toute } \\
\text { évidence le TVI, } \\
\text { car le VVAl } \\
\text { n'était pas } \\
\text { encore } \\
\text { approuvé pour } \\
\text { l'intervalle } \\
\text { d'âges des } \\
\text { sujets } \\
\text { Vaccination } \\
\text { complète } \\
\text { (toutes les } \\
\text { doses reçues } \geq \\
\text { 14 jours avant } \\
\text { l'apparition du } \\
\text { SG) : } 1 . \text { deux } \\
\text { doses à } \geq 24 \\
\text { jours } \\
\text { d'intervalle ou } \\
2 . \text { une dose et } \geq \\
1 \text { dose reçue } \\
\text { lors d'une } \\
\text { saison } \\
\text { précédente } \\
\text { Vaccination } \\
\text { partielle : } 1 . \\
\text { seulement } 1 \\
\text { des } 2 \text { doses } \\
\text { reçues } \geq 14 \\
\text { jours avant } \\
\text { l'apparition du } \\
\text { SG ou } 2 \text {. deux } \\
\text { doses reçues, } \\
\text { la } 2 \text { e dose ayant } \\
\text { été reçue }<24 \\
\text { jours après la } \\
\text { 1'e dose } \\
\text { sous-optimale } \\
\text { entre le vaccin les souches } \\
\text { en circulation } \\
\text { en } 2003-2004 \\
\text { et } 2004-2005\end{array}$ & $\begin{array}{l}\text { Étude } \\
\text { cas-témoins } \\
\text { prospective, } \\
\text { multicentrique } \\
\text { Saisons } \\
2003-2004 \text { et } \\
2004-2005 \\
\text { É.-U. }\end{array}$ & 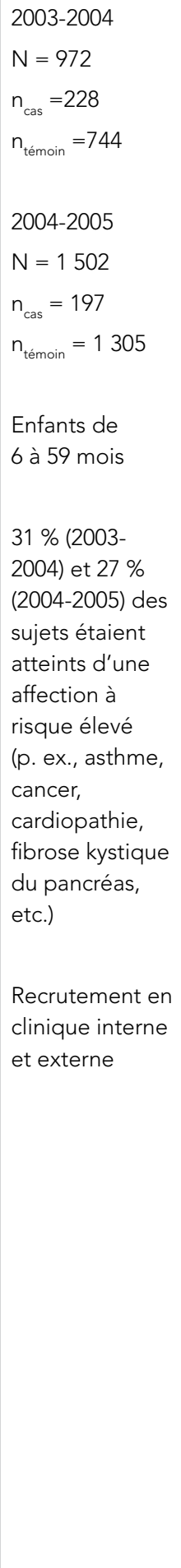 & $\begin{array}{l}\text { Exposition d'intérêt : Vaccination } \\
\text { antigrippale confirmée par consulta- } \\
\text { tion du principal dispensateur de soins } \\
\text { du sujet et de son dossier médical } \\
\text { Cas : Maladie respiratoire aiguë ou } \\
\text { fièvre et } 1 \text { culture virale positive } \\
\text { (patients hospitalisés seulement) ou } \\
2 \text { résultats positifs à la RT-PCR } \\
\text { Témoin : Maladie respiratoire aiguë } \\
\text { ou fièvre et culture virale ou RT-PCR } \\
\text { négative; fréquence appariée selon le } \\
\text { site, le contexte de la consultation et } \\
\text { la date de recrutement (témoins) ou la } \\
\text { date d'apparition des symptômes } \\
\text { grippaux (cas) } \\
\text { Efficacité réelle du vaccin : } \\
\text { 2003-2004 } \\
\text { Vaccination complète : } 63 \text { (16,84) } \\
\text { Vaccination incomplète : } 38 \text { (-53, } 75 \text { mois } \\
\text { Vaccination complète : } 66 \text { (-106, 94) } \\
\text { Vaccination incomplète : } 33 \text { (-109, 78) } \\
\text { entre les sujets complètement } \\
\text { vaccinés et les sujets partiellement } \\
\text { vaccinés }\end{array}$ & Niveau II-2 & $\begin{array}{l}\text { Bonne } \\
\text { Le faible } \\
\text { nombre } \\
\text { d'enfants } \\
\text { complète- } \\
\text { ment } \\
\text { vaccinés } \\
\text { en } \\
\text { 2003-2004 } \\
\text { rend } \\
\text { l'efficacité } \\
\text { potenti- } \\
\text { elle du } \\
\text { vaccin } \\
\text { difficile à } \\
\text { inter- } \\
\text { préter. }\end{array}$ \\
\hline
\end{tabular}




\begin{tabular}{|c|c|c|c|c|c|c|}
\hline \multicolumn{5}{|c|}{ DONNÉES CONCERNANT L'EFFICACITÉ RÉELLE ET POTENTIELLE DU VTI } & \multirow[b]{2}{*}{$\begin{array}{l}\text { Degré de } \\
\text { preuve }\end{array}$} & \multirow[b]{2}{*}{ Qualité } \\
\hline Étude & Vaccin & Plan d'étude & Participants & $\begin{array}{l}\text { Résumé des principaux résultats } \\
\text { (texte ou données) }\end{array}$ & & \\
\hline $\begin{array}{l}\text { Fujieda M, } \\
\text { Maeda A, } \\
\text { Kondo K, } \\
\text { et coll. } \\
\text { Influenza } \\
\text { vaccine } \\
\text { effectiveness } \\
\text { and con- } \\
\text { founding } \\
\text { factors among } \\
\text { young children. } \\
\text { Vaccine } \\
2008 ; 26(50) \text { : } \\
6481-6485 .(33)\end{array}$ & $\begin{array}{l}\text { VTI } \\
2 \text { doses à } \\
\text { 2-4 semaines } \\
\text { d'intervalle; } \\
0,1 \mathrm{ml} \text { pour les } \\
\text { enfants de } \\
<1 \text { an, } 0,2 \mathrm{ml} \\
\text { pour les enfants } \\
\text { de } \geq 1 \text { an }\end{array}$ & $\begin{array}{l}\text { Étude de } \\
\text { cohorte, } \\
\text { multicentrique } \\
\text { Saison } \\
2002-2003 \\
\text { Japon }\end{array}$ & $\begin{array}{l}\mathrm{N}=2913 \\
\mathrm{n}_{\text {vacciné }}=1512 \\
\mathrm{n}_{\text {nonvacciné }}=1401 \\
\text { Enfants de } \\
<6 \text { ans } \\
\text { Recrutement } \\
\text { dans des } \\
\text { cliniques } \\
\text { pédiatriques }\end{array}$ & $\begin{array}{l}\text { Paramètre primaire : SG (maladie } \\
\text { fébrile aiguë survenue pendant le pic } \\
\text { de l'épidémie d'influenzadans chaque } \\
\text { région à l'étude; température } \\
\text { maximale de l'enfant déclarée pour } \\
\text { chaque semaine) } \\
\text { Ajustement en fonction des facteurs } \\
\text { suivants : statut vaccinal, tranche } \\
\text { d'âge, nombre de frères et sœurs, } \\
\text { consultations médicales pour des } \\
\text { symptômes grippaux au cours des } \\
6 \text { derniers mois, fréquentation d'une } \\
\text { prématernelle, et dose du vaccin } \\
\text { (<2,0 ans seulement) pour les } \\
\text { températures observées (< 38,0, 38,0 } \\
\left.38,9, \geq 39,0{ }^{\circ} \mathrm{C}\right) \\
\text { Efficacité réelle du vaccin (ajustée) : } \\
2,0 \text { à } 3,9 \text { ans : } 41 \% \text { ( } 26,53) \\
4,0 \text { à } 5,9 \text { ans : } 25 \% \text { ( } 2,42) \\
\text { RC ajusté : } \\
2,0 \text { à } 3,9 \text { ans : } 0,59 \text { ( } 0,47,0,74) ; \\
\text { p < } 0,001 \\
4,0 \text { à } 5,9 \text { ans : } 0,75 \text { ( } 0,58,0,98) \text {; } \\
\text { p = 0,034 }\end{array}$ & Niveau II-2 & $\begin{array}{l}\text { Assez } \\
\text { bonne } \\
\text { L'auto- } \\
\text { sélection } \\
\text { de la } \\
\text { vaccina- } \\
\text { tion } \\
\text { par les } \\
\text { parents } \\
\text { pourrait } \\
\text { avoir } \\
\text { engendré } \\
\text { des } \\
\text { facteurs } \\
\text { de } \\
\text { confusion } \\
\text { non } \\
\text { pris en } \\
\text { compte }\end{array}$ \\
\hline
\end{tabular}




\begin{tabular}{|c|c|c|c|c|c|c|}
\hline \multicolumn{5}{|c|}{ DONNÉES CONCERNANT L'EFFICACITÉ RÉELLE ET POTENTIELLE DU VTI } & \multirow[b]{2}{*}{$\begin{array}{l}\text { Degré de } \\
\text { preuve }\end{array}$} & \multirow[b]{2}{*}{ Qualité } \\
\hline Étude & Vaccin & Plan d'étude & Participants & $\begin{array}{l}\text { Résumé des principaux résultats } \\
\text { (texte ou données) }\end{array}$ & & \\
\hline $\begin{array}{l}\text { Fujieda M, } \\
\text { Maeda A, } \\
\text { Kondo K, et } \\
\text { coll. Inactivated } \\
\text { influenza } \\
\text { vaccine } \\
\text { effectiveness in } \\
\text { children under } \\
6 \text { years of age } \\
\text { during the } \\
\text { 2002-2003 } \\
\text { season. Vaccine } \\
\text { 2006;24(7): } \\
957-963 .(34)\end{array}$ & $\begin{array}{l}\text { VTI } \\
2 \text { doses à } \\
\text { 2-4 semaines } \\
\text { d'intervalle; } \\
0,1 \mathrm{ml} \text { pour les } \\
\text { enfants de } \\
<1 \text { an, } 0,2 \mathrm{ml} \\
\text { pour les enfants } \\
\text { de } \geq 1 \text { an }\end{array}$ & $\begin{array}{l}\text { Étude de } \\
\text { cohorte, } \\
\text { multicentrique } \\
\text { Saison } \\
2002-2003 \\
\text { Japon }\end{array}$ & $\begin{array}{l}\mathrm{N}=2913 \\
\mathrm{n}_{\text {vacciné }}=1512 \\
\mathrm{n}_{\text {nonvacciné }}=1401 \\
\text { Enfants de } \\
<6 \text { ans } \\
\text { Recrutement } \\
\text { dans des } \\
\text { cliniques } \\
\text { pédiatriques }\end{array}$ & 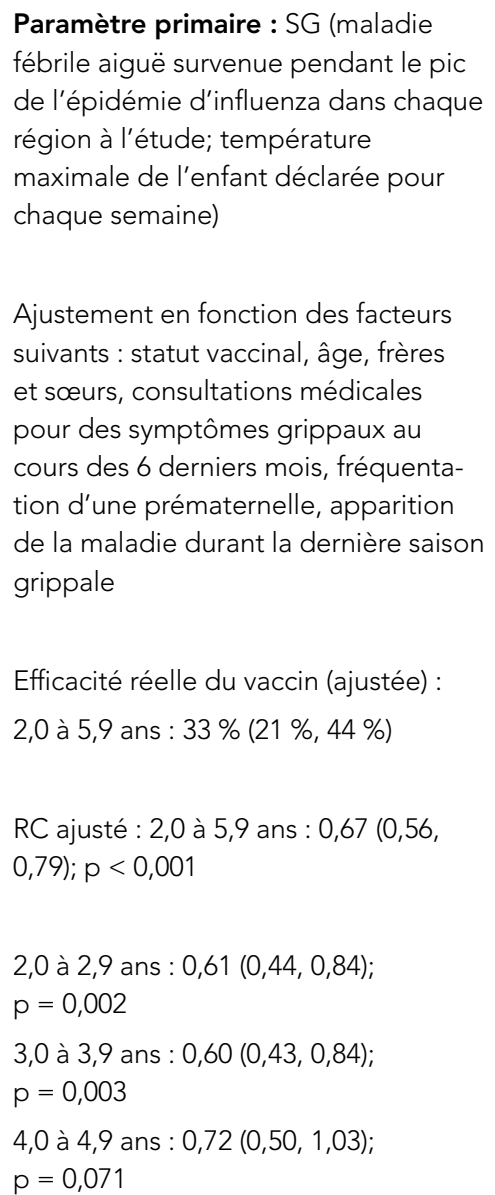 & Niveau II-2 & $\begin{array}{l}\text { Assez } \\
\text { bonne } \\
\text { L'auto- } \\
\text { sélection } \\
\text { de la } \\
\text { vaccina- } \\
\text { tion } \\
\text { par les } \\
\text { parents } \\
\text { pourrait } \\
\text { avoir } \\
\text { engendré } \\
\text { des } \\
\text { facteurs } \\
\text { de } \\
\text { confusion } \\
\text { non } \\
\text { pris en } \\
\text { compte }\end{array}$ \\
\hline
\end{tabular}




\begin{tabular}{|c|c|c|c|c|c|c|}
\hline \multicolumn{5}{|c|}{ DONNÉES CONCERNANT L'EFFICACITÉ RÉELLE ET POTENTIELLE DU VTI } & \multirow[b]{2}{*}{$\begin{array}{l}\text { Degré de } \\
\text { preuve }\end{array}$} & \multirow[b]{2}{*}{ Qualité } \\
\hline Étude & Vaccin & Plan d'étude & Participants & $\begin{array}{l}\text { Résumé des principaux résultats } \\
\text { (texte ou données) }\end{array}$ & & \\
\hline $\begin{array}{l}\text { Ghendon YZ, } \\
\text { Kaira AN, et } \\
\text { coll. The effect } \\
\text { of mass } \\
\text { influenza } \\
\text { immunization } \\
\text { in children on } \\
\text { the morbidity } \\
\text { of the unvaccin- } \\
\text { ated elderly. } \\
\text { Epidemiol } \\
\text { Infect } 2006 \\
\text { Feb;134(1): } \\
71-78 .(32)\end{array}$ & $\begin{array}{l}\left.\text { VTI (Influvac }{ }^{\circledR}\right) \\
\text { Bonne } \\
\text { correspon- } \\
\text { dance } \\
\text { antigénique } \\
\text { entre le vaccin } \\
\text { et les souches } \\
\text { A (H3N2) et B } \\
\text { en circulation } \\
\text { dans la région } \\
\text { à l'étude } \\
\text { 0,5 ml, dose } \\
\text { unique } \\
\text { seulement } \\
\text { Une dose pour } \\
\text { les enfants de } \\
>3 \text { ans }\end{array}$ & $\begin{array}{l}\text { Étude de } \\
\text { cohorte en } \\
\text { milieu } \\
\text { communautaire } \\
\text { dans plusieurs } \\
\text { régions (quatre } \\
\text { communautés : } \\
2 \text { ciblées et } \\
2 \text { témoins) } \\
\text { Vaccination } \\
\text { systématique } \\
\text { des enfants } \\
\text { d'âge scolaire } \\
\text { dans les } \\
\text { communautés } \\
\text { ciblées } \\
\text { Saison } \\
2001-2002 \\
\text { Russie }\end{array}$ & $\begin{array}{l}\mathrm{N}=89255 \\
\text { Communautés } \\
\text { ciblées } \\
\mathrm{n}_{\text {vaccinés-bans }}= \\
3658 \\
\mathrm{n}_{\text {vacciné-17ans }}= \\
24651 \\
\text { Communautés } \\
\text { témoins } \\
\mathrm{n}_{3-6 a n s}=11048 \\
\mathrm{n}_{7-17 a n s}=49898 \\
\text { Enfants en } \\
\text { bonne santé; } \\
\text { âge de la } \\
\text { maternelle } \\
\text { (3 à } 6 \text { ans) et } \\
\text { âge scolaire } \\
\text { (7 à } 17 \text { ans) } \\
\text { Personnes } \\
\text { âgées } \\
\text { (> } 60 \text { ans) } \\
\mathrm{N}=158451 \\
\mathrm{n}_{\text {cible }}=82051 \\
\mathrm{n}_{\text {témoin }}=76401 \\
\text { Faible taux } \\
\text { de vaccination } \\
\text { chez les } \\
\text { personnes } \\
\text { âgées ( } 1 \text { \%) }\end{array}$ & 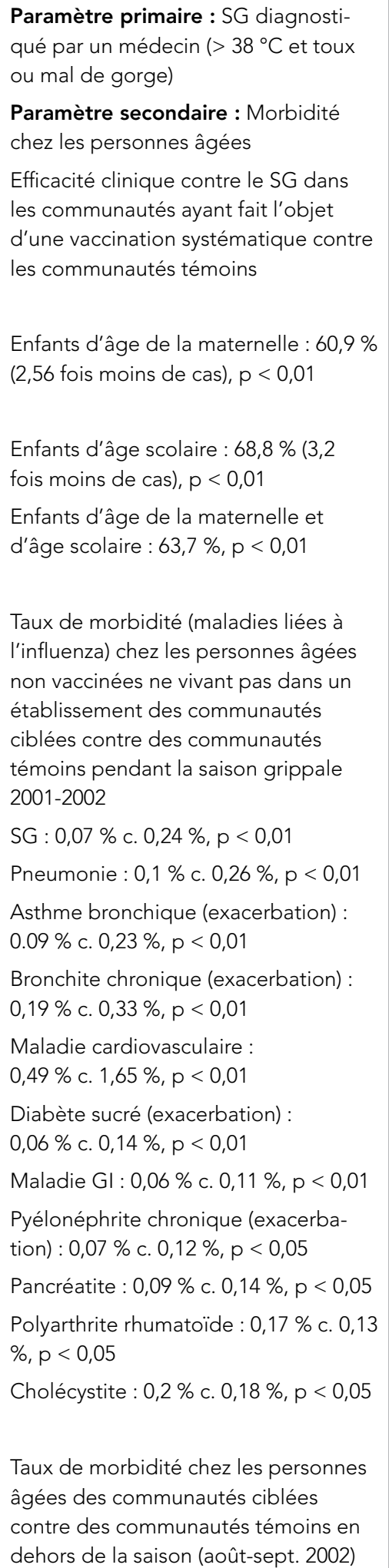 & Niveau II-2 & $\begin{array}{l}\text { Assez } \\
\text { bonne } \\
\text { L'inci- } \\
\text { dence de } \\
\text { référence } \\
\text { du SG } \\
\text { était } \\
\text { légère- } \\
\text { ment plus } \\
\text { élevée } \\
\text { dans les } \\
\text { com- } \\
\text { munautés } \\
\text { ciblées. }\end{array}$ \\
\hline
\end{tabular}




\begin{tabular}{|c|c|c|c|c|c|c|}
\hline \multicolumn{5}{|c|}{ DONNÉES CONCERNANT L'EFFICACITÉ RÉELLE ET POTENTIELLE DU VTI } & \multirow[b]{2}{*}{$\begin{array}{l}\text { Degré de } \\
\text { preuve }\end{array}$} & \multirow[b]{2}{*}{ Qualité } \\
\hline Étude & Vaccin & Plan d'étude & Participants & $\begin{array}{l}\text { Résumé des principaux résultats } \\
\text { (texte ou données) }\end{array}$ & & \\
\hline & & & & $\begin{array}{l}\text { Aucune différence significative pour } \\
\text { quelque maladie que ce soit, sauf: } \\
\text { Maladie cardiovasculaire : } \\
0,74 \% \text { c. } 1,04 \%, p<0,01 \\
\text { Polyarthrite rhumatoïde: } \\
0,04 \% \text { c. } 0,02 \%, p<0,05\end{array}$ & & \\
\hline $\begin{array}{l}\text { Heinonen S, } \\
\text { Silvennoinen H, } \\
\text { Lehtinen } \mathrm{P} \text {, } \\
\text { et coll. } \\
\text { Effectiveness } \\
\text { of inactivated } \\
\text { influenza } \\
\text { vaccine in } \\
\text { children aged } \\
9 \text { months to } \\
3 \text { years: an } \\
\text { observational } \\
\text { cohort study. } \\
\text { Lancet Infect } \\
\text { Dis 2011;11(1): } \\
\text { 23-29.(26) } \\
\text { NCT005935023 }\end{array}$ & $\begin{array}{l}\text { VTI (Vaxigrip }{ }^{\circledR} \text { ) } \\
\text { Doses de 0,5 ml } \\
\text { (une dose, ou } \\
\text { deux doses à } 4 \\
\text { semaines } \\
\text { d'intervalle }^{\prime} \text { dans le cas des } \\
\text { sujets n'ayant } \\
\text { jamais reçu le } \\
\text { vaccin) } \\
\\
\text { Bonne } \\
\text { concordance } \\
\text { avec les } \\
\text { souches A, mais } \\
\text { non avec la } \\
\text { souche B en } \\
\text { circulation }\end{array}$ & $\begin{array}{l}\begin{array}{l}\text { Cohorte } \\
\text { prospective }\end{array} \\
\text { Saison } \\
\text { 2007-2008 } \\
\text { Finlande }\end{array}$ & $\begin{array}{l}\mathrm{N}=631 \\
\mathrm{n}=278 \\
\text { (9 à } 23 \text { mois) } \\
\mathrm{n}=353 \\
(24 \text { à } 40 \text { mois) } \\
\\
\text { Enfants de } \\
9 \text { mois à } 3 \text { ans }\end{array}$ & $\begin{array}{l}\text { Paramètre primaire : Influenza } \\
\text { symptomatique confirmée en } \\
\text { laboratoire (par immunofluorescence } \\
\text { en temps résolu, culture virale, } \\
\text { coloration à l'immunoperoxydase avec } \\
\text { anticorps monoclonaux et/ou RT-PCR) } \\
\text { Efficacité réelle du vaccin } \\
2 \text { à } 3 \text { ans } \\
\text { Influenza A : } 100 \% \text { (6, 100); } p=0,05 \\
\text { Influenza B : } 33 \% \text { (-97, 78); } p=0,78 \\
\text { Toutes souches : } 63 \% \text { (-5, 88); } p=0,06 \\
\text { Étude cas-témoins par tranche d'âge } \\
\text { (les sujets partiellement vaccinés ont } \\
\text { été considérés comme non vaccinés) } \\
\text { Cas : Sujet dont au moins un } \\
\text { échantillon contenait le virus de } \\
\text { l'influenza durant la période à l'étude } \\
\text { Témoin : Sujet dont aucun échantillon } \\
\text { ne s'est avéré porteur de l'influenza } \\
\text { Influenza A : } 100 \% \text { (4, 100) } \\
\text { Influenza B : } 38 \% \text { (-121, 83) } \\
\text { Toutes souches : } 71 \% \text { (-1, } 92)\end{array}$ & Niveau II-2 & $\begin{array}{l}\text { Assez } \\
\text { bonne }\end{array}$ \\
\hline
\end{tabular}




\begin{tabular}{|c|c|c|c|c|c|c|}
\hline \multicolumn{7}{|c|}{ DONNÉES CONCERNANT L'EFFICACITÉ RÉELLE ET POTENTIELLE DU VTI } \\
\hline Étude & Vaccin & Plan d'étude & Participants & $\begin{array}{l}\text { Résumé des principaux résultats } \\
\text { (texte ou données) }\end{array}$ & $\begin{array}{l}\text { Degré de } \\
\text { preuve }\end{array}$ & Qualité \\
\hline $\begin{array}{l}\text { Hoen AG, } \\
\text { Buckeridge DL, } \\
\text { Charland KM, } \\
\text { et coll. Effect of } \\
\text { expanded US } \\
\text { recommenda- } \\
\text { tions for } \\
\text { seasonal } \\
\text { influenza } \\
\text { vaccination: } \\
\text { comparison of } \\
\text { two pediatric } \\
\text { emergency } \\
\text { departments } \\
\text { in the United } \\
\text { States and } \\
\text { Canada. CMAJ } \\
\text { 2011;183(13): } \\
\text { E1025-32. }{ }^{35)}\end{array}$ & $\begin{array}{l}\text { VTI (Canada) } \\
\text { Statut vaccinal } \\
\text { individuel non } \\
\text { disponible; } \\
\text { estimations de } \\
\text { la couverture } \\
\text { vaccinale } \\
\text { fondées sur des } \\
\text { sondages à } \\
\text { l'échelle } \\
\text { nationale } \\
\text { VTI/WVA (É.-U.) }\end{array}$ & $\begin{array}{l}\text { Écologique } \\
\text { Saisons } \\
2000-2001 \text { à } \\
2008-2009 \\
\\
2 \text { sites : } \\
\text { Montréal (Can.) } \\
\text { et Boston } \\
\text { (É.-U.) }\end{array}$ & $\begin{array}{l}\mathrm{N}=114657 \\
\text { consultations } \\
\text { pour un SG } \\
\text { sur } 1043989 \\
\text { consultations } \\
\text { au total } \\
\text { Enfants de } \\
0 \text { à } 18 \text { ans } \\
\text { Consultations } \\
\text { des services } \\
\text { d'urgence }\end{array}$ & $\begin{array}{l}\text { Paramètre primaire : Consultations } \\
\text { des services d'urgence liées au SG } \\
\text { (avant et après 2006, année de } \\
\text { modification de la politique des É.-U. } \\
\text { concernant la vaccination des enfants } \\
\text { de } 2 \text { à < } 5 \text { ans contre l'influenza) } \\
\text { Diminution du taux de consultations } \\
\text { des services d'urgence aux É.-U. } \\
\text { comparativement au Canada : taux } \\
\text { de risque ajusté de } 0,66 \text { ( } 0,58,0,75) \\
\text { Diminution de } 11 \text { à } 18 \% \text { dans les } \\
\text { tranches d'âge non ciblées à la suite } \\
\text { de la modification de la recommanda- } \\
\text { tion dans les modèles ajustés, mais } \\
\text { non dans les modèles non ajustés } \\
\text { Ajustement en fonction des effets } \\
\text { saisonniers et virologiques (compos- } \\
\text { ition des souches en circulation) }\end{array}$ & Niveau II-3 & $\begin{array}{l}\text { Faible } \\
\text { Esti- } \\
\text { mations } \\
\text { des taux } \\
\text { de } \\
\text { vaccina- } \\
\text { tion } \\
\text { fondées } \\
\text { sur des } \\
\text { sondages; } \\
\text { diffé- } \\
\text { rences sur } \\
\text { le plan } \\
\text { des } \\
\text { caractéris- } \\
\text { tiques } \\
\text { démo- } \\
\text { graph- } \\
\text { iques } \\
\text { et des } \\
\text { systèmes } \\
\text { de santé } \\
\text { non prises } \\
\text { en } \\
\text { compte }\end{array}$ \\
\hline $\begin{array}{l}\text { Joshi AY, lyer } \\
\text { VN, St Sauver } \\
\mathrm{JL} \text {, et coll. } \\
\text { Effectiveness } \\
\text { of inactivated } \\
\text { influenza } \\
\text { vaccine in } \\
\text { children less } \\
\text { than } 5 \text { years } \\
\text { of age over } \\
\text { multiple } \\
\text { influenza } \\
\text { seasons: a } \\
\text { case-control } \\
\text { study. Vaccine } \\
\text { 2009 Jul } \\
\text { 16;27(33): } \\
4457-4461 .(21)\end{array}$ & $\begin{array}{l}\text { VTI } \\
\text { Statut vaccinal } \\
\text { déterminé à } \\
\text { partir de } \\
\text { dossiers } \\
\text { médicaux } \\
\text { Mauvaise } \\
\text { concordance } \\
\text { entre le vaccin } \\
\text { et les souches } \\
\text { en circulation : } \\
\text { A (H3N2) de } \\
\text { 2001-2002 à } \\
\text { 2004-2005 et } \\
\text { en 2006-2007; } \\
\text { A (H1N1) en } \\
\text { 1999-2000, } \\
\text { 2001-2002 et } \\
\text { 2003-2004; B } \\
\text { en 2001-2002, } \\
\text { 2003-2004, } \\
\text { 2005-2006 et } \\
\text { 2006-2007 }\end{array}$ & $\begin{array}{l}\text { Étude } \\
\text { cas-témoins } \\
\text { Saisons } \\
1999-2000 \text { à } \\
2006-2007 \\
\text { É.-U. }\end{array}$ & $\begin{array}{l}\mathrm{N}=206 \\
\mathrm{n}_{\text {cas }}=103 \\
\mathrm{n}_{\text {témoin }}=103 \\
\text { Enfants de } \\
6 \text { à } 59 \text { mois }\end{array}$ & $\begin{array}{l}\text { Cas : Sujet atteint d'une affection } \\
\text { grippale confirmée en laboratoire } \\
\text { ayant nécessité une intervention } \\
\text { médicale et dont les antécédents } \\
\text { de vaccination sont établis } \\
\text { Témoin : Sujet ayant obtenu un } \\
\text { résultat négatif pour l'influenza et dont } \\
\text { les antécédents de vaccination sont } \\
\text { établis; appariement en fonction de } \\
\text { l'âge et du sexe } \\
\text { Rapport de cotes (sujets vaccinés } \\
\text { contre non vaccinés): } \\
\text { Série vaccinale complète : } \\
0,14(0,03,0,71) \\
\text { Série vaccinale partielle : } \\
0,27(0,07,0,97) ; p=0,04 \\
\text { Efficacité potentielle du vaccin } \\
\text { (sujets vaccinés c. non vaccinés) } \\
\text { Série vaccinale complète : } \\
86 \% \text { (29, 97) } \\
\text { Série vaccinale partielle : } 73 \% \text { (3, 93) } \\
\text { Nombre nécessaire à traiter : } 3-11 \\
\text { enfants (taux d'attaque estimé } \\
\text { à } 10-40 \%)\end{array}$ & Niveau II-2 & $\begin{array}{l}\text { Assez } \\
\text { bonne } \\
\text { Affections } \\
\text { à risque } \\
\text { élevé non } \\
\text { exclues ni } \\
\text { évaluées } \\
\text { chez les } \\
\text { cas et les } \\
\text { témoins }\end{array}$ \\
\hline
\end{tabular}




\begin{tabular}{|c|c|c|c|c|c|c|}
\hline \multicolumn{5}{|c|}{ DONNÉES CONCERNANT L’EFFICACITÉ RÉELLE ET POTENTIELLE DU VTI } & \multirow[b]{2}{*}{$\begin{array}{l}\text { Degré de } \\
\text { preuve }\end{array}$} & \multirow[b]{2}{*}{ Qualité } \\
\hline Étude & Vaccin & Plan d'étude & Participants & $\begin{array}{l}\text { Résumé des principaux résultats } \\
\text { (texte ou données) }\end{array}$ & & \\
\hline $\begin{array}{l}\text { Katayose M, } \\
\text { Hosoya M, } \\
\text { Haneda T, } \\
\text { et coll. The } \\
\text { effectiveness } \\
\text { of trivalent } \\
\text { inactivated } \\
\text { influenza } \\
\text { vaccine in } \\
\text { children over } \\
\text { six consecutive } \\
\text { influenza } \\
\text { seasons. } \\
\text { Vaccine } \\
\text { 2011;29(9): } \\
\text { 1844-1849.(29) }\end{array}$ & $\begin{array}{l}\text { VTI } \\
\text { Deux doses à } \\
\text { 3-4 semaines } \\
\text { d'intervalle } \\
\text { recomman- } \\
\text { dées, peu } \\
\text { importe les } \\
\text { doses } \\
\text { antérieures du } \\
\text { VTI reçues } \\
0,1 \text { ml pour les } \\
\text { enfants de } 6 \text { à } \\
11 \text { mois; } 0,2 \text { ml } \\
\text { pour les enfants } \\
\text { de } 1 \text { à < } 6 \text { ans }\end{array}$ & $\begin{array}{l}\text { Étude } \\
\text { d'observation } \\
\text { prospective, } \\
\text { non } \\
\text { randomisée } \\
\\
\text { Saisons } \\
\text { 2002-2003 à } \\
\text { 2007-2008 } \\
\text { Japon }\end{array}$ & $\begin{array}{l}\mathrm{N}=14788 \\
\text { Statut vaccinal } \\
\text { avant la saison } \\
\text { suivante : } \\
\mathrm{n}_{\text {vaccinationcomplète }}= \\
6933 \\
\mathrm{n}_{\text {vaccinationpartielle }}= \\
887 \\
\mathrm{n}_{\text {aucunvaccin }}= \\
6968 \\
\\
\text { Enfants de } 6 \\
\text { mois à }<6 \text { ans }\end{array}$ & 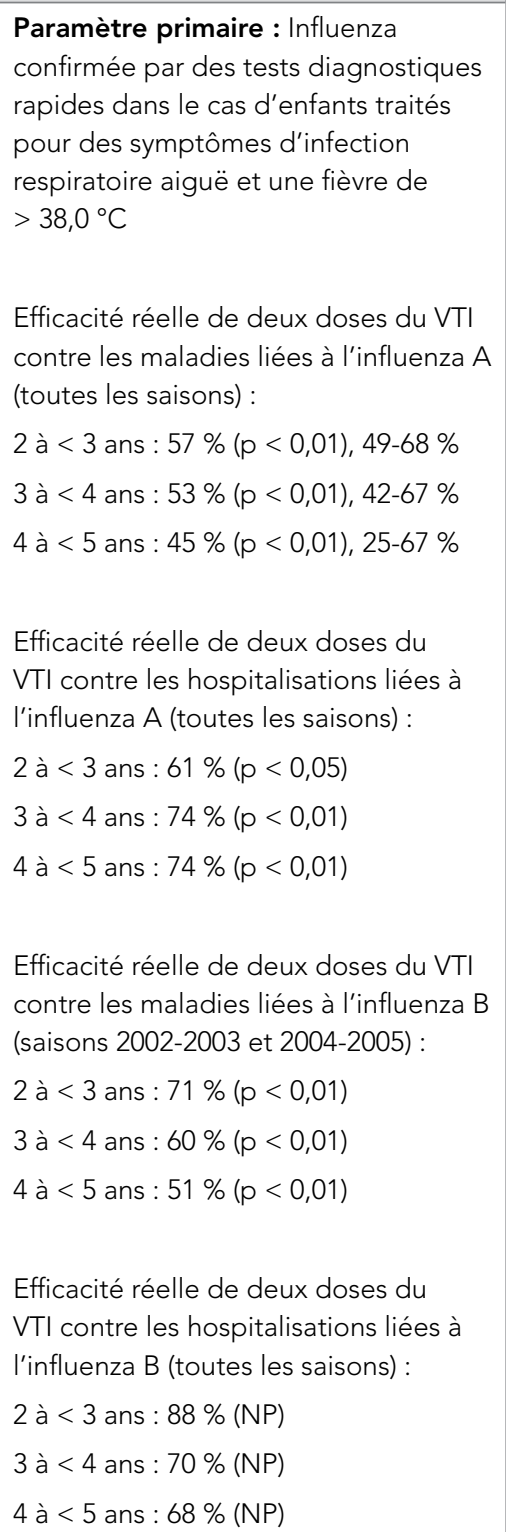 & Niveau II-3 & \begin{tabular}{|l} 
Assez \\
bonne \\
Des \\
diffé- \\
rences \\
aux \\
chapitres \\
de \\
l'auto- \\
sélection \\
de la \\
vacci- \\
nation \\
et des \\
démar- \\
ches \\
visant \\
l'obten- \\
tion de \\
soins de \\
santé \\
pour- \\
raient \\
exister \\
entre les \\
sujets \\
vaccinés \\
et non \\
vaccinés
\end{tabular} \\
\hline
\end{tabular}




\begin{tabular}{|c|c|c|c|c|c|c|}
\hline \multicolumn{5}{|c|}{ DONNÉES CONCERNANT L'EFFICACITÉ RÉELLE ET POTENTIELLE DU VTI } & \multirow[b]{2}{*}{$\begin{array}{l}\text { Degré de } \\
\text { preuve }\end{array}$} & \multirow[b]{2}{*}{ Qualité } \\
\hline Étude & Vaccin & Plan d'étude & Participants & $\begin{array}{l}\text { Résumé des principaux résultats } \\
\text { (texte ou données) }\end{array}$ & & \\
\hline $\begin{array}{l}\text { Kelly H, Jacoby } \\
\text { P, Dixon GA, } \\
\text { et coll. Vaccine } \\
\text { Effectiveness } \\
\text { Against } \\
\text { Laboratory- } \\
\text { confirmed } \\
\text { Influenza in } \\
\text { Healthy Young } \\
\text { Children: A } \\
\text { Case-Control } \\
\text { Study. Pediatr } \\
\text { Infect Dis J } \\
\text { 2011 Feb;30(2): } \\
\text { 107-111. } 22)\end{array}$ & $\begin{array}{l}\text { VTI } \\
\text { Enfants de } \geq 3 \text { à } \\
\leq 4 \text { ans : } 0,5 \mathrm{ml} \\
\text { (15 } \mu \mathrm{g} \text { par } \\
\text { souche) } \\
\text { Enfants de } \geq 6 \\
\text { mois à }<3 \text { ans : } \\
0,25 \text { ml (7,5 } \mu \mathrm{g} \\
\text { par souche) } \\
\text { Vaccination } \\
\text { complète } \\
\text { (toutes les } \\
\text { doses reçues }> \\
14 \text { jours avant } \\
\text { l'apparition du } \\
\text { SG) : } 1 . \text { deux } \\
\text { doses à } \geq 21 \\
\text { jours d'inter- } \\
\text { valle ou } 2 \text {. une } \\
\text { dose et } \geq 2 \\
\text { doses lors de } \\
\text { toute saison } \\
\text { antérieure } \\
\text { Statut vaccinal } \\
\text { déclaré par les } \\
\text { parents; validé } \\
\text { auprès du } \\
\text { dispensateur } \\
\text { de soins dans } \\
87 \% \text { des cas }\end{array}$ & $\begin{array}{l}\text { Étude } \\
\text { cas-témoins de } \\
\text { densité de } \\
\text { fréquence } \\
\text { prospective } \\
\text { Saison } 2008 \\
\text { Australie }\end{array}$ & $\begin{array}{l}\mathrm{N}=289 \\
\mathrm{n}_{\mathrm{su}}=214 \\
\mathrm{n}_{\mathrm{MG}}=75 \\
\text { Enfants de } 6 \text { à } \\
59 \text { mois (50,2\% } \\
\text { des sujets âgés } \\
\text { de }>2 \text { ans) } \\
\text { Recrutement } \\
\text { dans les } \\
\text { services } \\
\text { d'urgence (SU) } \\
\text { et de médecine } \\
\text { générale (MG) } \\
\text { 6,9\% des sujets } \\
\text { atteints d'une } \\
\text { comorbidité }\end{array}$ & 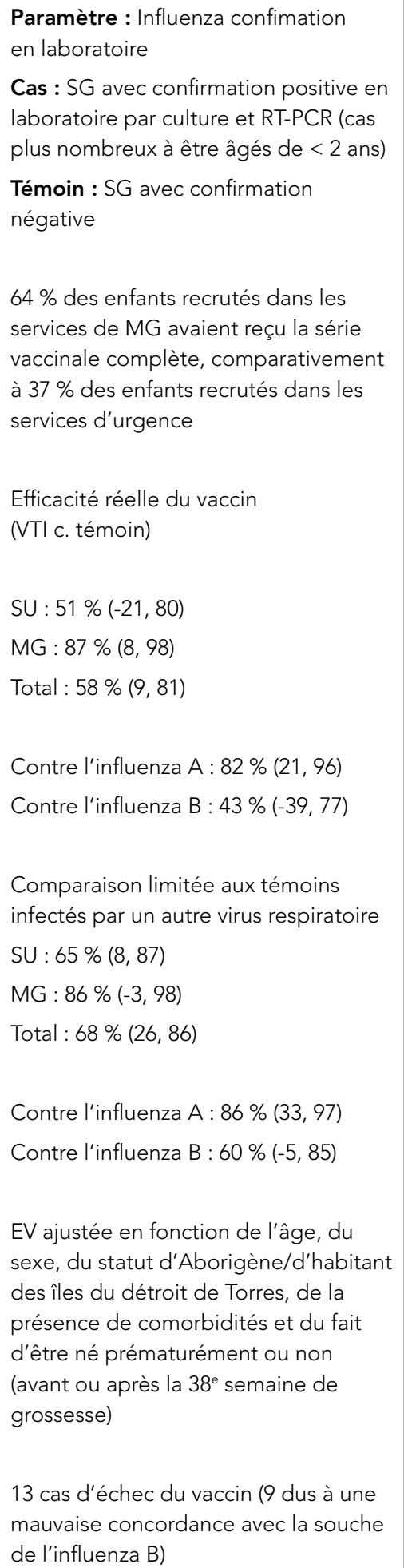 & Niveau II-2 & $\begin{array}{l}\text { Assez } \\
\text { bonne } \\
\text { Plus de } \\
\text { la moitié } \\
\text { des } \\
\text { enfants } \\
\text { recrutés } \\
\text { dans le } \\
\text { groupe } \\
\text { SU } \\
\text { fréquen- } \\
\text { taient un } \\
\text { centre } \\
\text { médical } \\
\text { ayant un } \\
\text { pro- } \\
\text { gramme } \\
\text { rigoureux } \\
\text { de } \\
\text { vaccina- } \\
\text { tion des } \\
\text { enfants }\end{array}$ \\
\hline
\end{tabular}




\begin{tabular}{|c|c|c|c|c|c|c|}
\hline \multicolumn{5}{|c|}{ DONNÉES CONCERNANT L'EFFICACITÉ RÉELLE ET POTENTIELLE DU VTI } & \multirow[b]{2}{*}{$\begin{array}{l}\text { Degré de } \\
\text { preuve }\end{array}$} & \multirow[b]{2}{*}{ Qualité } \\
\hline Étude & Vaccin & Plan d'étude & Participants & $\begin{array}{l}\text { Résumé des principaux résultats } \\
\text { (texte ou données) }\end{array}$ & & \\
\hline $\begin{array}{l}\text { Maeda T, } \\
\text { Shintani Y, } \\
\text { Miyamoto H, } \\
\text { et coll. } \\
\text { Prophylactic } \\
\text { effect of } \\
\text { inactivated } \\
\text { influenza } \\
\text { vaccine on } \\
\text { young children. } \\
\text { Pediatr Int } \\
2002 ; 44(1) \text { : } \\
43-46 .{ }^{(30)}\end{array}$ & $\begin{array}{l}\text { VTI } \\
\text { Deux doses à } \\
14 \text { jours } \\
\text { d'intervalle } \\
0,1 \mathrm{ml} \text { pour les } \\
\text { enfants de } 6 \text { à } \\
11 \text { mois; } 0,2 \mathrm{ml} \\
\text { pour les enfants } \\
\text { de } 1 \text { à }<6 \text { ans }\end{array}$ & $\begin{array}{l}\begin{array}{l}\text { Étude de } \\
\text { cohorte } \\
\text { prospective }\end{array} \\
\text { Saison } \\
1999-2000 \\
\text { Japon }\end{array}$ & $\begin{array}{l}\mathrm{N}=180 \\
\mathrm{n}_{\text {vacciné }}=86 \\
\mathrm{n}_{\text {nonvacciné }}=94 \\
\text { Nourrissons } \\
\text { et enfants en } \\
\text { bonne santé } \\
\text { de } 5 \text { à } 83 \text { mois } \\
\text { Groupe témoin } \\
\text { (aucune } \\
\text { vaccination } \\
\text { antigrippale } \\
\text { au cours de la } \\
\text { dernière année) } \\
\text { apparié selon } \\
\text { l'âge à partir } \\
\text { de dossiers } \\
\text { d'hôpitaux }\end{array}$ & $\begin{array}{l}\text { Paramètre primaire : Influenza A } \\
\text { confirmée par dosage immunenzyma- } \\
\text { tique sur membrane chez des enfants } \\
\text { atteints d'une maladie fébrile ayant } \\
\text { nécessité une intervention médicale ( }> \\
37,8^{\circ} \mathrm{C} \text { ) } \\
\text { Effet préventif contre l'influenza A } \\
\text { (par âge) } \\
\text { Groupe vacciné, groupe témoin } \\
2 \text { ans : } 11,1 \%, 8,0 \%, p=0,562 \\
3 \text { ans : } 0,26,3 \%, p=0,023 \\
4 \text { ans : } 0,18,2 \%, p=0,199 \\
80 \%(4 / 5) \text { des enfants immunisés } \\
\text { contre l'influenza A avaient }<3 \text { ans }\end{array}$ & Niveau II-2 & $\begin{array}{l}\text { Faible } \\
\text { Groupes } \\
\text { compar- } \\
\text { ables en } \\
\text { fonction } \\
\text { de l'âge } \\
\text { et du } \\
\text { sexe, mais } \\
\text { échantil- } \\
\text { lon de } \\
\text { faible } \\
\text { taille }\end{array}$ \\
\hline
\end{tabular}




\begin{tabular}{|c|c|c|c|c|c|c|}
\hline \multicolumn{5}{|c|}{ DONNÉES CONCERNANT L'EFFICACITÉ RÉELLE ET POTENTIELLE DU VTI } & \multirow[b]{2}{*}{$\begin{array}{l}\text { Degré de } \\
\text { preuve }\end{array}$} & \multirow[b]{2}{*}{ Qualité } \\
\hline Étude & Vaccin & Plan d'étude & Participants & $\begin{array}{l}\text { Résumé des principaux résultats } \\
\text { (texte ou données) }\end{array}$ & & \\
\hline $\begin{array}{l}\text { Ochiai H, } \\
\text { Fujieda M, } \\
\text { Ohfuji S, et coll. } \\
\text { Inactivated } \\
\text { influenza } \\
\text { vaccine } \\
\text { effectiveness } \\
\text { against } \\
\text { influenza-like } \\
\text { illness among } \\
\text { young children } \\
\text { in Japan- } \\
\text { with special } \\
\text { reference to } \\
\text { minimizing } \\
\text { outcome } \\
\text { misclassifica- } \\
\text { tion. Vaccine } \\
\text { 2009;27(50): } \\
\text { 7031-7035.(31) }\end{array}$ & $\begin{array}{l}\text { VTI } \\
\text { Deux doses à } \\
\text { 2-4 semaines } \\
\text { d'intervalle } \\
0,1 \mathrm{ml} \text { chez les } \\
\text { enfants de } 6 \text { à } \\
11 \text { mois; } 0,2 \text { ml } \\
\text { chez les enfants } \\
\text { de } 1 \text { à < } 6 \text { ans }\end{array}$ & $\begin{array}{l}\text { Cohorte } \\
\text { prospective, } \\
\text { multicentrique } \\
\text { Saison } \\
2000-2001 \\
\text { Japon }\end{array}$ & $\begin{array}{l}\mathrm{N}=2265 \\
\mathrm{n}_{\text {vacciné }}=1166 \\
\mathrm{n}_{\text {nonvacciné }}=1099 \\
\text { Enfants de } \\
<6 \text { ans } \\
\mathrm{n}=1249 \\
\text { (2 à } 5 \text { ans) }\end{array}$ & 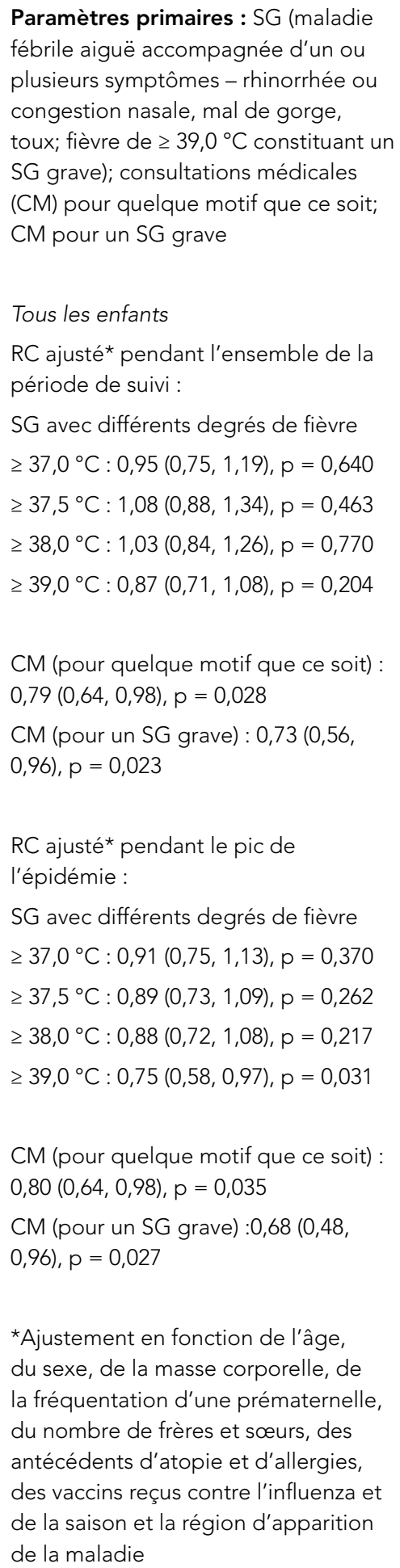 & Niveau II-2 & $\begin{array}{l}\text { Faible } \\
\text { Auto- } \\
\text { sélection } \\
\text { de la } \\
\text { vaccina- } \\
\text { tion } \\
\text { par les } \\
\text { parents; } \\
\text { les } \\
\text { groupes } \\
\text { présentai- } \\
\text { ent des } \\
\text { diffé- } \\
\text { rences } \\
\text { signifi- } \\
\text { catives à } \\
\text { certains } \\
\text { égards, } \\
\text { malgré les } \\
\text { ajuste- } \\
\text { ments } \\
\text { statisti- } \\
\text { ques } \\
\text { effectués } \\
\text { dans le } \\
\text { cadre de } \\
\text { l'analyse }\end{array}$ \\
\hline
\end{tabular}




\begin{tabular}{|c|c|c|c|c|c|c|}
\hline \multicolumn{7}{|c|}{ DONNÉES CONCERNANT L'EFFICACITÉ RÉELLE ET POTENTIELLE DU VTI } \\
\hline Étude & Vaccin & Plan d'étude & Participants & $\begin{array}{l}\text { Résumé des principaux résultats } \\
\text { (texte ou données) }\end{array}$ & $\begin{array}{l}\text { Degré de } \\
\text { preuve }\end{array}$ & Qualité \\
\hline & & & & $\begin{array}{l}R C \text { par tranche d'âge } \\
R C \text { ajusté* pendant le pic de } \\
\text { l'épidémie: } \\
\text { SG grave } \\
2,0 \text { à } 2,9 \text { ans : } 0,56(0,29,1,07) \\
3,0 \text { à } 3,9 \text { ans : } 0,50(0,26,0,96) \\
4,0 \text { à } 4,9 \text { ans : } 1,32(0,71,2,47) \\
\text { CM pour un } \mathrm{SG} \text { grave } \\
2,0 \text { à } 2,9 \text { ans : } 0,60(0,25,1,41) \\
3,0 \text { à } 3,9 \text { ans : } 0,38(0,15,0,97) \\
4,0 \text { à } 4,9 \text { ans : } 0,92(0,40,2,11)\end{array}$ & & \\
\hline $\begin{array}{l}\text { Ozgur SK, } \\
\text { Beyazova U, } \\
\text { Kemaloglu YK, } \\
\text { et coll. } \\
\text { Effectiveness } \\
\text { of inactivated } \\
\text { influenza } \\
\text { vaccine for } \\
\text { prevention of } \\
\text { otitis media in } \\
\text { children. } \\
\text { Pediatr Infect } \\
\text { Dis J 2006 } \\
\text { May;25(5): } \\
401-404 .(46)\end{array}$ & $\begin{array}{l}\text { VTI } \\
0,25 \mathrm{ml} \text { pour les } \\
\text { enfants de }<3 \\
\text { ans, } 0,5 \mathrm{ml} \text { pour } \\
\text { les enfants de } \geq \\
3 \text { ans } \\
\text { Une ou deux } \\
\text { doses, selon les } \\
\text { antécédents de } \\
\text { vaccination; } \\
\text { statut vaccinal } \\
\text { validé par les } \\
\text { dossiers } \\
\text { médicaux }\end{array}$ & $\begin{array}{l}\text { Étude de } \\
\text { cohorte } \\
\text { prospective, à } \\
\text { l'insu de } \\
\text { l'évaluateur, } \\
\text { multicentrique } \\
\text { Saison } \\
\text { 2003-2004 } \\
\text { Turquie }\end{array}$ & $\begin{array}{l}\mathrm{N}=119 \\
\mathrm{n}_{\mathrm{VTI}}=61 \\
\mathrm{n}_{\text {témoin }}=58 \\
\text { Enfants de } 6 \\
\text { à } 60 \text { mois (âge } \\
\text { moyen : } 43,7 \pm \\
11,4 \text { mois); } 63 \% \\
\text { des sujets âgés } \\
\text { de } 2 \text { à } 5 \text { ans } \\
\text { Garderies }\end{array}$ & $\begin{array}{l}\text { Paramètre : Vérification de la } \\
\text { présence d'une otite séreuse (OS), } \\
\text { d'une otite moyenne aiguë (OMA) et } \\
\text { d'une otite moyenne (OM) au départ, } \\
\text { puis toutes les } 6 \text { semaines pendant } \\
6 \text { mois } \\
\text { Incidence pendant la saison grippale } \\
\text { (VTI contre témoin) } \\
\text { OS : } 25,8 \% \text { c. } 36,3 \% \text { ( } p=0,040) \\
\text { OMA : } 3,3 \% \text { c. } 8,8 \% \text { ( } p=0,048) \\
\text { OM : } 29,1 \% \text { c. } 45,1 \% \text { ( } p=0,012) \\
\text { Incidence après la saison grippale } \\
\text { (VTI contre témoin), phase tardive } \\
\text { (mars-avril } 2004) \\
\text { OM : } 16,1 \% \text { c. } 28,6 \%(p=0,032) \\
\text { Incidence totale } \\
\text { OS : } 22,8 \% \text { c. } 31,1 \% \text { ( } p=0,002) \\
\text { OMA : } 2,3 \% \text { c. } 5,2 \% \text { ( } p=0,012) \\
\text { OM : } 25,2 \% \text { c. } 36,3 \% \text { ( } p<0,001) \\
\text { La fréquence de l'OS, de l'OMA et de } \\
\text { l'OM ne variait pas de façon significa- } \\
\text { tive avant ou après la saison grippale. }\end{array}$ & Niveau II-2 & $\begin{array}{l}\text { Assez } \\
\text { bonne }\end{array}$ \\
\hline
\end{tabular}




\begin{tabular}{|c|c|c|c|c|c|c|}
\hline \multicolumn{7}{|c|}{ DONNÉES CONCERNANT L'EFFICACITÉ RÉELLE ET POTENTIELLE DU VTI } \\
\hline Étude & Vaccin & Plan d'étude & Participants & $\begin{array}{l}\text { Résumé des principaux résultats } \\
\text { (texte ou données) }\end{array}$ & $\begin{array}{l}\text { Degré de } \\
\text { preuve }\end{array}$ & Qualité \\
\hline $\begin{array}{l}\text { Ritzwoller DP, } \\
\text { Bridges CB, } \\
\text { Shetterly S, } \\
\text { et coll. } \\
\text { Effectiveness of } \\
\text { the 2003-2004 } \\
\text { influenza } \\
\text { vaccine among } \\
\text { children } 6 \\
\text { months to } 8 \\
\text { years of age, } \\
\text { with } 1 \text { vs } 2 \\
\text { doses. } \\
\text { Pediatrics } \\
\text { 2005;116(1): } \\
\text { 153-159.(19) }\end{array}$ & $\begin{array}{l}\text { VTI } \\
\text { Vaccination } \\
\text { complète } \\
\text { (toutes les } \\
\text { doses reçues > } \\
\text { 14 jours avant } \\
\text { l'apparition du } \\
\text { SG) : 1. deux } \\
\text { doses ou } 2 \text {. une } \\
\text { dose précédée } \\
\text { d'une immuni- } \\
\text { sation lors } \\
\text { d'une saison } \\
\text { antérieure } \\
\text { Vaccination } \\
\text { partielle : } \\
\text { 1. une dose } \\
\text { reçue } \geq 14 \text { jours } \\
\text { avant } \\
\text { l'apparition du } \\
\text { SG }\end{array}$ & $\begin{array}{l}\text { Étude de } \\
\text { cohorte } \\
\text { rétrospective } \\
\text { Saison } \\
\text { 2003-2004 } \\
\text { (semaines de } \\
\text { pointe de } \\
\text { I'activité } \\
\text { grippale } \\
\text { seulement) : } \\
\text { du } 19 \text { nov. au } \\
7 \text { déc. 2003) } \\
\\
\text { É.-U. }\end{array}$ & $\begin{array}{l}\mathrm{N}=29726 \\
\mathrm{n}=5139 \\
\text { (6 à } 23 \text { mois) } \\
\mathrm{n}=24587 \\
(2 \text { à } 8 \text { ans) } \\
\text { Enfants de } \\
6 \text { mois à } 8 \text { ans }\end{array}$ & 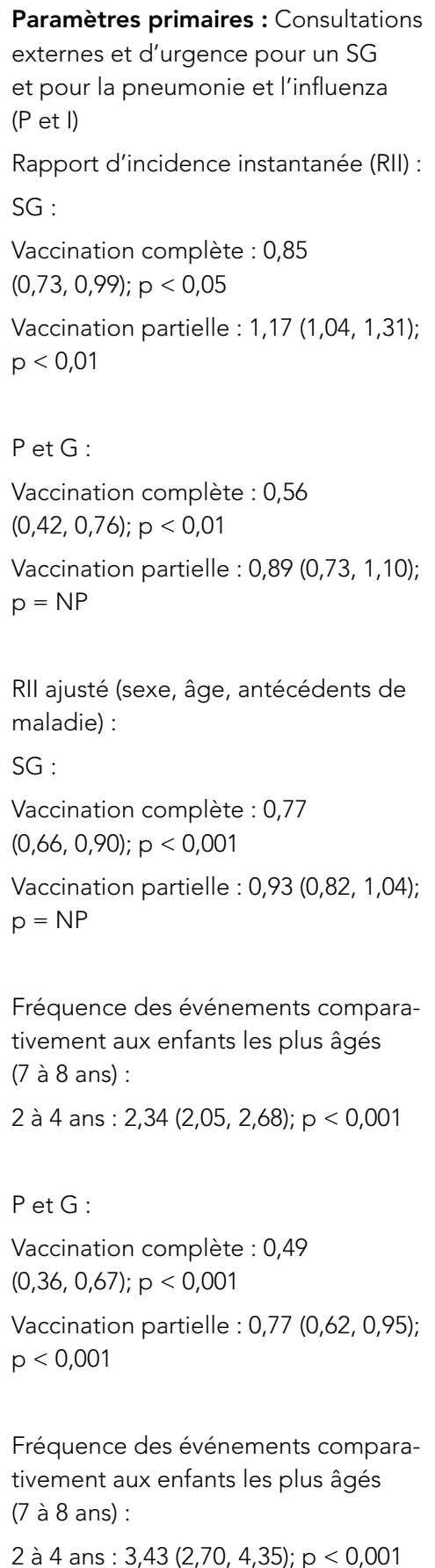 & Niveau II-2 & $\begin{array}{l}\text { Assez } \\
\text { bonne } \\
\text { L'étude } \\
\text { repose } \\
\text { sur des } \\
\text { données } \\
\text { adminis- } \\
\text { tratives } \\
\text { non } \\
\text { confir- } \\
\text { mées en } \\
\text { labora- } \\
\text { toire, } \\
\text { créant un } \\
\text { risque de } \\
\text { classifica- } \\
\text { tion } \\
\text { erronée. }\end{array}$ \\
\hline
\end{tabular}




\begin{tabular}{|c|c|c|c|c|c|c|}
\hline \multicolumn{5}{|c|}{ DONNÉES CONCERNANT L'EFFICACITÉ RÉELLE ET POTENTIELLE DU VTI } & \multirow[b]{2}{*}{$\begin{array}{l}\text { Degré de } \\
\text { preuve }\end{array}$} & \multirow[b]{2}{*}{ Qualité } \\
\hline Étude & Vaccin & Plan d'étude & Participants & $\begin{array}{l}\text { Résumé des principaux résultats } \\
\text { (texte ou données) }\end{array}$ & & \\
\hline $\begin{array}{l}\text { Shuler CM, } \\
\text { Iwamoto M, } \\
\text { Bridges CB, } \\
\text { et coll. Vaccine } \\
\text { effectiveness } \\
\text { against } \\
\text { medically } \\
\text { attended, } \\
\text { laboratory- } \\
\text { confirmed } \\
\text { influenza } \\
\text { among children } \\
\text { aged 6 to } \\
59 \text { months, } \\
2003-2004 . \\
\text { Pediatrics } \\
\text { 2007;119(3): } \\
\text { e587-95.(24) }\end{array}$ & $\begin{array}{l}\text { VTI } \\
\text { Vaccination } \\
\text { complète } \\
\text { (toutes les } \\
\text { doses reçues } \geq \\
14 \text { jours avant } \\
\text { l'apparition du } \\
\text { SG) : 1. deux } \\
\text { doses à } \geq 1 \\
\text { mois } \\
\text { d'intervalle ou } \\
\text { 2. une dose } \\
\text { précédée d'une } \\
\text { immunisation } \\
\text { lors d'une } \\
\text { saison } \\
\text { antérieure } \\
\\
\text { Vaccination } \\
\text { partielle : } 1 . \\
\text { deux doses } \\
\text { reçues, mais SG } \\
\text { apparu < } 14 \\
\text { jours après la } \\
\text { dernière dose; } \\
2 . \text { une dose, } \\
\text { sans immunisa- } \\
\text { tion lors de } \\
\text { la saison } \\
\text { précédente, et } \\
\geq 14 \text { jours avant } \\
\text { l'apparition du } \\
\text { SG } \\
\text { Concordance } \\
\text { antigénique } \\
\text { sous-optimale } \\
\text { entre le vaccin } \\
\text { et les souches } \\
\text { en circulation }\end{array}$ & $\begin{array}{l}\begin{array}{l}\text { Étude } \\
\text { cas-témoins }\end{array} \\
\text { Saison } \\
\text { 2003-2004 } \\
\text { É.-U. }\end{array}$ & $\begin{array}{l}\mathrm{N}=870 \\
\mathrm{n}_{\text {ca }}=290 \\
\mathrm{n}_{\text {témoin }}=580 \\
\\
\text { Enfants de } 6 \text { à } \\
59 \text { mois d'un } \\
\text { centre d'étude } \\
\text { (de } 19,0 \text { à } \\
22,1 \% \text { des } \\
\text { sujets étaient } \\
\text { atteints d'une } \\
\text { affection à } \\
\text { risque élevée, } \\
\text { telle qu'une } \\
\text { maladie rénale, } \\
\text { un déficit } \\
\text { immunitaire, } \\
\text { une maladie } \\
\text { métabolique) }\end{array}$ & $\begin{array}{l}\text { Cas : Influenza confirmée en labora- } \\
\text { toire ayant nécessité une intervention } \\
\text { médicale (confirmation par test } \\
\text { QuickVue) } \\
\text { Témoin : Apparié selon l'âge, né le } \\
\text { même mois que le cas (deux témoins } \\
\text { par cas) } \\
\text { RC ajusté (6 à } 59 \text { mois) } \\
\text { Vaccination complète vs non } \\
\text { vaccination : } 0,51 \text { ( } 0,4,0,7) ; p<0,01 \\
\text { (EV = } 49 \%) \\
\text { Vaccination partielle vs non vaccina- } \\
\text { tion : } 0,76(0,5,1,2) ; p=N P \\
\text { RC ajusté ( } 24 \text { à } 59 \text { mois) } \\
\text { Vaccination complète contre non } \\
\text { vaccination : } 0,55 \text { ( } 0,3,0,9) ; p<0,05 \\
\text { (EV = } 45 \% \text { ) } \\
\text { Vaccination partielle contre non } \\
\text { vaccination : } 0,35 \text { ( } 0,2,0,7) ; p<0,05 \\
\text { (EV = } 65 \% \text { ) } \\
\text { Ajustement en fonction de la présence } \\
\text { d'un risque élevé et de l'utilisation du } \\
\text { système de santé selon la tranche } \\
\text { d'âge }\end{array}$ & Niveau II-2 & $\begin{array}{l}\text { Assez } \\
\text { bonne } \\
\text { La } \\
\text { connais- } \\
\text { sance du } \\
\text { statut } \\
\text { vaccinal } \\
\text { par les } \\
\text { évalua- } \\
\text { teurs } \\
\text { pourrait } \\
\text { avoir } \\
\text { engendré } \\
\text { un biais } \\
\text { au } \\
\text { chapitre } \\
\text { des tests } \\
\text { diagnos- } \\
\text { tiques } \\
\text { (classifica- } \\
\text { tion } \\
\text { erronée } \\
\text { des cas } \\
\text { comme } \\
\text { des } \\
\text { témoins) }\end{array}$ \\
\hline
\end{tabular}




\begin{tabular}{|c|c|c|c|c|c|c|}
\hline \multicolumn{5}{|c|}{ DONNÉES CONCERNANT L'EFFICACITÉ RÉELLE ET POTENTIELLE DU VTI } & \multirow[b]{2}{*}{$\begin{array}{l}\text { Degré de } \\
\text { preuve }\end{array}$} & \multirow[b]{2}{*}{ Qualité } \\
\hline Étude & Vaccin & Plan d'étude & Participants & $\begin{array}{l}\text { Résumé des principaux résultats } \\
\text { (texte ou données) }\end{array}$ & & \\
\hline $\begin{array}{l}\text { Staat MA, } \\
\text { Griffin MR, } \\
\text { Donauer S, } \\
\text { et coll. Vaccine } \\
\text { effectiveness } \\
\text { for laboratory- } \\
\text { confirmed } \\
\text { influenza in } \\
\text { children 6-59 } \\
\text { months of age, } \\
\text { 2005-2007. } \\
\text { Vaccine } \\
2011 ; 29(48) \text { : } \\
9005-9011.23)\end{array}$ & $\begin{array}{l}\text { VTI } \\
\text { Vaccination } \\
\text { complète } \\
\text { (toutes les } \\
\text { doses reçues } \geq \\
14 \text { jours avant } \\
\text { l'apparition du } \\
\text { SG) : } 1 \text {. deux } \\
\text { doses à } \geq \\
24 \text { jours } \\
\text { d'intervalle ou } \\
2 \text {. une dose et } \\
\geq 1 \text { dose reçue } \\
\text { lors d'une } \\
\text { saison } \\
\text { antérieure } \\
\text { Vaccination } \\
\text { partielle : } 1 . \\
\text { seulement } 1 \\
\text { des } 2 \text { doses } \\
\text { reçues } \geq 14 \\
\text { jours avant } \\
\text { l'apparition du } \\
\text { SG ou } 2 \text {. deux } \\
\text { doses reçues, la } \\
\text { deuxième } \\
\text { remontant à < } \\
24 \text { jours après } \\
\text { la première }\end{array}$ & $\begin{array}{l}\text { Étude } \\
\text { cas-témoins, } \\
\text { multicentrique } \\
\text { Saisons } \\
2005-2006 \text { et } \\
2006-2007 \\
\text { É.-U. }\end{array}$ & $\begin{array}{l}2005-2006 \\
N=268 \\
n_{\text {cas }}=85 \\
n_{\text {témoin }}=183 \\
20062007 \\
N=528 \\
n_{\text {cas }}=158 \\
n_{\text {témoin }}=370 \\
\text { Enfants de 6 } \\
\text { à } 59 \text { mois } \\
\text { Recrutement } \\
\text { en consultation } \\
\text { interne et } \\
\text { externe }\end{array}$ & 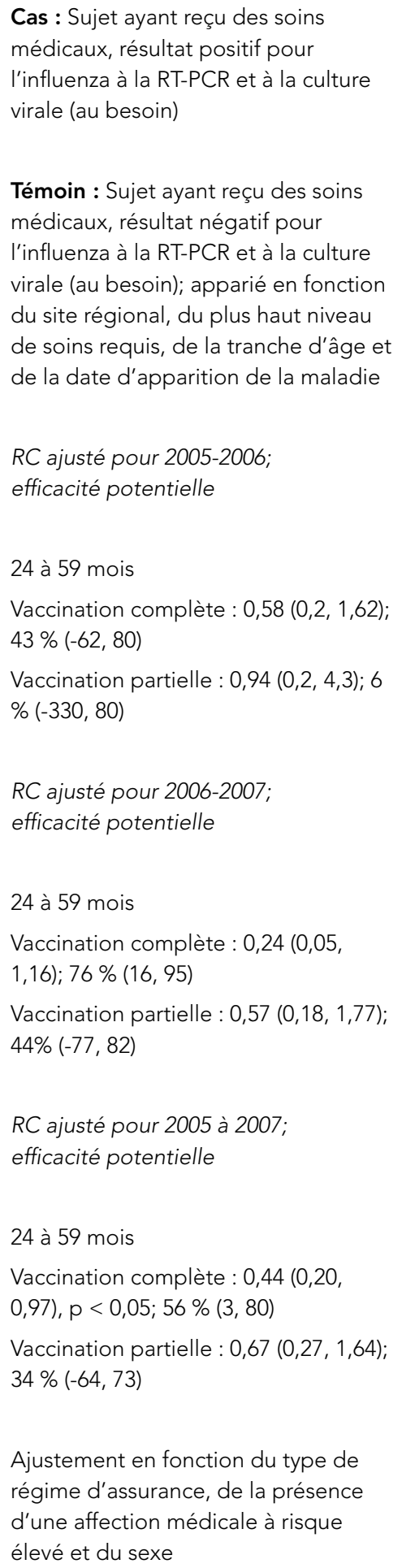 & Niveau II-2 & Bonne \\
\hline
\end{tabular}




\begin{tabular}{|c|c|c|c|c|c|c|}
\hline \multicolumn{5}{|c|}{ DONNÉES CONCERNANT L'EFFICACITÉ RÉELLE ET POTENTIELLE DU VTI } & \multirow[b]{2}{*}{$\begin{array}{l}\text { Degré de } \\
\text { preuve }\end{array}$} & \multirow[b]{2}{*}{ Qualité } \\
\hline Étude & Vaccin & Plan d'étude & Participants & $\begin{array}{l}\text { Résumé des principaux résultats } \\
\text { (texte ou données) }\end{array}$ & & \\
\hline $\begin{array}{l}\text { Szilagyi PG, } \\
\text { Fairbrother G, } \\
\text { Griffin MR, } \\
\text { et coll. } \\
\text { Influenza } \\
\text { vaccine } \\
\text { effectiveness } \\
\text { among children } \\
6 \text { to } 59 \text { months } \\
\text { of age during } \\
2 \text { influenza } \\
\text { seasons: a } \\
\text { case-cohort } \\
\text { study. Arch } \\
\text { Pediatr } \\
\text { Adolesc Med } \\
2008 ; 162(10): \\
943-951 .(28)\end{array}$ & 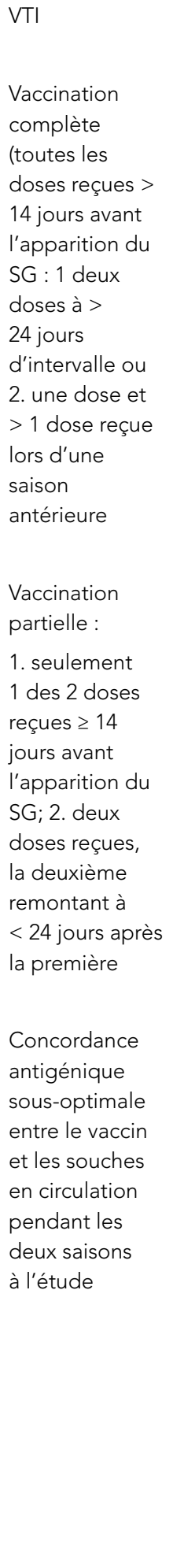 & $\begin{array}{l}\text { Étude } \\
\text { cas-cohorte, } \\
\text { multicentrique } \\
\text { Saisons } \\
2003-2004 \\
\text { et 2004-2005 } \\
\text { É.-U. }\end{array}$ & 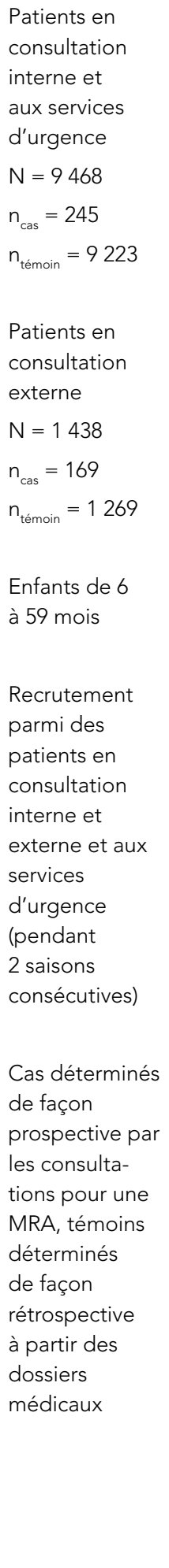 & 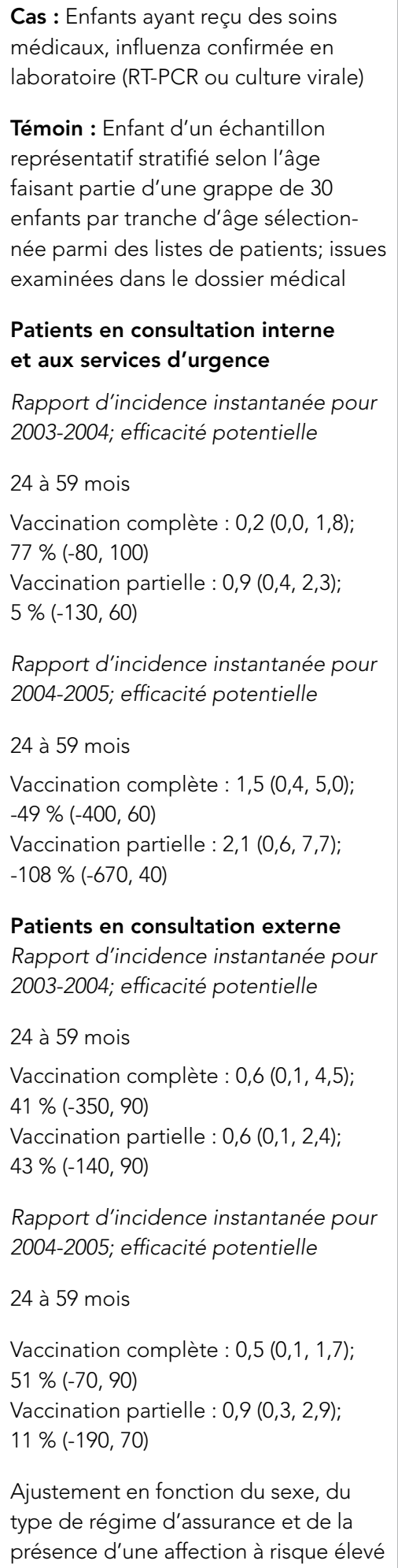 & Niveau II-2 & $\begin{array}{l}\text { Assez } \\
\text { bonne } \\
\\
\text { Il est } \\
\text { possible } \\
\text { que le } \\
\text { plan } \\
\text { d'étude } \\
\text { ne } \\
\text { permette } \\
\text { pas de } \\
\text { cerner } \\
\text { certains } \\
\text { facteurs } \\
\text { influant } \\
\text { sur les } \\
\text { estima- } \\
\text { tions, par } \\
\text { exemple } \\
\text { la } \\
\text { propen- } \\
\text { sion à } \\
\text { consulter } \\
\text { un } \\
\text { médecin }\end{array}$ \\
\hline
\end{tabular}


TABLEAU 5B : Sommaire des données concernant les enfants de 24 à 59 mois - Évidences liées aux effets indirects

\begin{tabular}{|c|c|c|c|c|c|c|}
\hline \multicolumn{7}{|c|}{ DONNÉES CONCERNANT L'EFFICACITÉ RÉELLE ET POTENTIELLE DU VTI } \\
\hline Étude & Vaccin & Plan d'étude & Participants & $\begin{array}{l}\text { Résumé des principaux résultats } \\
\text { (texte ou données) }\end{array}$ & $\begin{array}{l}\text { Degré de } \\
\text { preuve }\end{array}$ & Qualité \\
\hline $\begin{array}{l}\text { Hurwitz ES, } \\
\text { Haber M, } \\
\text { Chang A, } \\
\text { et coll. } \\
\text { Effectiveness } \\
\text { of influenza } \\
\text { vaccination } \\
\text { of day care } \\
\text { children in } \\
\text { reducing } \\
\text { influenza- } \\
\text { related } \\
\text { morbidity } \\
\text { among } \\
\text { household } \\
\text { contacts. } \\
\text { JAMA 2000; } \\
\text { 284(13): } \\
\text { 1677-1682.(47) }\end{array}$ & $\begin{array}{l}\text { VTI } \\
\text { Vaccin de } \\
\text { comparaison: } \\
\text { vaccin contre } \\
\text { l'hépatite A } \\
\\
\text { Dans le cas des } \\
\text { deux vaccins: } \\
2 \text { doses } \\
\text { administrées } \\
\text { à } 1 \text { mois } \\
\text { d'intervalle } \\
\text { suivant la } \\
\text { posologie } \\
\text { standard } \\
\text { recommandée }\end{array}$ & $\begin{array}{l}\text { ECR, à simple } \\
\text { insu (parents) } \\
\text { Saison } \\
\text { 1996-1997 } \\
\text { É.-U. }\end{array}$ & $\begin{array}{l}\mathrm{N}=127 \\
\mathrm{n}_{\mathrm{VT}}=60 \\
\mathrm{n}_{\text {HepA }}=67 \\
\text { Enfants de } 24 \\
\text { à } 60 \text { mois } \\
\text { Sujets n'ayant } \\
\text { jamais été } \\
\text { vaccinés contre } \\
\text { l'influenza } \\
\\
\text { Garderies } \\
\text { affiliées aux } \\
\text { Forces navales } \\
\text { des É.-U. }\end{array}$ & $\begin{array}{l}\text { EV non statistiquement significative } \\
\text { chez les enfants vaccinés } \\
\text { EV chez les contacts familiaux non } \\
\text { vaccinés } \\
\text { Atteinte respiratoire avec fièvre: } \\
42 \% \text { ( } p=0,04) \\
\text { Atteinte respiratoire avec fièvre } \geq 38^{\circ} \mathrm{C} \text { : } \\
48 \% \text { ( } p=0,04) \\
\text { EV chez les contacts familiaux vaccinés } \\
\text { Total : } 28 \% \text { ( } p=0,04) \\
\text { EV chez les contacts familiaux non } \\
\text { vaccinés de } 5 \text { à } 17 \text { ans se situant } \\
\text { entre } 45 \text { et } 100 \% \text { en ce qui concerne } \\
\text { l'absentéisme à l'école et au travail, } \\
\text { les consultations médicales, les maux } \\
\text { d'oreille, la prescription d'antibiotiques } \\
\text { et la prise de médicaments en vente } \\
\text { libre (résultat statistiquement significatif } \\
\text { dans tous les cas) - non observée } \\
\text { chez les adultes ni chez les enfants } \\
\text { de }<5 \text { ans }\end{array}$ & Niveau I & $\begin{array}{l}\text { Bonne } \\
\text { Nombres } \\
\text { faibles } \\
\text { pour } \\
\text { certaines } \\
\text { sous- } \\
\text { analyses }\end{array}$ \\
\hline $\begin{array}{l}\text { Loeb M, Russell } \\
\text { ML, Moss L, } \\
\text { et coll. Effect } \\
\text { of influenza } \\
\text { vaccination } \\
\text { of children on } \\
\text { infection rates } \\
\text { in Hutterite } \\
\text { communities. } \\
\text { JAMA 2010; } \\
\text { 303(10): } \\
943-950 .{ }^{(50)}\end{array}$ & $\begin{array}{l}\text { VTI } \\
\text { Vaccin de } \\
\text { comparaison: } \\
\text { vaccin contre } \\
\text { I'hépatite A }\end{array}$ & $\begin{array}{l}\text { ECR en grappes } \\
\text { (49 collectivités) } \\
\text { Saison } \\
\text { 2008-2009 } \\
\text { Canada }\end{array}$ & $\begin{array}{l}N=3273 \\
n_{\text {nonvacciné }}=2326 \\
n_{\text {vacciné }}=947 \\
\text { Seuls les } \\
\text { enfants de } \\
36 \text { mois à } \\
15 \text { ans ont } \\
\text { reçu le vaccin } \\
n_{\text {vTI }}=502 \\
n_{\text {HepA }}=445\end{array}$ & $\begin{array}{l}\text { Paramètre : Influenza confirmée } \\
\text { en laboratoire (RT-PCR) } \\
\text { Effet protecteur indirect du vaccin } \\
\text { (sujets non vaccinés) : } 61 \%(8,83 ; \\
p=0,03) \\
\text { Rapport d'incidence des prescriptions } \\
\text { d'antimicrobiens : } 0,58(0,34,0,99, \\
p=0,046) \\
\text { Aucun rapport d'incidence statistique- } \\
\text { ment significatif en ce qui concerne les } \\
\text { consultations médicales pour une } \\
\text { maladie respiratoire, un syndrome } \\
\text { grippal ou une OM }\end{array}$ & Niveau I & Bonne \\
\hline
\end{tabular}




\begin{tabular}{|c|c|c|c|c|c|c|}
\hline \multicolumn{5}{|c|}{ DONNÉES CONCERNANT L'EFFICACITÉ RÉELLE ET POTENTIELLE DU VTI } & \multirow[b]{2}{*}{$\begin{array}{l}\text { Degré de } \\
\text { preuve }\end{array}$} & \multirow[b]{2}{*}{ Qualité } \\
\hline Étude & Vaccin & Plan d'étude & Participants & $\begin{array}{l}\text { Résumé des principaux résultats } \\
\text { (texte ou données) }\end{array}$ & & \\
\hline $\begin{array}{l}\text { Piedra PA, } \\
\text { Gaglani MJ, } \\
\text { Kozinetz CA, } \\
\text { et coll. Herd } \\
\text { immunity in } \\
\text { adults against } \\
\text { influenza- } \\
\text { related illnesses } \\
\text { with use of the } \\
\text { trivalent-live } \\
\text { attenuated } \\
\text { influenza } \\
\text { vaccine (CAIV-T) } \\
\text { in children. } \\
\text { Vaccine } \\
\text { 2005;23(13): } \\
\text { 1540-8. }{ }^{(49)}\end{array}$ & VAI & $\begin{array}{l}\text { Essai ouvert, } \\
\text { non randomisé, } \\
\text { communautaire } \\
\text { Saisons } \\
1998-1999 \text { et } \\
2000-2001\end{array}$ & $\begin{array}{l}\text { Nombre } \\
\text { cumulatif } \\
\text { d'enfants } \\
\text { vaccinés dans } \\
\text { la collectivité } \\
\mathrm{N}=9765 \\
\\
\text { Nombre } \\
\text { cumulatif } \\
\text { d'enfants } \\
\text { vaccinés } \\
\text { couverts par } \\
\text { le Scott White } \\
\text { Health Plan } \\
\mathrm{N}=4774 \\
\\
\text { Enfants de } 18 \\
\text { mois à } 18 \text { ans } \\
\text { admissibles } \\
\text { au vaccin }\end{array}$ & $\begin{array}{l}\text { Paramètre : MRAIM } \\
\text { WAI administré à } 20 \text { à } 25 \% \text { des } \\
\text { enfants admissibles chaque année } \\
\text { Comparaison des taux de MRAIM chez } \\
\text { l'ensemble des personnes couvertes } \\
\text { par le Scott and White Health Plan : le } \\
\text { risque de MRAIM a été réduit pendant } \\
\text { les trois années de vaccination chez les } \\
\text { adultes de } \geq 35 \text { ans par rapport aux } \\
\text { collectivités témoins } \\
\text { RR pour les MRAIM chez les adultes } \\
\text { de } \geq 35 \text { ans : de } 0,08 \text { à } 0,18 \\
\text { Nombre estimé de consultations } \\
\text { médicales évitées chez les adultes de } \\
\geq 35 \text { ans : de } 303 \text { à } 781\end{array}$ & Niveau II-3 & $\begin{array}{l}\text { Assez } \\
\text { bonne }\end{array}$ \\
\hline
\end{tabular}


TABLEAU 5C : Sommaire des données concernant les enfants de 24 à 59 mois - Évidences liées à l'innocuité des vaccinse

\begin{tabular}{|c|c|c|c|c|c|c|}
\hline \multicolumn{7}{|c|}{ DONNÉES CONCERNANT L'EFFICACITÉ RÉELLE ET POTENTIELLE DU VTI } \\
\hline Étude & Vaccin & Plan d'étude & Participants & $\begin{array}{l}\text { Résumé des principaux résultats } \\
\text { (texte ou données) }\end{array}$ & $\begin{array}{l}\text { Degré de } \\
\text { preuve }\end{array}$ & Qualité \\
\hline $\begin{array}{l}\text { Baxter R, } \\
\text { Jeanfreau R, } \\
\text { Block SL, et } \\
\text { coll. A Phase III } \\
\text { evaluation of } \\
\text { immunogenicity } \\
\text { and safety of } \\
\text { two trivalent } \\
\text { inactivated } \\
\text { seasonal } \\
\text { influenza } \\
\text { vaccines in US } \\
\text { children. } \\
\text { Pediatr Infect } \\
\text { Dis J 2010 } \\
\text { Oct;29(10): } \\
\text { 924-930.(57) } \\
\text { (NCT00383123) }\end{array}$ & 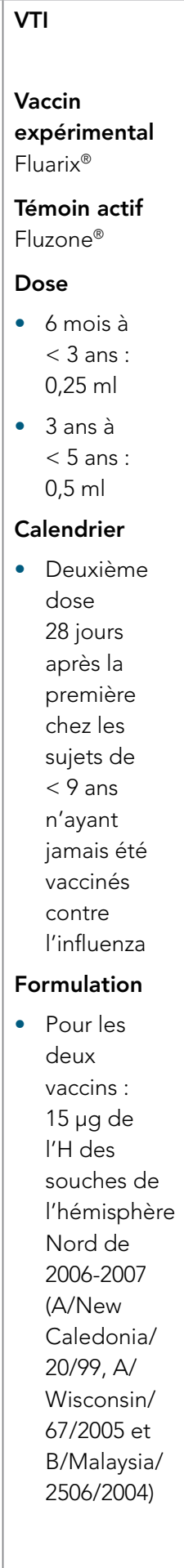 & $\begin{array}{l}\text { Essai randomisé } \\
\text { de phase III, à } \\
\text { simple insu, } \\
\text { multicentrique } \\
\text { Saison grippale } \\
2006-2007 \\
\text { É.-U. (42 sites) }\end{array}$ & $\begin{array}{l}\text { Enfants de } \\
6 \text { mois à } 18 \text { ans } \\
\text { (sauf les cas de } \\
\text { maladie aiguë) } \\
\mathrm{n}=3325 \\
(2115 \text { ayant } \\
\text { reçu le vaccin } \\
\text { expérimental } \\
\text { et } 1210, \text { le } \\
\text { témoin actif) } \\
\\
\text { Sous-ensemble } \\
\text { de sujets } \\
\text { vaccinés de } \\
6 \text { mois à } 5 \text { ans } \\
\\
\mathrm{n}=2 \text { 992 } \\
\text { Groupe } \\
\text { expérimental } \\
: 375 \text { sujets } \\
\text { (18\%) de } 6 \text { à } \\
36 \text { mois et } 373 \\
\text { (12\%) de } 3 \text { à } \\
5 \text { ans; groupe } \\
\text { témoin : } \\
379 \text { sujets } \\
(31 \%) \text { de } 6 \text { à } \\
36 \text { mois et } 369 \\
(30 \%) \text { de } 3 \text { à } \\
5 \text { ans }\end{array}$ & 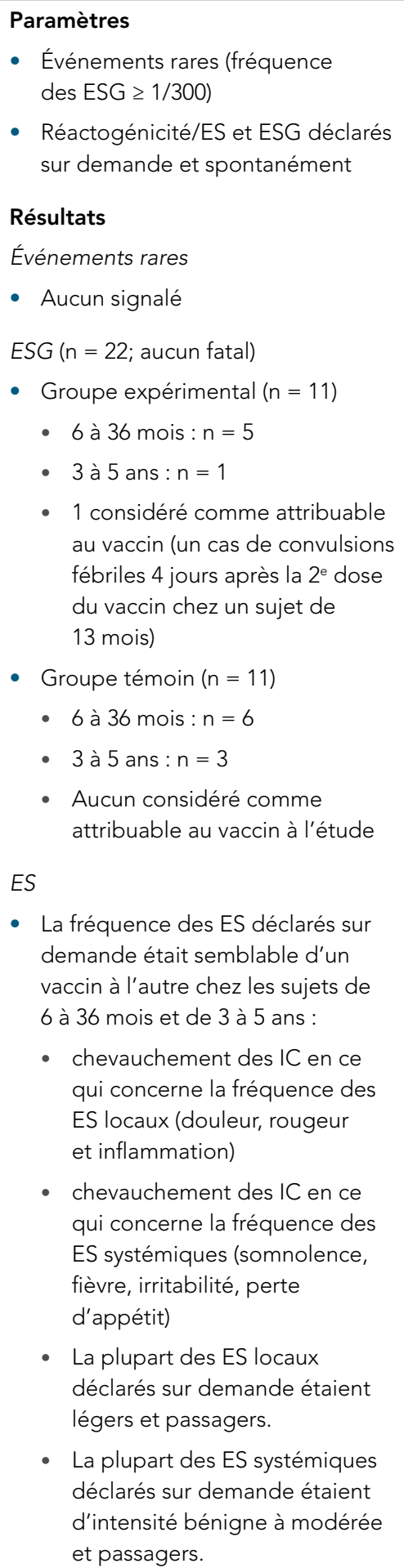 & Niveau I & Bonne \\
\hline
\end{tabular}




\begin{tabular}{|c|c|c|c|c|c|c|}
\hline \multicolumn{7}{|c|}{ DONNÉES CONCERNANT L'EFFICACITÉ RÉELLE ET POTENTIELLE DU VTI } \\
\hline \multirow[t]{2}{*}{ Étude } & Vaccin & Plan d'étude & Participants & $\begin{array}{l}\text { Résumé des principaux résultats } \\
\text { (texte ou données) }\end{array}$ & $\begin{array}{l}\text { Degré de } \\
\text { preuve }\end{array}$ & Qualité \\
\hline & & & & $\begin{array}{l}\text { - La fréquence des ES } \\
\text { systémiques déclarés sur } \\
\text { demande était généralement } \\
\text { plus faible après la } 2^{e} \text { dose (dans } \\
\text { les deux groupes à l'étude). } \\
\text { - Aucune différence cliniquement } \\
\text { pertinente sur le plan des ES } \\
\text { déclarés sur demande entre les } \\
\text { deux groupes à l'étude }\end{array}$ & & \\
\hline $\begin{array}{l}\text { Glanz JM, } \\
\text { Newcomer SR, } \\
\text { Hambidge SJ, } \\
\text { et coll. Safety } \\
\text { of trivalent } \\
\text { inactivated } \\
\text { influenza } \\
\text { vaccine in } \\
\text { children aged } \\
24 \text { to } 59 \text { months } \\
\text { in the vaccine } \\
\text { safety datalink. } \\
\text { Arch Pediatr } \\
\text { Adolesc Med } \\
\text { 2011 } \\
\text { Aug;165(8): } \\
749-755 .(59)\end{array}$ & VTI & 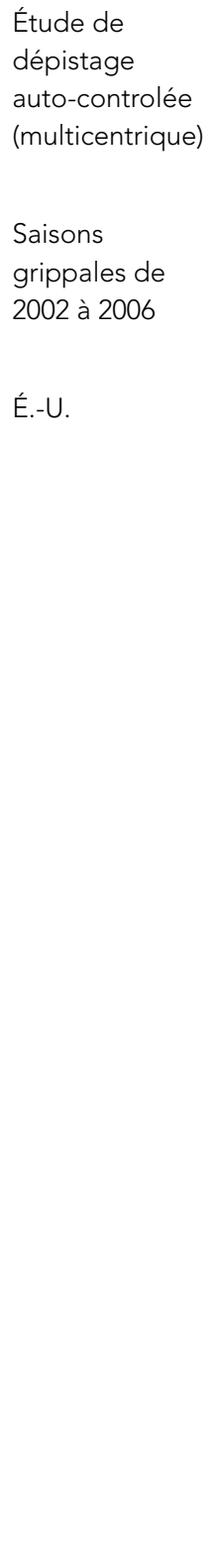 & $\begin{array}{l}\text { Enfants de } 24 \text { à } \\
59 \text { mois ayant } \\
\text { reçu } \geq 1 \text { dose } \\
\text { du VTI pendant } \\
\text { la période à } \\
\text { l'étude } \\
n=66283 \\
\text { (enfants) } \\
\text { (sujets atteints } \\
\text { d'une affection } \\
\text { à risque élevé : } \\
n=2584 \\
\text { [3,9\%]) } \\
n=91692 \\
\text { (doses) }\end{array}$ & 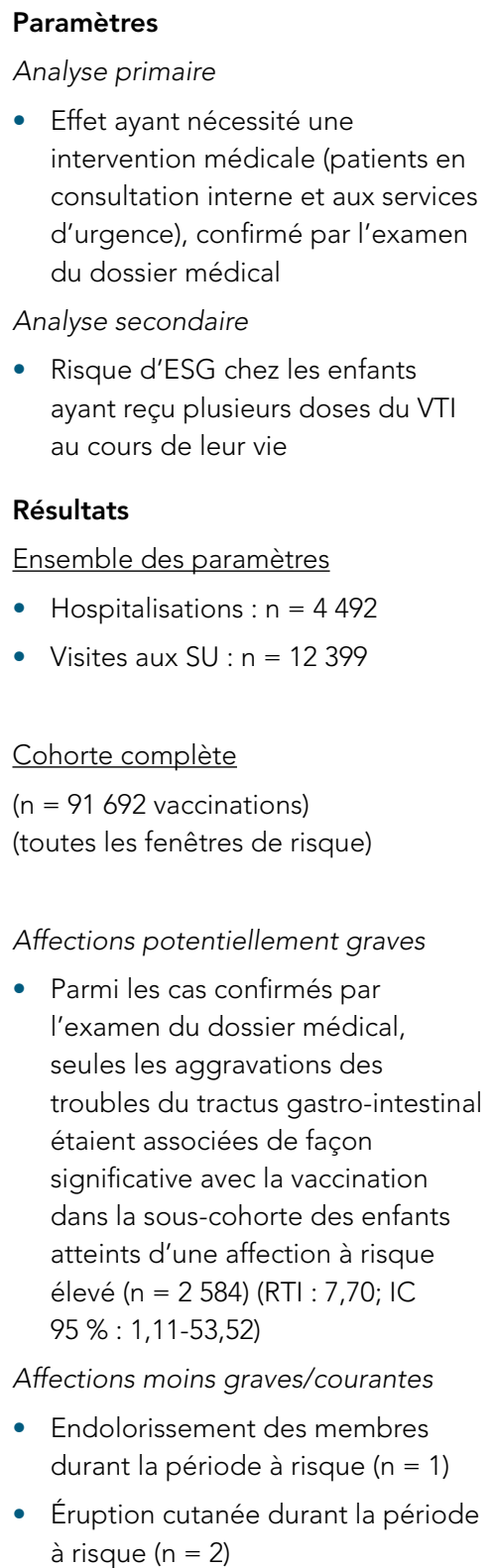 & Niveau II-2 & $\begin{array}{l}\text { Assez } \\
\text { bonne }\end{array}$ \\
\hline
\end{tabular}




\begin{tabular}{|c|c|c|c|c|c|c|}
\hline \multicolumn{7}{|c|}{ DONNÉES CONCERNANT L'EFFICACITÉ RÉELLE ET POTENTIELLE DU VTI } \\
\hline Étude & Vaccin & Plan d'étude & Participants & $\begin{array}{l}\text { Résumé des principaux résultats } \\
\text { (texte ou données) }\end{array}$ & $\begin{array}{l}\text { Degré de } \\
\text { preuve }\end{array}$ & Qualité \\
\hline & & & & 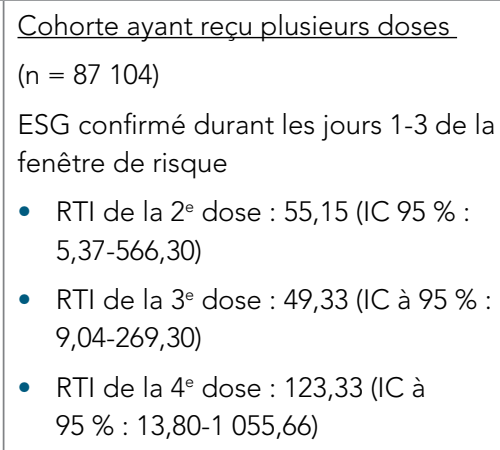 & & \\
\hline $\begin{array}{l}\text { Jansen AG, } \\
\text { Sanders EA, } \\
\text { Smulders S, et } \\
\text { coll. Adverse } \\
\text { reactions to } \\
\text { simultaneous } \\
\text { influenza and } \\
\text { pneumococcal } \\
\text { conjugate } \\
\text { vaccinations in } \\
\text { children: } \\
\text { randomized } \\
\text { double-blind } \\
\text { controlled trial. } \\
\text { Pediatr Allergy } \\
\text { Immunol 2008 } \\
\text { Sep;19(6):552- } \\
\text { 558.(58) }\end{array}$ & $\begin{array}{l}\text { VTI } \\
\text { Groupe } \\
\text { expérimental } \\
\text { VTI + vaccin } \\
\text { antipneumo- } \\
\text { coccique } \\
\text { heptavalent } \\
\text { (PCV7) } \\
\text { Groupe } \\
\text { témoin } 1 \\
\text { VTI + placebo } \\
\text { Groupe } \\
\text { témoin } 2 \\
\text { VHB + placebo } \\
\text { Calendrier } \\
2 \text { ensembles } \\
\text { de vaccins à } \\
\text { 4-8 semaines } \\
\text { d'intervalle }\end{array}$ & 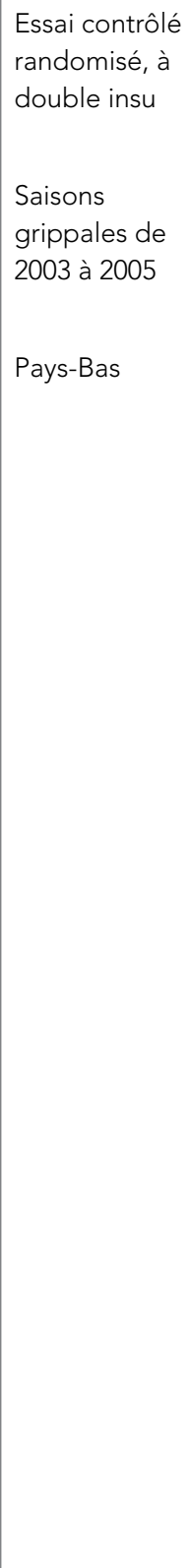 & $\begin{array}{l}\text { Enfants de } 18 \text { à } \\
72 \text { mois atteints } \\
\text { d'une infection }^{\prime} \text { des voies } \\
\text { respiratoires } \\
n=567 \\
n_{\mathrm{VTI}+\mathrm{PCV} 7}=194 \\
n_{\mathrm{VHB}+\text { placebo }}=190 \\
n_{\mathrm{VTI}+\text { placebo }}=183\end{array}$ & 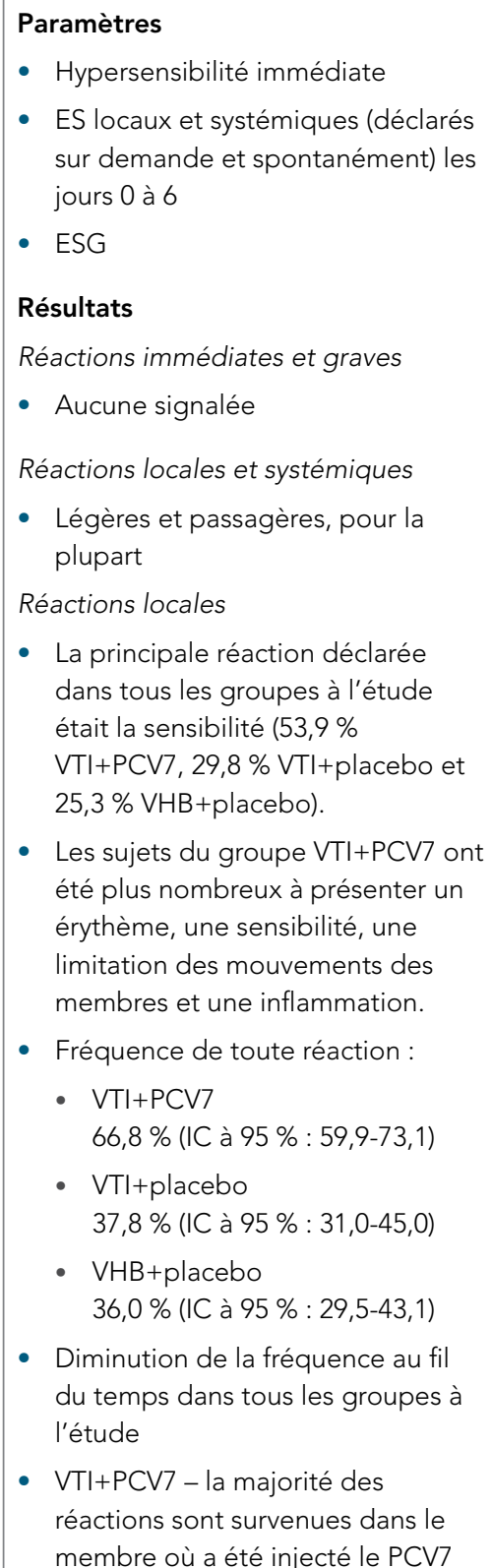 & Niveau I & Bonne \\
\hline
\end{tabular}




\begin{tabular}{|c|c|c|c|c|c|c|}
\hline \multicolumn{7}{|c|}{ DONNÉES CONCERNANT L'EFFICACITÉ RÉELLE ET POTENTIELLE DU VTI } \\
\hline Étude & Vaccin & Plan d'étude & Participants & $\begin{array}{l}\text { Résumé des principaux résultats } \\
\text { (texte ou données) }\end{array}$ & $\begin{array}{l}\text { Degré de } \\
\text { preuve }\end{array}$ & Qualité \\
\hline & & & & 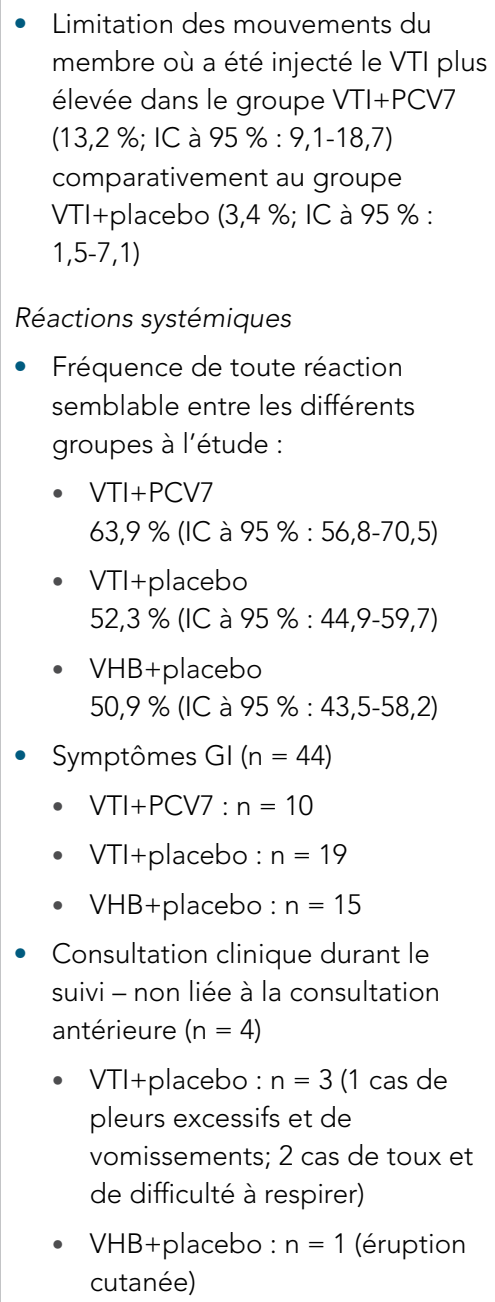 & & \\
\hline
\end{tabular}




\begin{tabular}{|c|c|c|c|c|c|c|}
\hline \multicolumn{5}{|c|}{ DONNÉES CONCERNANT L'EFFICACITÉ RÉELLE ET POTENTIELLE DU VTI } & \multirow[b]{2}{*}{$\begin{array}{l}\text { Degré de } \\
\text { preuve }\end{array}$} & \multirow[b]{2}{*}{ Qualité } \\
\hline Étude & Vaccin & Plan d'étude & Participants & $\begin{array}{l}\text { Résumé des principaux résultats } \\
\text { (texte ou données) }\end{array}$ & & \\
\hline $\begin{array}{l}\text { Ashkenazi S, } \\
\text { Vertruyen A, } \\
\text { Aristegui J, } \\
\text { et coll. Superior } \\
\text { relative } \\
\text { efficacy of live } \\
\text { attenuated } \\
\text { influenza } \\
\text { vaccine } \\
\text { compared } \\
\text { with inactivated } \\
\text { influenza } \\
\text { vaccine in } \\
\text { young children } \\
\text { with recurrent } \\
\text { respiratory } \\
\text { tract infections. } \\
\text { Pediatr Infect } \\
\text { Dis J. 2006; } \\
25(10): 870-9 .{ }^{(37)}\end{array}$ & $\begin{array}{l}\text { VTI/VVAI } \\
\text { Vaccin à } \\
\text { I'étude } \\
\text { VVAI } \\
\text { Dose - 0,1 ml } \\
\text { par narine } \\
\text { Vaccin de } \\
\text { comparaison } \\
\text { VTI - types A } \\
\text { et B, à virion } \\
\text { fragmenté } \\
\text { Dose } \\
6 \text { à } 36 \text { mois : } \\
0,25 \text { ml par } \\
\text { dose } \\
36 \text { à } 72 \text { mois : } \\
0,5 \text { ml par dose } \\
\text { Calendrier de } \\
\text { vaccination } \\
2 \text { doses à } 35 \pm \\
7 \text { jours } \\
\text { d'intervalle }\end{array}$ & $\begin{array}{l}\text { ECR de } \\
\text { phase III, } \\
\text { ouvert, avec } \\
\text { comparateur } \\
\text { actif, } \\
\text { multicentrique } \\
\text { Saison grippale } \\
2002-2003 \\
\text { Sites en Europe } \\
\text { et en Israël }\end{array}$ & $\begin{array}{l}\mathrm{n}=2187 \\
\mathrm{n}_{\mathrm{VTI}}=1086 \\
\mathrm{n}_{\mathrm{VAI}}=1101 \\
\text { Enfants de } 6 \text { à } \\
71 \text { mois ayant } \\
\text { des antécé- } \\
\text { dents } \\
\text { d'infection } \\
\text { récurrente des } \\
\text { voies respira- } \\
\text { toires ( } \geq 2 \text { IVR } \\
\text { au cours des } \\
12 \text { derniers } \\
\text { mois ou depuis } \\
\text { la naissance si } \\
<12 \text { mois) } \\
\\
23 \% \text { avaient } \\
\text { déjà reçu un } \\
\text { diagnostic } \\
\text { d'asthme }\end{array}$ & 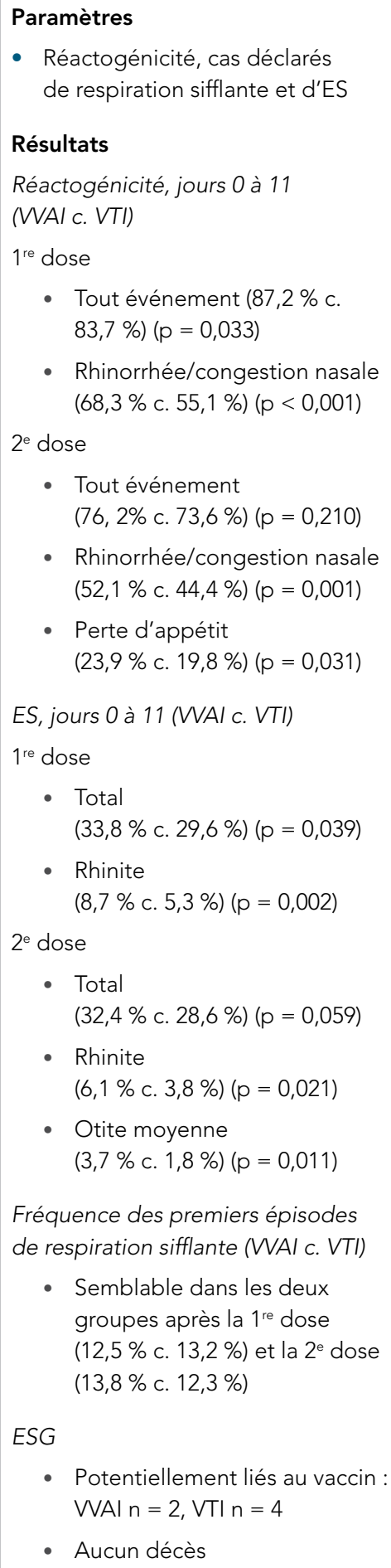 & Niveau I & Bonne \\
\hline
\end{tabular}




\begin{tabular}{|c|c|c|c|c|c|c|}
\hline \multicolumn{5}{|c|}{ DONNÉES CONCERNANT L'EFFICACITÉ RÉELLE ET POTENTIELLE DU VTI } & \multirow[b]{2}{*}{$\begin{array}{l}\text { Degré de } \\
\text { preuve }\end{array}$} & \multirow[b]{2}{*}{ Qualité } \\
\hline Étude & Vaccin & Plan d'étude & Participants & $\begin{array}{l}\text { Résumé des principaux résultats } \\
\text { (texte ou données) }\end{array}$ & & \\
\hline $\begin{array}{l}\text { Belshe RB, } \\
\text { Edwards KM, } \\
\text { Vesikari T, } \\
\text { et coll. Live } \\
\text { attenuated } \\
\text { versus } \\
\text { inactivated } \\
\text { influenza } \\
\text { vaccine in } \\
\text { infants and } \\
\text { young children. } \\
\text { N Engl J Med } \\
2007 \text { Feb } \\
\text { 15;356(7): } \\
685-696 .(39) \\
\text { (NCT00128167) }\end{array}$ & $\begin{array}{l}\text { VTI/VVAI } \\
\text { VVAI } \\
\text { FluMist }{ }^{\circledR} \\
\text { VTI } \\
\text { Fluzone }{ }^{\circledR} \\
\text { (É.-U. et Asie) } \\
\text { et Vaxigrip }{ }^{\circledR} \\
\text { (Europe et } \\
\text { Moyen-Orient) } \\
\text { Dose } \\
\text { - } 0,25 \text { ml } \\
\text { (6 à } 35 \text { mois) } \\
\text { - } 0,5 \text { ml (36 à } \\
59 \text { mois) } \\
\text { Calendrier } \\
\text { - 2 doses } \\
\text { (jours } 0 \text { et } \\
28-42 \text { ) chez les } \\
\text { sujets n'ayant } \\
\text { jamais reçu le } \\
\text { vaccin }\end{array}$ & $\begin{array}{l}\text { Essai randomisé } \\
\text { multicentrique } \\
\text { Saison grippale } \\
2004-2005 \\
\text { É.-U., Europe, } \\
\text { Moyen-Orient } \\
\text { et Asie }\end{array}$ & $\begin{array}{l}\text { Enfants de } 6 \\
\text { à } 59 \text { mois } \\
N_{\text {total }}=8352 \\
\text { (24 à } 59 \text { mois, } \\
n=4384) \\
n_{\text {vAl }}=4179 \\
(24 \text { à } 59 \text { mois, } \\
n=2187) \\
n_{V T 1}=4173 \\
(24 \text { à } 59 \text { mois, } \\
n=2197)\end{array}$ & 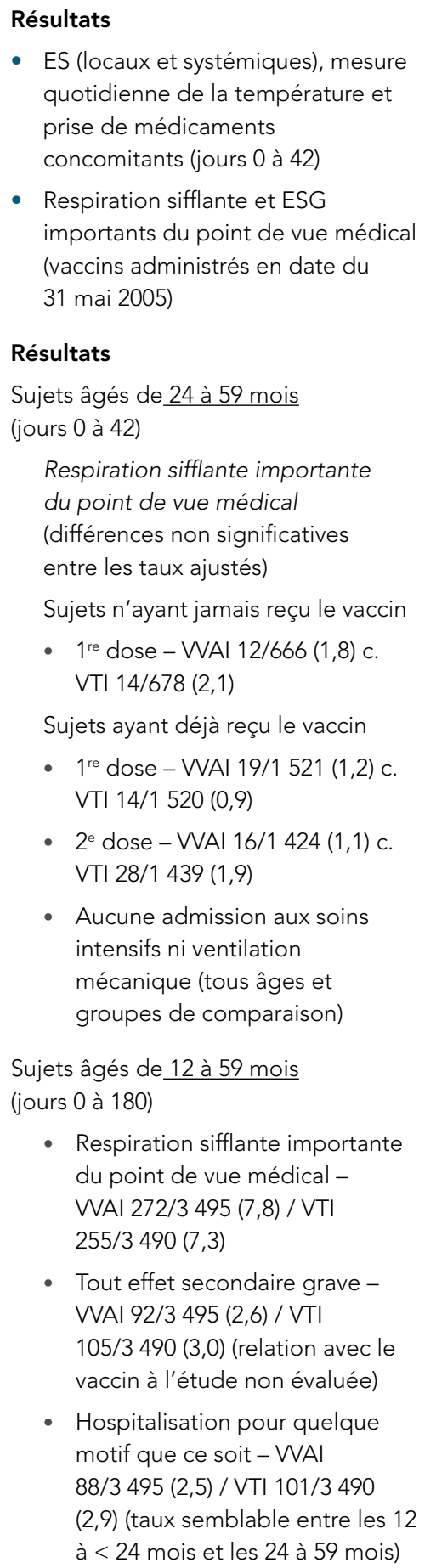 & Niveau I & Bonne \\
\hline
\end{tabular}




\begin{tabular}{|c|c|c|c|c|c|c|}
\hline \multicolumn{5}{|c|}{ DONNÉES CONCERNANT L'EFFICACITÉ RÉELLE ET POTENTIELLE DU VTI } & \multirow[b]{2}{*}{$\begin{array}{l}\text { Degré de } \\
\text { preuve }\end{array}$} & \multirow[b]{2}{*}{ Qualité } \\
\hline Étude & Vaccin & Plan d'étude & Participants & $\begin{array}{l}\text { Résumé des principaux résultats } \\
\text { (texte ou données) }\end{array}$ & & \\
\hline & & & & 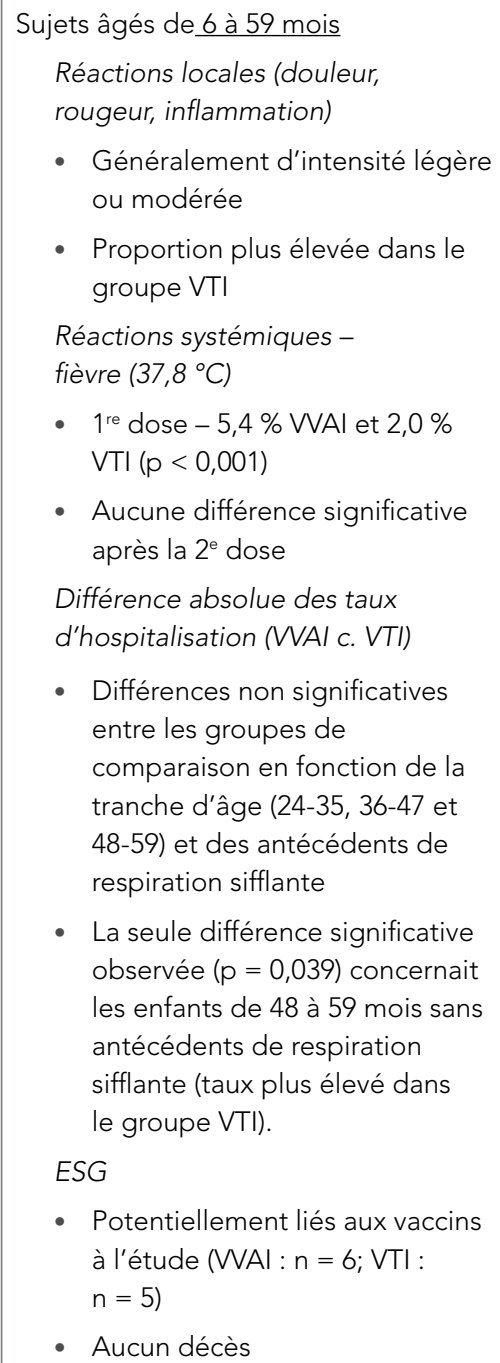 & & \\
\hline
\end{tabular}




\begin{tabular}{|c|c|c|c|c|c|c|}
\hline \multicolumn{5}{|c|}{ DONNÉES CONCERNANT L'EFFICACITÉ RÉELLE ET POTENTIELLE DU VTI } & \multirow[b]{2}{*}{$\begin{array}{l}\text { Degré de } \\
\text { preuve }\end{array}$} & \multirow[b]{2}{*}{ Qualité } \\
\hline Étude & Vaccin & Plan d'étude & Participants & $\begin{array}{l}\text { Résumé des principaux résultats } \\
\text { (texte ou données) }\end{array}$ & & \\
\hline $\begin{array}{l}\text { Neuzil KM, } \\
\text { Dupont WD, } \\
\text { Wright PF, et } \\
\text { coll. Efficacy of } \\
\text { inactivated and } \\
\text { cold-adapted } \\
\text { vaccines } \\
\text { against } \\
\text { influenza A } \\
\text { infection, } 1985 \\
\text { to 1990: the } \\
\text { pediatric } \\
\text { experience. } \\
\text { Pediatr Infect } \\
\text { Dis J 2001 } \\
\text { Aug;20(8): } \\
\text { 733-740.(54) }\end{array}$ & $\begin{array}{l}\text { VTI/VVAI } \\
\text { 1re année } \\
\text { (pilote) } \\
\text { VVAI (H1N1 et } \\
\text { H3N2) et vaccin } \\
\text { inactivé contre } \\
\text { I'influenza B } \\
\text { Vaccin inactivé } \\
\text { bivalent (H1N1, } \\
\text { H3N2) } \\
\text { 2e à 5e années } \\
\text { VVAI (H1N1 et } \\
\text { H3N2) et vaccin } \\
\text { inactivé contre } \\
\text { I'influenza B } \\
\text { VTI (H1N1, } \\
\text { H3N2, B) } \\
\text { Témoin (vaccin } \\
\text { inactivé contre } \\
\text { I'influenza B) } \\
\text { Dose - < 3 ans } \\
\text { - Vaccin } \\
\text { inactivé : } \\
\text { 0,25 ml } \\
\text { - 0,5 ml d'une } \\
\text { dilution 1:10 } \\
\text { de chacune } \\
\text { des deux } \\
\text { préparations } \\
\text { vaccinales } \\
\text { adaptées au } \\
\text { froid sous } \\
\text { forme de } \\
\text { dose unique }\end{array}$ & $\begin{array}{l}\text { Essai contrôlé } \\
\text { randomisé, à } \\
\text { double insu } \\
\text { Saisons } \\
\text { grippales de } \\
1985 \text { à } 1990 \\
\text { É.-U. (Nashville, } \\
\text { Tennessee) }\end{array}$ & $\begin{array}{l}\text { Enfants de } 1 \text { à } \\
16 \text { ans } \\
N_{\text {doses }}=1809 \\
(791 \text { enfants) } \\
1<6 \text { ans } \\
\text { (doses) } \\
N_{\text {témoin }}=130 \\
N_{\text {WAlinactivéB }}=144 \\
N_{\text {VTI }}=200\end{array}$ & 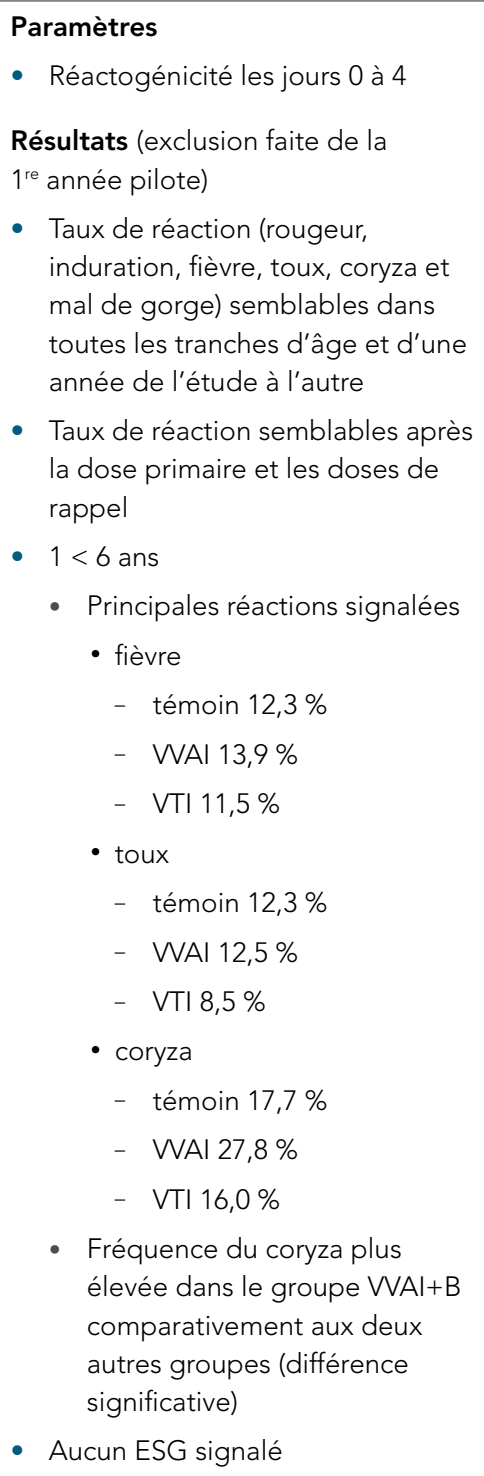 & Niveau I & Bonne \\
\hline
\end{tabular}




\begin{tabular}{|c|c|c|c|c|c|c|}
\hline \multicolumn{5}{|c|}{ DONNÉES CONCERNANT L'EFFICACITÉ RÉELLE ET POTENTIELLE DU VTI } & \multirow[b]{2}{*}{$\begin{array}{l}\text { Degré de } \\
\text { preuve }\end{array}$} & \multirow[b]{2}{*}{ Qualité } \\
\hline Étude & Vaccin & Plan d'étude & Participants & $\begin{array}{l}\text { Résumé des principaux résultats } \\
\text { (texte ou données) }\end{array}$ & & \\
\hline $\begin{array}{l}\text { Bergen R, Black } \\
\text { S, Shinefield H, } \\
\text { et coll. Safety of } \\
\text { cold-adapted } \\
\text { live attenuated } \\
\text { influenza } \\
\text { vaccine in a } \\
\text { large cohort } \\
\text { of children and } \\
\text { adolescents. } \\
\text { Pediatr Infect } \\
\text { Dis J 2004 } \\
\text { Feb;23(2): } \\
\text { 138-144.(62) }\end{array}$ & $\begin{array}{l}\text { VVAl } \\
\text { Dose } \\
0,25 \mathrm{ml} \text { par } \\
\text { narine } \\
\text { Formulation } \\
10^{7} \text { DICT } \\
50 \text { par } \\
\text { souche } \\
\text { Calendrier } \\
2 \text { doses } \\
\text { administrées } \\
\text { à des sujets } \\
\text { de }<9 \text { ans } \\
\text { (à } 28 \text { à } 42 \text { jours } \\
\text { d'intervalle) }\end{array}$ & $\begin{array}{l}\text { Essai rando- } \\
\text { misé, à double } \\
\text { insu, contrôlé } \\
\text { par placebo } \\
\text { Saison grippale } \\
\text { 1999-2000 } \\
\text { É.-U. }\end{array}$ & 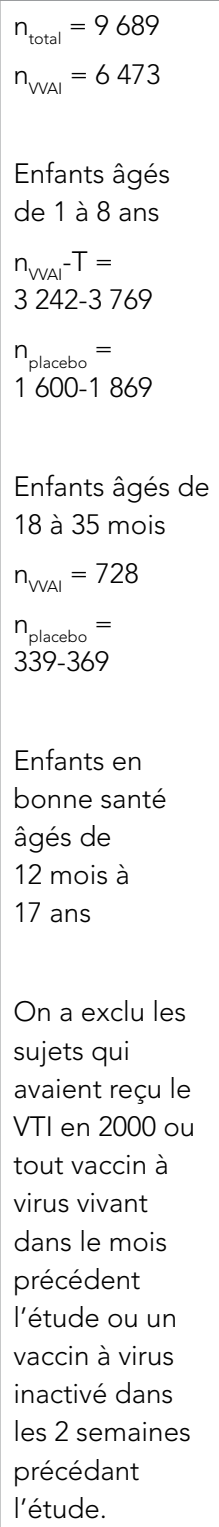 & 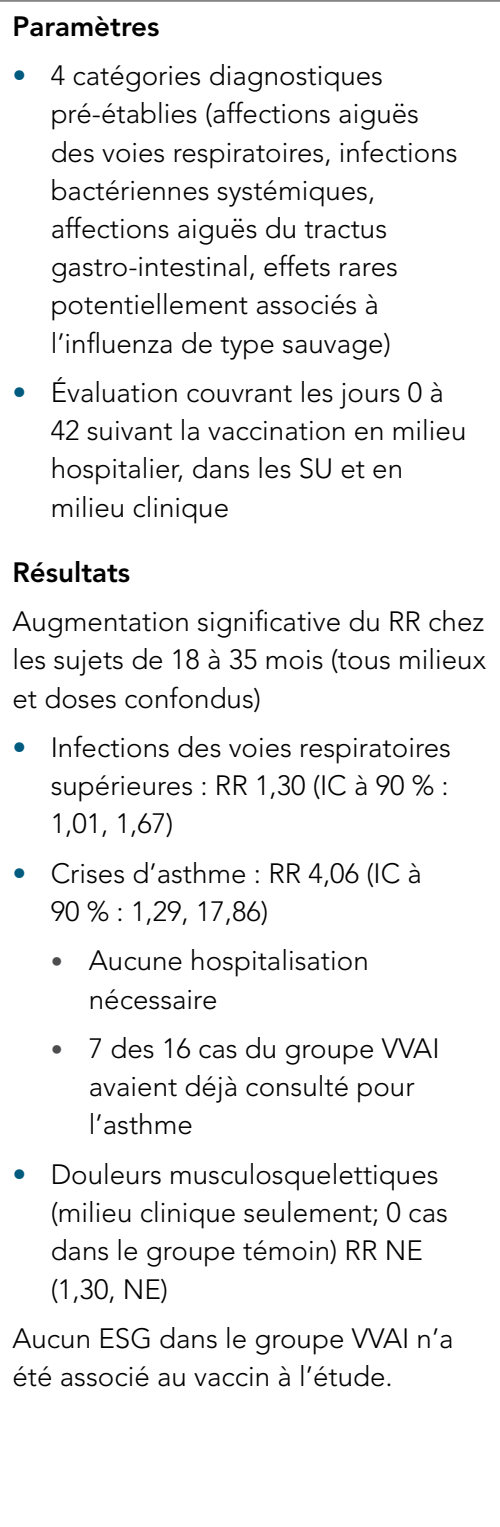 & Niveau I & Bonne \\
\hline
\end{tabular}




\begin{tabular}{|c|c|c|c|c|c|c|}
\hline \multicolumn{5}{|c|}{ DONNÉES CONCERNANT L'EFFICACITÉ RÉELLE ET POTENTIELLE DU VTI } & \multirow[b]{2}{*}{$\begin{array}{l}\text { Degré de } \\
\text { preuve }\end{array}$} & \multirow[b]{2}{*}{ Qualité } \\
\hline Étude & Vaccin & Plan d'étude & Participants & $\begin{array}{l}\text { Résumé des principaux résultats } \\
\text { (texte ou données) }\end{array}$ & & \\
\hline $\begin{array}{l}\text { Bracco Neto H, } \\
\text { Farhat CK, } \\
\text { Tregnaghi MW, } \\
\text { et coll. Efficacy } \\
\text { and safety of } 1 \\
\text { and } 2 \text { doses of } \\
\text { live attenuated } \\
\text { influenza } \\
\text { vaccine in } \\
\text { vaccine-naive } \\
\text { children. } \\
\text { Pediatr Infect } \\
\text { Dis J 2009 } \\
\text { May;28(5):365- } \\
\text { 371.(44) } \\
\text { (NCT00192283) }\end{array}$ & $\begin{array}{l}\text { VVAI } \\
\text { Dose } \\
0,1 \mathrm{ml} \text { par } \\
\text { narine } \\
\text { Formulation } \\
10^{7 \pm 0.5} \text { UFF par } \\
\text { souche } \\
\text { Calendrier } \\
\text { Deux doses la } \\
1^{\text {re }} \text { année, une } \\
\text { dose la } \\
2^{\text {e }} \text { année } \\
\\
\text { Bonne } \\
\text { concordance } \\
\text { entre le vaccin } \\
\text { et les souches } \\
\text { en circulation }\end{array}$ & $\begin{array}{l}\text { Essai rando- } \\
\text { misé, à double } \\
\text { insu, contrôlé } \\
\text { par placebo, } \\
\text { multicentrique } \\
\text { Saisons } \\
\text { grippales de } \\
2001 \text { à } 2002 \\
\text { Afrique du Sud, } \\
\text { Brésil, } \\
\text { Argentine }\end{array}$ & $\begin{array}{l}1^{\text {re }} \text { année, } \\
1^{\text {re }} \text { dose } \\
n_{\text {WAl }}=2127 \\
n_{\text {placebolexcipient) }}= \\
546 \\
n_{\text {placebolsalin) }}=527 \\
1^{\text {re année, }} \\
2^{\text {e dose }} \\
n_{\text {wAl }}=964 \\
n_{\text {placebolexcipient) }}= \\
484 \\
n_{\text {placebolsalin) }}=527 \\
2^{\text {e dose }} \\
n_{\text {wal }}=1461 \\
n_{\text {placebo }}=741 \\
\end{array}$ & 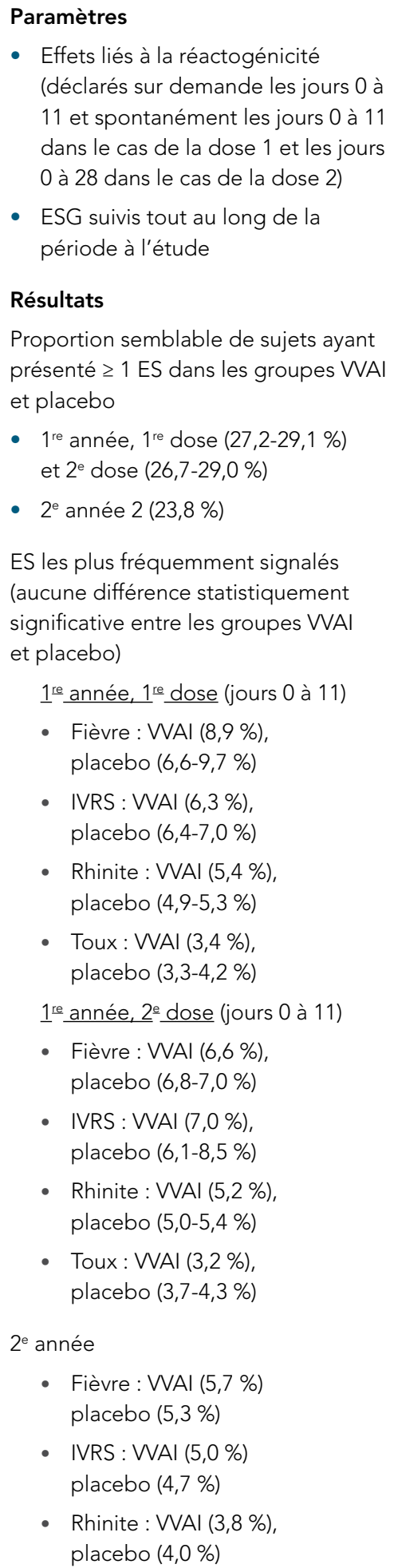 & Niveau I & $\begin{array}{l}\text { Bonne } \\
\text { Une erreur } \\
\text { dans le } \\
\text { codage } \\
\text { de la } \\
\text { répartition } \\
\text { du } \\
\text { traitement } \\
\text { et } \\
\text { l'étique- } \\
\text { tage la } \\
2^{e} \text { année } \\
\text { est à } \\
\text { l'origine de } \\
2 \text { proto- } \\
\text { coles de } \\
\text { traitement } \\
\text { supplé- } \\
\text { mentaires. }\end{array}$ \\
\hline
\end{tabular}




\begin{tabular}{|c|c|c|c|c|c|c|}
\hline \multicolumn{7}{|c|}{ DONNÉES CONCERNANT L'EFFICACITÉ RÉELLE ET POTENTIELLE DU VTI } \\
\hline Étude & Vaccin & Plan d'étude & Participants & $\begin{array}{l}\text { Résumé des principaux résultats } \\
\text { (texte ou données) }\end{array}$ & $\begin{array}{l}\text { Degré de } \\
\text { preuve }\end{array}$ & Qualité \\
\hline & & & & $\begin{array}{l}\text { Toux : WAI (2,8 \%), } \\
\text { placebo (2,4\%) } \\
\text { - La bronchite était le seul ES } \\
\text { significatif }(3,1 \% \text { dans le groupe } \\
\text { WVAl et } 1,6 \% \text { dans le groupe } \\
\text { placebo; } p=0,046) \\
\text { Les ESG notés durant l'année } 1 \text { qui } \\
\text { étaient liés à l'étude ( } n=29) \text { compre- } \\
\text { naient la pneumonie, la bronchopneu- } \\
\text { monie, la bronchiolite et la bronchite. } \\
\text { Aucun décès lié au produit à l'étude }\end{array}$ & & \\
\hline
\end{tabular}




\begin{tabular}{|c|c|c|c|c|c|c|}
\hline \multicolumn{5}{|c|}{ DONNÉES CONCERNANT L'EFFICACITÉ RÉELLE ET POTENTIELLE DU VTI } & \multirow[b]{2}{*}{$\begin{array}{l}\text { Degré de } \\
\text { preuve }\end{array}$} & \multirow[b]{2}{*}{ Qualité } \\
\hline Étude & Vaccin & Plan d'étude & Participants & $\begin{array}{l}\text { Résumé des principaux résultats } \\
\text { (texte ou données) }\end{array}$ & & \\
\hline $\begin{array}{l}\text { Breiman RF, } \\
\text { Brooks WA, } \\
\text { Goswami D, } \\
\text { et coll. A } \\
\text { multinational, } \\
\text { randomized, } \\
\text { placebo-con- } \\
\text { trolled trial to } \\
\text { assess the } \\
\text { immunogen- } \\
\text { icity, safety, } \\
\text { and tolerability } \\
\text { of live } \\
\text { attenuated } \\
\text { influenza } \\
\text { vaccine } \\
\text { coadministered } \\
\text { with oral } \\
\text { poliovirus } \\
\text { vaccine in } \\
\text { healthy young } \\
\text { children. } \\
\text { Vaccine 2009 } \\
\text { Sep 4;27(40): } \\
5472-5479 .(63) \\
\text { (NCT00192491) }\end{array}$ & $\begin{array}{l}\text { VVAl } \\
\text { Dose } \\
0,2 \mathrm{ml}(0,1 \mathrm{ml} \\
\text { par narine) } \\
\text { Formulation } \\
10^{7 \pm 0.5} \text { UFF par } \\
\text { souche } \\
\text { Calendrier } \\
2^{\text {e }} \text { dose du WAI } \\
\text { (ou du placebo) } \\
\text { administrée } 28 \\
\text { à } 42 \text { jours après } \\
\text { la } 1^{\text {re }} \text { dose }\end{array}$ & $\begin{array}{l}\text { Essai contrôlé } \\
\text { randomisé de } \\
\text { non-infériorité, } \\
\text { à insu partiel, } \\
\text { multicentrique } \\
\text { Vaccin } \\
\text { concomitant: } \\
\text { VPO } \\
\text { (différentes } \\
\text { sources), ouvert } \\
\text { Saison grippale } \\
2002 \\
\text { Asie, Amérique } \\
\text { du Sud }\end{array}$ & 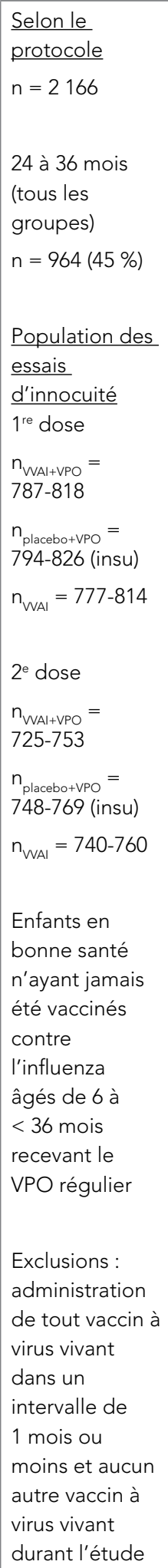 & 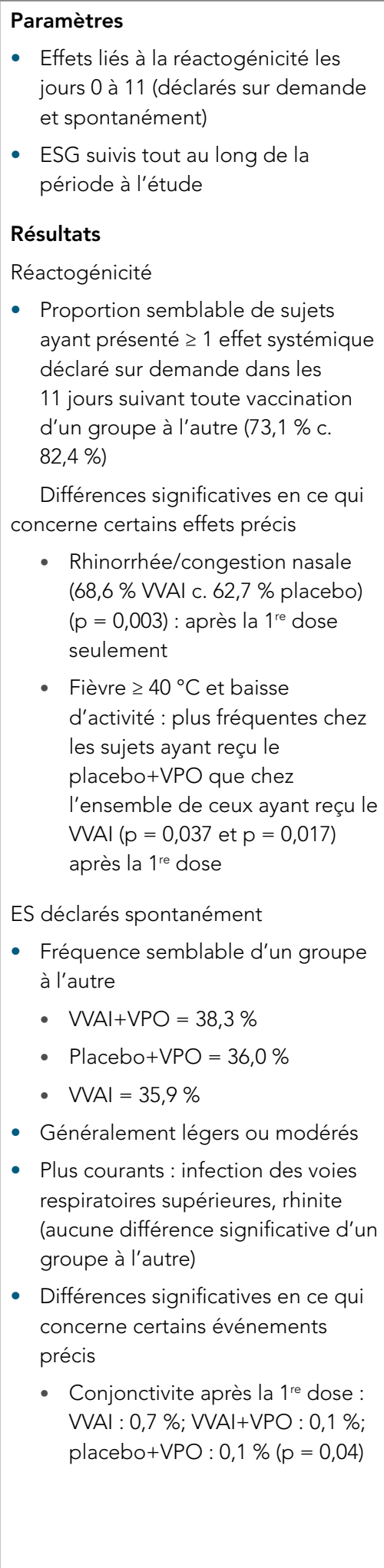 & Niveau I & Bonne \\
\hline
\end{tabular}




\begin{tabular}{|c|c|c|c|c|c|c|}
\hline \multicolumn{7}{|c|}{ DONNÉES CONCERNANT L'EFFICACITÉ RÉELLE ET POTENTIELLE DU VTI } \\
\hline Étude & Vaccin & Plan d'étude & Participants & $\begin{array}{l}\text { Résumé des principaux résultats } \\
\text { (texte ou données) }\end{array}$ & $\begin{array}{l}\text { Degré de } \\
\text { preuve }\end{array}$ & Qualité \\
\hline & & & & 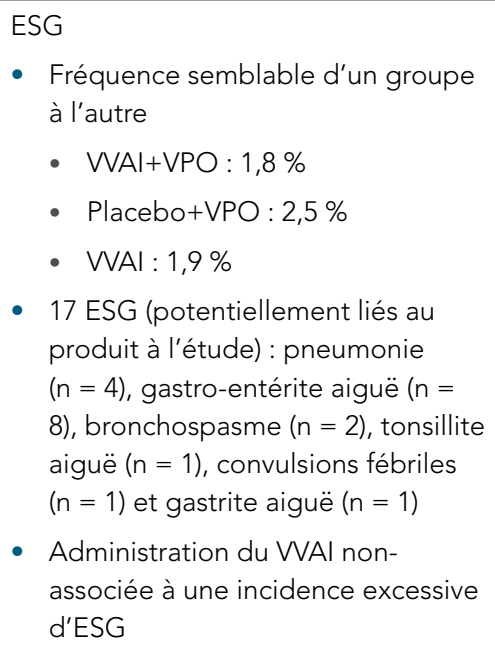 & & \\
\hline
\end{tabular}




\begin{tabular}{|c|c|c|c|c|c|c|}
\hline \multicolumn{5}{|c|}{ DONNÉES CONCERNANT L'EFFICACITÉ RÉELLE ET POTENTIELLE DU VTI } & \multirow[b]{2}{*}{$\begin{array}{l}\text { Degré de } \\
\text { preuve }\end{array}$} & \multirow[b]{2}{*}{ Qualité } \\
\hline Étude & Vaccin & Plan d'étude & Participants & $\begin{array}{l}\text { Résumé des principaux résultats } \\
\text { (texte ou données) }\end{array}$ & & \\
\hline $\begin{array}{l}\text { Piedra PA, Yan } \\
\text { L, Kotloff K, et } \\
\text { coll. Safety of } \\
\text { the trivalent, } \\
\text { cold-adapted } \\
\text { influenza } \\
\text { vaccine in } \\
\text { preschool-aged } \\
\text { children. } \\
\text { Pediatrics } 2002 \\
\text { Oct;110(4): } \\
662-672 .(64)\end{array}$ & 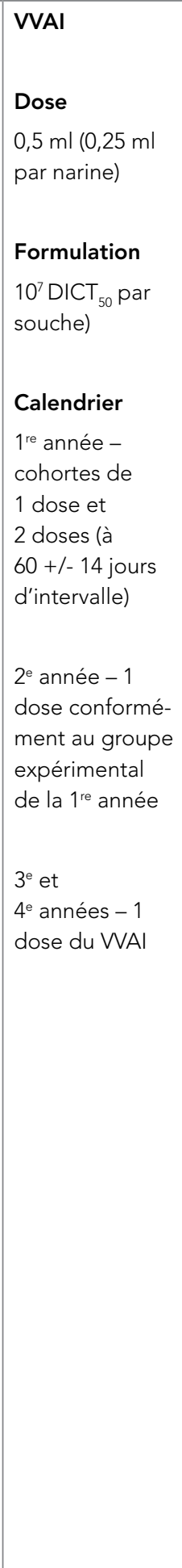 & $\begin{array}{l}\text { ECR, à double } \\
\text { insu, multicen- } \\
\text { trique, contrôlé } \\
\text { par placebo } \\
\text { Quatre saisons } \\
\text { de } 1996 \text { à } 2002 \\
\text { É.-U. }\end{array}$ & $\begin{array}{l}1_{\text {re année }} \\
n_{\text {WAI }}=1070 \\
n_{\text {placebo }}=532 \\
2^{e} \text { année } \\
n_{\text {WAI }}=917 \\
n_{\text {placebo }}=441 \\
3^{e} \text { année } \\
n_{\text {WAI }}=642 \\
4 \text { e année } \\
n_{\text {wAI }}=549 \\
\text { Enfants en } \\
\text { bonne santé de } \\
15 \text { à } 71 \text { mois }\end{array}$ & 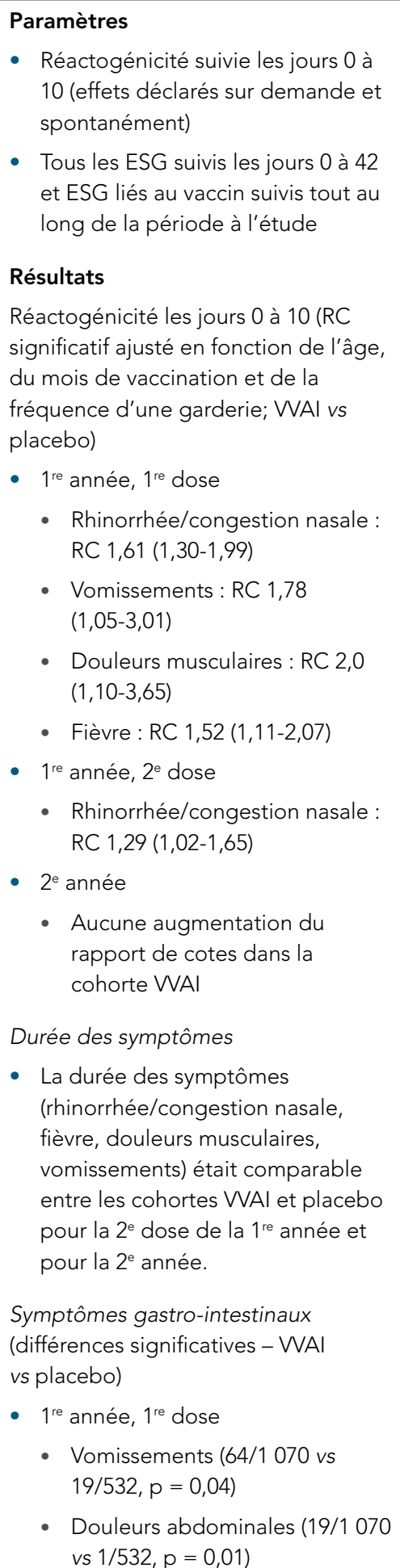 & Niveau I & Bonne \\
\hline
\end{tabular}




\begin{tabular}{|c|c|c|c|c|c|c|}
\hline \multicolumn{7}{|c|}{ DONNÉES CONCERNANT L'EFFICACITÉ RÉELLE ET POTENTIELLE DU VTI } \\
\hline Étude & Vaccin & Plan d'étude & Participants & $\begin{array}{l}\text { Résumé des principaux résultats } \\
\text { (texte ou données) }\end{array}$ & $\begin{array}{l}\text { Degré de } \\
\text { preuve }\end{array}$ & Qualité \\
\hline & & & & $\begin{array}{l}\text { - Douleurs musculaires (55/1070 } \\
\text { vs } 14 / 532, \mathrm{p}=0,02) \\
\text { - } 2^{\mathrm{e}} \text { dose de la } 1^{\text {re }} \text { année et } \\
2^{\mathrm{e}} \text { année }- \text { aucune différence } \\
\text { significative } \\
\text { ESG } \\
\text { - Tous jugés certainement pas ou } \\
\text { probablement pas liés au vaccin } \\
\text { à l'étude } \\
\text { Doses séquentielles annuelles } \\
\text { - Proportions de symptômes des } \\
3^{\mathrm{e}} \text { et } 4{ }^{\mathrm{e}} \text { années semblables à celles } \\
\text { de la } 2^{\mathrm{e}} \text { année et plus faibles que } \\
\text { celles associées à la } 1^{\text {re }} \text { dose de } \\
\text { la } 1^{\text {re }} \text { année }\end{array}$ & & \\
\hline $\begin{array}{l}\text { Piedra PA, } \\
\text { Gaglani MJ, } \\
\text { Riggs M, et coll. } \\
\text { Live attenuated } \\
\text { influenza } \\
\text { vaccine, } \\
\text { trivalent, is safe } \\
\text { in healthy } \\
\text { children } 18 \\
\text { months to } 4 \\
\text { years, } 5 \text { to } 9 \\
\text { years, and } \\
10 \text { to } 18 \text { years } \\
\text { of age in a } \\
\text { community- } \\
\text { based, non- } \\
\text { randomized, } \\
\text { open-label trial. } \\
\text { Pediatrics } 2005 \\
\text { Sep;116(3): } \\
\text { e397-407.(49) }\end{array}$ & $\begin{array}{l}\text { VVAI } \\
\text { Dose } \\
0,25 \mathrm{ml} \text { par } \\
\text { narine } \\
\text { Formulation } \\
10^{7} \mathrm{DICT}_{50} \text { par } \\
\text { souche }\end{array}$ & $\begin{array}{l}\text { Essai non } \\
\text { randomisé, } \\
\text { prospectif, } \\
\text { pluriannuel, } \\
\text { ouvert } \\
\text { Saisons } \\
\text { grippales de } \\
1997 \text { à } 2002 \\
\text { É.-U. }\end{array}$ & $\begin{array}{l}\text { Total } \\
\mathrm{N}= \\
18780 \text { doses } \\
\text { (11 } 096 \text { enfants) } \\
\text { De } 18 \text { mois à } \\
4 \text { ans } \\
\mathrm{N}=4529 \\
\text { doses } \\
\\
\text { Enfants en } \\
\text { bonne santé de } \\
1,5 \text { à } 18 \text { ans } \\
\\
\text { Enfants ayant } \\
\text { des antécé- } \\
\text { dents de } \\
\text { respiration } \\
\text { sifflante } \\
\text { intermittente, } \\
\text { de maladie } \\
\text { respiratoire } \\
\text { aiguë ayant } \\
\text { nécessité une } \\
\text { intervention } \\
\text { médicale, y } \\
\text { compris } \\
\text { d'exacerbation } \\
\text { de l'asthme }\end{array}$ & $\begin{array}{l}\text { Paramètres } \\
\text { - ESG évalués sur une période de } \\
6 \text { semaines (chez tous les sujets } \\
\text { vaccinés) } \\
\text { - Maladie respiratoire aiguë ayant } \\
\text { nécessité une intervention } \\
\text { médicale (MRAIM) et asthme } \\
\text { évalués sur une période de } \\
6 \text { semaines (sous-ensemble de } \\
\text { sujets vaccinés) } \\
\text { Résultats } \\
\text { ESG } \\
\text { - Aucun attribué au WVAI } \\
\text { MRAIM/asthme } \\
\text { 18 mois à } 4 \text { ans - aucune hausse } \\
\text { significative de l'utilisation du } \\
\text { système de santé pour une MRAIM, } \\
\text { des sous-catégories de MRAIM ni } \\
\text { I'asthme pendant les jours } 0 \text { à } 14 \text { et } \\
\text { seulement une hausse significative } \\
\text { (asthme) pendant les jours } 15 \text { à } \\
42 \text { la } 1 \text { re année; RR } 2,85 \text { (IC à } 95 \% \text { : } \\
1,01-8,03 \text { ) } \\
\text { - } 18 \text { mois à } 4 \text { ans - aucune hausse } \\
\text { significative de l'utilisation du } \\
\text { système de santé pour une MRAIM } \\
\text { pendant les jours } 0 \text { à } 14 \text { après } \\
\text { stratification en fonction du nombre } \\
\text { de doses reçues (1 à } 4 \text { ) }\end{array}$ & Niveau II-3 & Bonne \\
\hline
\end{tabular}




\begin{tabular}{|c|c|c|c|c|c|c|}
\hline \multicolumn{5}{|c|}{ DONNÉES CONCERNANT L’EFFICACITÉ RÉELLE ET POTENTIELLE DU VTI } & \multirow[b]{2}{*}{$\begin{array}{l}\text { Degré de } \\
\text { preuve }\end{array}$} & \multirow[b]{2}{*}{ Qualité } \\
\hline Étude & Vaccin & Plan d'étude & Participants & $\begin{array}{l}\text { Résumé des principaux résultats } \\
\text { (texte ou données) }\end{array}$ & & \\
\hline $\begin{array}{l}\text { Tam JS, } \\
\text { Capeding MR, } \\
\text { Lum LC, et coll. } \\
\text { Efficacy and } \\
\text { safety of a live } \\
\text { attenuated, } \\
\text { cold-adapted } \\
\text { influenza } \\
\text { vaccine, } \\
\text { trivalent } \\
\text { against culture- } \\
\text { confirmed } \\
\text { influenza in } \\
\text { young children } \\
\text { in Asia. Pediatr } \\
\text { Infect Dis J } \\
2007 \text { Jul;26(7): } \\
619-628 .{ }^{(41)} \\
\text { (NCT00192244) }\end{array}$ & 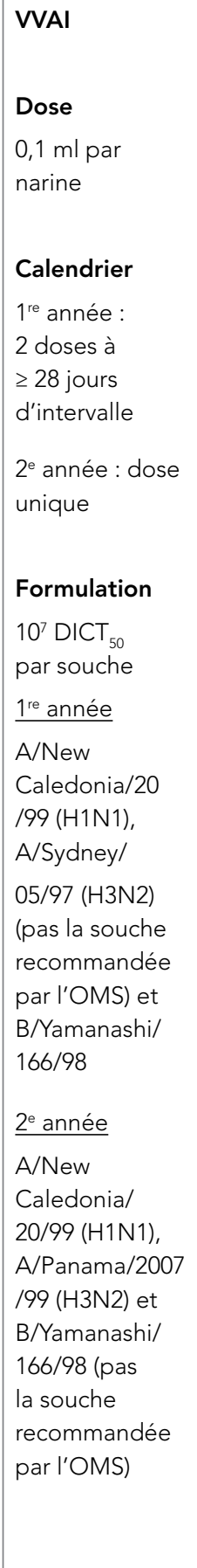 & $\begin{array}{l}\text { ERC, à double } \\
\text { insu, contrôlé } \\
\text { par placebo, } \\
\text { multicentrique } \\
\text { Saisons } \\
2000-2001 \text { et } \\
2001-2002 \\
\text { Asie }\end{array}$ & 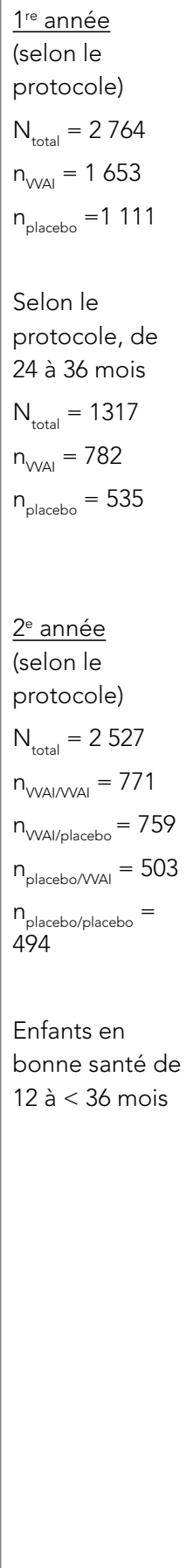 & 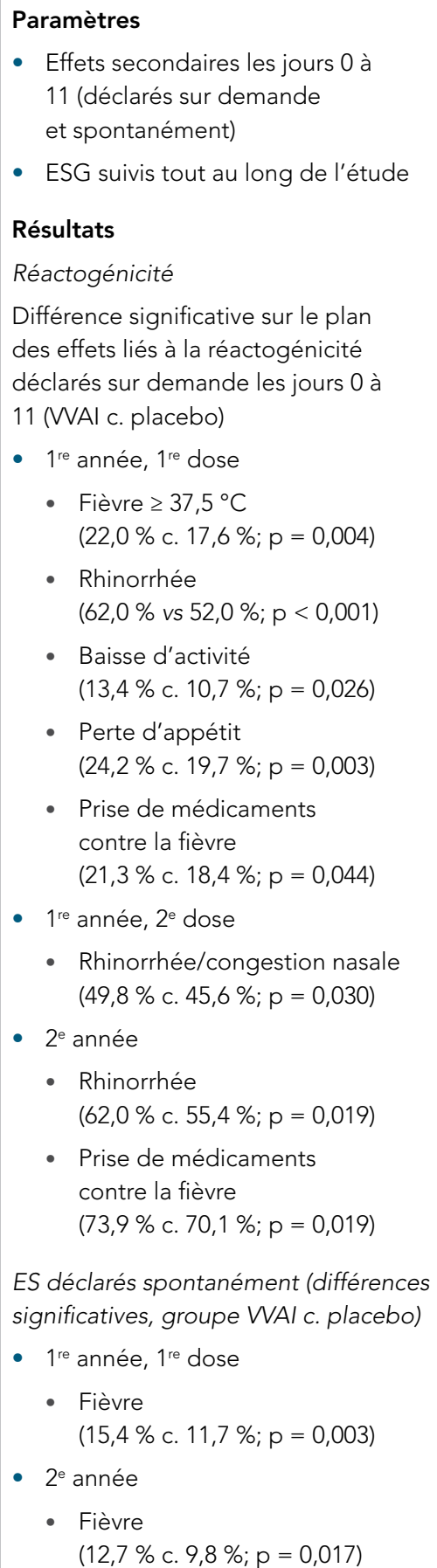 & Niveau I & Bonne \\
\hline
\end{tabular}




\begin{tabular}{|c|c|c|c|c|c|c|}
\hline \multicolumn{7}{|c|}{ DONNÉES CONCERNANT L'EFFICACITÉ RÉELLE ET POTENTIELLE DU VTI } \\
\hline Étude & Vaccin & Plan d'étude & Participants & $\begin{array}{l}\text { Résumé des principaux résultats } \\
\text { (texte ou données) }\end{array}$ & $\begin{array}{l}\text { Degré de } \\
\text { preuve }\end{array}$ & Qualité \\
\hline & $\begin{array}{l}\text { Mauvaise } \\
\text { concordance } \\
\text { entre le } \\
\text { composant B } \\
\text { du vaccin et les } \\
\text { souches en } \\
\text { circulation les } \\
\text { deux années } \\
\text { (différence de } \\
29,2 \% \text { la } \\
1^{\text {re }} \text { année et de } \\
77 \% \text { la } \\
2^{e} \text { année) }\end{array}$ & & & $\begin{array}{l}\text { ESG } \\
\text { Peu courants et semblables d'un } \\
\text { groupe à l'autre } \\
\text { - } 1^{\text {re }} \text { année (VVAl c. placebo) - } \\
\text { bronchospasme (7 c. 3), bronchite } \\
\text { (3 c. 2) et rhinite ( } 3 \text { c. 0) } \\
\text { - Retrait de l'étude en raison d'un } \\
\text { ESG lié au vaccin la } 1^{\text {re }} \text { année - } \\
\text { fièvre x } 3 \text { jours chez un enfant de } \\
20 \text { mois } \\
\text { - } 2^{\text {e }} \text { année : } 1 \text { cas de pneumonie } \\
\text { dans les } 6 \text { jours suivant } \\
\text { l'administration du vaccin (VVAl) } \\
\text { - Aucun décès lié à l'étude }\end{array}$ & & \\
\hline $\begin{array}{l}\text { Vesikari T, } \\
\text { Fleming DM, } \\
\text { Aristegui JF, } \\
\text { et coll. Safety, } \\
\text { efficacy, and } \\
\text { effectiveness of } \\
\text { cold-adapted } \\
\text { influenza } \\
\text { vaccine-tri- } \\
\text { valent against } \\
\text { community- } \\
\text { acquired, } \\
\text { culture-con- } \\
\text { firmed influenza } \\
\text { in young } \\
\text { children } \\
\text { attending } \\
\text { day care. } \\
\text { Pediatrics 2006 } \\
\text { Dec;118(6): } \\
\text { 2298-2312.(42) }\end{array}$ & 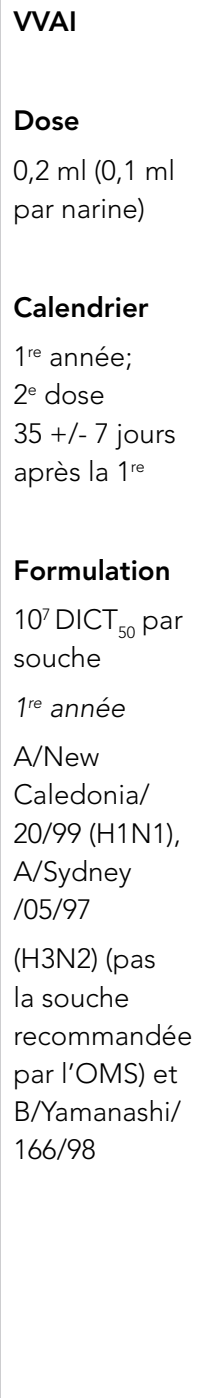 & $\begin{array}{l}\text { ECR, prospectif, } \\
\text { à double insu, } \\
\text { contrôlé par } \\
\text { placebo, } \\
\text { multicentrique } \\
\text { Saisons } \\
\text { grippales } \\
2000-2001 \text { et } \\
2001-2002 \\
\text { Belgique, } \\
\text { Finlande, Israël, } \\
\text { Espagne, R.-U. }\end{array}$ & $\begin{array}{l}1^{\text {re }} \text { année (selon } \\
\text { le protocole) } \\
n_{\text {placebo }}=1616 \\
n_{\text {val }}=951 \\
n_{\text {placebo }}=665 \\
\geq 24 \text { à } 36 \text { mois } \\
n=844 \text { (52,2\%) } \\
n_{\text {val }}=490 \\
n_{\text {placebo }}=354 \\
2^{e} \text { année (selon } \\
\text { le protocole) } \\
n_{\text {placebo }}=1090 \\
n_{\text {wal }}=640 \\
n_{\text {placebo }}=450 \\
\text { Données sur les } \\
\geq 24 \text { à } 36 \text { mois } \\
\text { non publiées }\end{array}$ & 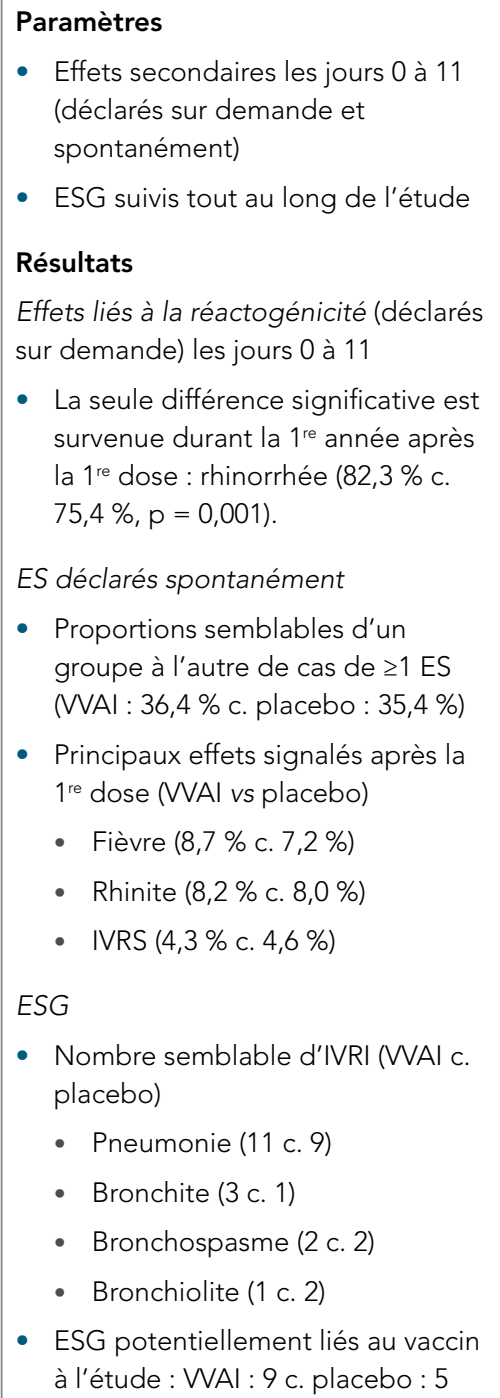 & Niveau I & Bonne \\
\hline
\end{tabular}




\begin{tabular}{|c|c|c|c|c|c|c|}
\hline \multicolumn{7}{|c|}{ DONNÉES CONCERNANT L’EFFICACITÉ RÉELLE ET POTENTIELLE DU VTI } \\
\hline Étude & Vaccin & Plan d'étude & Participants & $\begin{array}{l}\text { Résumé des principaux résultats } \\
\text { (texte ou données) }\end{array}$ & $\begin{array}{l}\text { Degré de } \\
\text { preuve }\end{array}$ & Qualité \\
\hline & 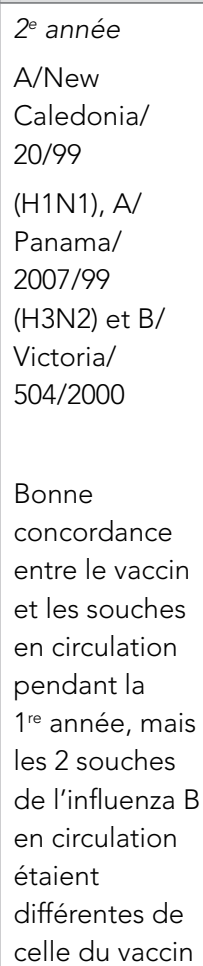 & & & $\begin{array}{l}\text { - Aucune différence statistiquement } \\
\text { significative d'un groupe à l'autre } \\
\text { sur le plan des ESG pendant la } \\
2^{\mathrm{e}} \text { année } \\
\text { - Aucun décès pendant la période à } \\
\text { l'étude }\end{array}$ & & \\
\hline
\end{tabular}




\section{Liste des abréviations}

$\mu g$

AAA

ACIP

ACMTS

AF

AMMI Association pour la microbiologie médicale et
l'infectiologie Canada adapté au froid

ASPC Agence de la santé publique du Canada

AVAQ année de vie ajustée pour la qualité

CCMTMV Comité consultatif de la médecine tropicale et de la médecine des voyages

CCNI Comité consultatif national de l'immunisation

CDC Centers for Disease Control and Prevention des États-Unis

CEPCM Centre européen de prévention et de contrôle des maladies

CIM Classification internationale des maladies

CIMRI Centre de l'immunisation et des maladies respiratoires infectieuses

ECR essai comparatif randomisé

El écart interquartile

EIM événement ayant nécessité une intervention médicale

ESG effet secondaire grave

ESLD établissement de soins de longue durée

ESSI effet secondaire suivant l'immunisation

É.-U. États-Unis

EV efficacité du vaccin

DS durée du séjour

GT gastro-intestinal

GTI Groupe de travail sur l'influenza

H hémagglutinine

IAVR infection aiguë des voies respiratoires

IC intervalle de confiance

ID intradermique
lgE immunoglobuline $\mathrm{E}$

IgG immunoglobuline $G$

IM intramusculaire

IMC indice de masse corporelle

IMPACT Programme de surveillance active des effets secondaires associés aux vaccins

IVRI infection des voies respiratoires inférieures

IVRS infection des voies respiratoires supérieures

LNM Laboratoire national de microbiologie

ml millilitre

MCO organisme de gestion des soins

MRAIM maladie respiratoire ayant nécessité une intervention médicale

N neuraminidase

NE non-estimé

OE oxygénation extracorporelle

OMA otite moyenne aiguë

OME otite moyenne avec épanchement

OMS Organisation mondiale de la Santé

PCSIN Programme canadien de surveillance des infections nosocomiales

pH1N1 virus pandémique de l'influenza H1N1 de 2009

PUVI Programme universel de vaccination contre I'influenza (Ontario)

$\mathbf{R} \quad$ réactogénicité

R.-U. Royaume-Uni

RC rapport de cotes

RMTC Relevé des maladies transmissibles au Canada

RR risque relatif

RTI ratio des taux d'incidence

SD écart-type

SG syndrome grippal

SCAIC Société canadienne d'allergie et d'immunologie clinique

SCSESSI Système canadien de surveillance des effets secondaires suivant l'immunisation

SGB syndrome de Guillain-Barré 
SIP $\quad$ soins intensifs pédiatriques

SOR syndrome oculo-respiratoire

SV service des urgences

TESSy European Surveillance System

TS travailleur de la santé

UFF unité de foyers fluorescents

USI unité de soins intensifs

VAERS Vaccine Adverse Event Reporting System (É.-U.)

VAO vaccin antipoliomyélitique oral
VIH virus de l'immunodéficience humaine

VHB vaccin contre l'hépatite B

VL vente libre

VRS virus respiratoire syncytial

VTI vaccin trivalent inactivé

VTI-ID vaccin trivalent inactivé administré par voie intradermique

VVAl vaccin à virus vivant atténué contre l'influenza 


\section{Références}

(1) American Academy of Pediatrics - Committee on Infectious Diseases. Prevention of influenza: recommendations for influenza immunization of children, 2007-2008. Pediatrics. 2008;121(4):e1016-31.

(2) Neuzil KM, Zhu Y, Griffin MR, et coll. Burden of interpandemic influenza in children younger than 5 years: a 25-year prospective study. J Infect Dis. 2002;185(2):147-52.

(3) Neuzil KM, Mellen BG, Wright PF, et coll. The effect of influenza on hospitalizations, outpatient visits, and courses of antibiotics in children. N Engl J Med. 2000;342(4):225-31.

(4) Izurieta HS, Thompson WW, Kramarz P, et coll. Influenza and the rates of hospitalization for respiratory disease among infants and young children. N Engl J Med. 2000;342(4):232-9.

(5) Thompson WW, Shay DK, Weintraub E, et coll. Influenza-associated hospitalizations in the United States. JAMA. 2004;292(11):1333-40.

(6) Poehling KA, Edwards KM, Weinberg GA, et coll. The underrecognized burden of influenza in young children. N Engl J Med. 2006;355(1):31-40.

(7) Hurwitz ES, Haber M, Chang A, et coll. Studies of the 1996-1997 inactivated influenza vaccine among children attending day care: immunologic response, protection against infection, and clinical effectiveness. J Infect Dis. 2000;182(4):1218-21.

(8) Louie JK, Schechter R, Honarmand S, et coll. Severe pediatric influenza in California, 2003-2005: implications for immunization recommendations. Pediatrics. 2006;117(4):e610-8.

(9) Peltola V, Ziegler T, Ruuskanen O. Influenza A and B virus infections in children. Clinical infectious diseases. 2003;36(3):299-305.

(10) Chiu SS, Tse CY, Lau YL, et coll. Influenza A infection is an important cause of febrile seizures. Pediatrics. 2001;108(4):E63.

(11) Schanzer DL, Langley JM, Tam TW. Hospitalization attributable to influenza and other viral respiratory illnesses in Canadian children. Pediatr Infect Dis J. 2006;25(9):795-800.
(12) Agence de la santé publique du Canada. Surveillance de l'influenza. 2012; Disponible au : http://www. phac-aspc.gc.ca/fluwatch/index-fra.php

(13) O'Brien MA, Uyeki TM, Shay DK, et coll. Incidence of outpatient visits and hospitalizations related to influenza in infants and young children. Pediatrics. 2004;113(3 Pt 1):585-93.

(14) Bourgeois FT, Valim C, Wei JC, et coll. Influenza and other respiratory virus-related emergency department visits among young children. Pediatrics. 2006;118(1):e1-8.

(15) Coffin SE, Zaoutis TE, Rosenquist AB, et coll. Incidence, complications, and risk factors for prolonged stay in children hospitalized with community-acquired influenza. Pediatrics. 2007;119(4):740-8.

(16) Thompson WW, Shay DK, Weintraub E, et coll. Mortality associated with influenza and respiratory syncytial virus in the United States. JAMA. 2003;289(0098-7484; 0098-7484; 2):179-86.

(17) Bhat N, Wright JG, Broder KR, et coll. Influenzaassociated deaths among children in the United States, 2003-2004. N Engl J Med. 2005;353(24):2559-67.

(18) Centers for Disease Control and Prevention (CDC). Update: Influenza activity -- United States and worldwide, 2006-07 season, and composition of the 2007-08 influenza vaccine. Morb Mortal Wkly Rep. 2007;56(31):789-94.

(19) Ritzwoller DP, Bridges CB, Shetterly S, et coll. Effectiveness of the 2003-2004 influenza vaccine among children 6 months to 8 years of age, with 1 vs 2 doses. Pediatrics. 2005;116(1):153-9.

(20) Eisenberg KW, Szilagyi PG, Fairbrother G, et coll. Vaccine effectiveness against laboratory-confirmed influenza in children 6 to 59 months of age during the 2003-2004 and 2004-2005 influenza seasons. Pediatrics. 2008;122(5):911-9.

(21) Joshi AY, lyer VN, St Sauver JL, et coll. Effectiveness of inactivated influenza vaccine in children less than 5 years of age over multiple influenza seasons: a case-control study. Vaccine. 2009;27(33):4457-61. 
(22) Kelly H, Jacoby P, Dixon GA, et coll. Vaccine Effectiveness Against Laboratory-confirmed Influenza in Healthy Young Children: A Case-Control Study. Pediatr Infect Dis J. 2011;30(2):107-11.

(23) Staat MA, Griffin MR, Donauer S, etcoll. Vaccine effectiveness for laboratory-confirmed influenza in children 6-59 months of age, 2005-2007. Vaccine. 2011;29(48):9005-11.

(24) Shuler CM, Iwamoto M, Bridges CB, et coll. Vaccine effectiveness against medically attended, laboratoryconfirmed influenza among children aged 6 to 59 months, 2003-2004. Pediatrics. 2007;119(3):e587-95.

(25) Belongia EA, Kieke BA, Donahue JG, et coll. Effectiveness of inactivated influenza vaccines varied substantially with antigenic match from the 2004-2005 season to the 2006-2007 season. J Infect Dis. 2009;199(2):159-67.

(26) Heinonen S, Silvennoinen $\mathrm{H}$, Lehtinen $\mathrm{P}$, et coll. Effectiveness of inactivated influenza vaccine in children aged 9 months to 3 years: an observational cohort study. Lancet Infect Dis. 2011;11(1):23-9.

(27) Dixon GA, Moore HC, Kelly H, et coll. Lessons from the first year of the WAIVE study investigating the protective effect of influenza vaccine against laboratory-confirmed influenza in hospitalised children aged 6-59 months. Influenza other respi viruses. 2010;4(4):231-4.

(28) Szilagyi PG, Fairbrother G, Griffin MR, et coll. Influenza vaccine effectiveness among children 6 to 59 months of age during 2 influenza seasons: a case-cohort study. Arch Pediatr Adolesc Med. 2008;162(10):943-51.

(29) Katayose M, Hosoya M, Haneda T, et coll. The effectiveness of trivalent inactivated influenza vaccine in children over six consecutive influenza seasons. Vaccine. 2011;29(9):1844-9.

(30) Maeda T, Shintani Y, Miyamoto H, et coll. Prophylactic effect of inactivated influenza vaccine on young children. Pediatr Int. 2002;44(1):43-6.

(31) Ochiai H, Fujieda M, Ohfuji S, et coll. Inactivated influenza vaccine effectiveness against influenza-like illness among young children in Japan--with special reference to minimizing outcome misclassification. Vaccine. 2009;27(50):7031-5.
(32) Ghendon YZ, Kaira AN, Elshina GA. The effect of mass influenza immunization in children on the morbidity of the unvaccinated elderly. Epidemiol Infect. 2006;134(1):71-8.

(33) Fujieda M, Maeda A, Kondo K, et coll. Influenza vaccine effectiveness and confounding factors among young children. Vaccine. 2008;26(50):6481-5.

(34) Fujieda M, Maeda A, Kondo K, et coll. Inactivated influenza vaccine effectiveness in children under 6 years of age during the 2002-2003 season. Vaccine. 2006;24(7):957-63.

(35) Hoen AG, Buckeridge DL, Charland KM, et coll. Effect of expanded US recommendations for seasonal influenza vaccination: comparison of two pediatric emergency departments in the United States and Canada. CMAJ. 2011;183(13):E1025-32.

(36) Comité consultatif national de l'immunisation (CCNI) Recommandations relatives à I'utilisation du vaccin antigrippal vivant atténué (FluMist $₫)$ : Déclaration complémentaire sur la vaccination antigrippale pour la saison 2011-2012, RMTC 2011;37(DCC - 7) : le 6 mars 2012

(37) Ashkenazi S, Vertruyen A, Aristegui J, et coll. Superior relative efficacy of live attenuated influenza vaccine compared with inactivated influenza vaccine in young children with recurrent respiratory tract infections. Pediatr Infect Dis J. 2006;25(10):870-9.

(38) Ambrose CS, Levin MJ, Belshe RB. The relative efficacy of trivalent live attenuated and inactivated influenza vaccines in children and adults. Influenza other respi viruses. 2011;5(2):67-75.

(39) Belshe RB, Edwards KM, Vesikari T, et coll. Live attenuated versus inactivated influenza vaccine in infants and young children. N Engl J Med. 2007;356(7):685-96.

(40) Belshe RB, Toback SL, Yi T, et coll. Efficacy of live attenuated influenza vaccine in children 6 months to 17 years of age. Influenza other respi viruses. 2010;4(3):141-5.

(41) Tam JS, Capeding MR, Lum LC, et coll. Efficacy and safety of a live attenuated, cold-adapted influenza vaccine, trivalent against culture-confirmed influenza in young children in Asia. Pediatr Infect Dis J. 2007;26(7):619-28. 
(42) Vesikari T, Fleming DM, Aristegui JF, et coll. Safety, efficacy, and effectiveness of cold-adapted influenza vaccine-trivalent against community-acquired, culture-confirmed influenza in young children attending day care. Pediatrics. 2006;118(6):2298-312

(43) Gaglani MJ, Piedra PA, Herschler GB, et coll. Direct and total effectiveness of the intranasal, live-attenuated, trivalent cold-adapted influenza virus vaccine against the 2000-2001 influenza $A(H 1 N 1)$ and $\mathrm{B}$ epidemic in healthy children. Arch Pediatr Adolesc Med. 2004;158(1):65-73.

(44) Bracco Neto H, Farhat CK, Tregnaghi MW, et coll. Efficacy and safety of 1 and 2 doses of live attenuated influenza vaccine in vaccine-naive children. Pediatr Infect Dis J. 2009;28(5):365-71.

(45) Rhorer J, Ambrose CS, Dickinson S, et coll. Efficacy of live attenuated influenza vaccine in children: A meta-analysis of nine randomized clinical trials. Vaccine. 2009;27(7):1101-10.

(46) Ozgur SK, Beyazova U, Kemaloglu YK, et coll. Effectiveness of inactivated influenza vaccine for prevention of otitis media in children. Pediatr Infect Dis J. 2006;25(5):401-4.

(47) Hurwitz ES, Haber M, Chang A, et coll. Effectiveness of influenza vaccination of day care children in reducing influenza-related morbidity among household contacts. JAMA. 2000;284(13):1677-82.

(48) Principi N, Esposito S, Marchisio P, et coll. Socioeconomic impact of influenza on healthy children and their families. Pediatr Infect Dis J. 2003;22(10 Suppl):S207-10.

(49) Piedra PA, Gaglani MJ, Kozinetz CA, et coll. Herd immunity in adults against influenza-related illnesses with use of the trivalent-live attenuated influenza vaccine (CAIV-T) in children. Vaccine. 2005;23(13):1540-8.

(50) Loeb M, Russell ML, Moss L, et coll. Effect of influenza vaccination of children on infection rates in Hutterite communities: a randomized trial. JAMA. 2010;303(10):943-50.

(51) Pitman RJ, White LJ, Sculpher M. Estimating the clinical impact of introducing paediatric influenza vaccination in England and Wales. Vaccine. 2011 (sous presse);30:1224.
(52) Skowronski DM, Hottes TS, De Serres G, et al. Influenza B/Victoria antigen induces strong recall of $\mathrm{B} /$ Yamagata but lower B/Victoria response in children primed with two doses of B/Yamagata. Pediatr Infect Dis J. 2011;30(10):833-9.

(53) Zeman AM, Holmes TH, Stamatis S, et coll. Humoral and cellular immune responses in children given annual immunization with trivalent inactivated influenza vaccine. Pediatr Infect Dis J. 2007;26(2):107-15.

(54) Neuzil KM, Dupont WD, Wright PF, et coll. Efficacy of inactivated and cold-adapted vaccines against influenza A infection, 1985 to 1990: the pediatric experience. Pediatr Infect Dis J. 2001;20(8):733-40.

(55) Ambrose CS, Wu X, Belshe RB. The efficacy of live attenuated and inactivated influenza vaccines in children as a function of time postvaccination. Pediatr Infect Dis J. 2010;29(9):806-11.

(56) Gruber WC, Taber LH, Glezen WP, et coll. Live attenuated and inactivated influenza vaccine in school-age children. Am J Dis Child. 1990;144(5):595-600.

(57) Baxter R, Jeanfreau R, Block SL, et coll. A Phase III evaluation of immunogenicity and safety of two trivalent inactivated seasonal influenza vaccines in US children. Pediatr Infect Dis J. 2010;29(10):924-30.

(58) Jansen AG, Sanders EA, Smulders S, et coll. Adverse reactions to simultaneous influenza and pneumococcal conjugate vaccinations in children: randomized double-blind controlled trial. Pediatr Allergy Immunol. 2008;19(6):552-8.

(59) Glanz JM, Newcomer SR, Hambidge SJ, et coll. Safety of trivalent inactivated influenza vaccine in children aged 24 to 59 months in the vaccine safety datalink. Arch Pediatr Adolesc Med. 2011;165(8):749-55.

(60) Muhammad RD, Haber P, Broder KR, et coll. Adverse events following trivalent inactivated influenza vaccination in children: Analysis of the vaccine adverse event reporting system. Pediatr Infect Dis $J$. 2011;30(1):e1-8.

(61) Agence de la santé publique du Canada. Système canadien de surveillance des effets secondaires suivant l'immunisation (SCSESSI). 2012. 
(62) Bergen R, Black S, Shinefield H, et coll. Safety of cold-adapted live attenuated influenza vaccine in a large cohort of children and adolescents. Pediatr Infect Dis J. 2004;23(2):138-44.

(63) Breiman RF, Brooks WA, Goswami D, et coll. A multinational, randomized, placebo-controlled trial to assess the immunogenicity, safety, and tolerability of live attenuated influenza vaccine coadministered with oral poliovirus vaccine in healthy young children. Vaccine. 2009;27(40):5472-9.

(64) Piedra PA, Yan L, Kotloff K, et coll. Safety of the trivalent, cold-adapted influenza vaccine in preschoolaged children. Pediatrics. 2002;110(4):662-72.

(65) Mallory RM, Yi T, Ambrose CS. Shedding of Ann Arbor strain live attenuated influenza vaccine virus in children 6-59 months of age. Vaccine. 2011; [Publication-e avant impression].
(66) Zangwill KM, Droge J, Mendelman P, et coll. Prospective, randomized, placebo-controlled evaluation of the safety and immunogenicity of three lots of intranasal trivalent influenza vaccine among young children. Pediatr Infect Dis J. 2001;20(8):740-6.

(67) Mendelman PM, Cordova J, Cho I. Safety, efficacy and effectiveness of the influenza virus vaccine, trivalent, types A and B, live, cold-adapted (CAIV-T) in healthy children and healthy adults. Vaccine. 2001;19(17-19):2221-6.

(68) Haber P, Arana J, Walton K. Safety of live attenuated influenza vaccine in children aged 24-59 months, Vaccine Adverse Event Reporting System (VAERS), 2007-2009. 49th Interscience conference on antimicrobial agents and chemotherapy, San Francisco, CA. September 12-14, 2009. Abstract GI-872. 2009. 